\title{
VI. ENTZAUBERTE MONARCHEN
}

Blickt man auf die Geschichte der westlichen Monarchien im 19. Jahrhundert, so lassen sich zwei gegenläufige Entwicklungen beobachten. Einerseits verloren die Monarchen signifikant an politischer Macht, insbesondere durch die Ausbildung von Verfassungen, gewählten Parlamenten und den Bedeutungsgewinn von Regierungen. Andererseits nahm die öffentliche Präsenz der Monarchen deutlich zu, was ihre Stellung stärken konnte. Gerade im ausgehenden 19. Jahrhundert entwickelte sich hieraus ein besonders markantes und erklärungsbedürftiges Spannungsverhältnis, in dem sich insbesondere der deutsche Kaiser Wilhelm II. sowie die späte Queen Victoria und ihr Nachfolger Edward VII. bewegten.

Beide Prozesse hingen im hohen Maße mit der Medialisierung zusammen. Zweifelsohne begrenzte die rasante Ausdehnung der Medienöffentlichkeit unübersehbar die Spielräume von Monarchen, insbesondere, wenn ihr Handeln als Willkür oder gegen die öffentliche Meinung gerichtet erschien. Diese Kritik entlud sich mitunter in Form von Skandalen, die durch eine breite Empörung die Stellung und das Ansehen der Monarchie erschütterten - wie etwa bei der Halsband-Affäre 1785/86, dem Queen Caroline-Skandal 1820 oder der Daily Telegraph-Affäre 1908. Derartige Skandale schufen eine emotional aufgeladene generelle Kritik an den jeweiligen Monarchen und führten zu nachdrücklich formulierten Verhaltensanforderungen. Die mediale Dauerbeobachtung, unter der die Monarchen im 19. Jahrhundert zunehmend standen, verstärkte dabei die Wahrscheinlichkeit, dass etwaige Normbrüche veröffentlicht wurden.

Zugleich konnten die Monarchen die zunehmende Medialisierung im 19. Jahrhundert vielfach nutzen, um auf neue Weise in den Mittelpunkt der Öffentlichkeit zu rücken. Diese verstärkte mediale Präsenz der Königshäuser wurde bereits verschiedentlich hervorgehoben. So bezeichnete John Plunkett Queen Victoria pointiert als „First Media Monarch“1, da sie trotz ihrer zeitweiligen Öffentlichkeitsscheu eine ubiquitäre mediale Verbreitung fand. Ebenso betitelten verschiedene Arbeiten Kaiser Wilhelm II. als „media monarch“ 2 und „ersten deutschen Filmstar“. ${ }^{3}$ Nicht nur für den Kaiser war demnach die direkte und mediale Kommunikation mit der Öffentlichkeit essentiell, sondern auch die Medien ihrerseits stellten bevorzugt den Kaiser in den Mittelpunkt. Die Monarchen versuchten dabei, eher bürgerliche Formen der Öffentlichkeit zur Festigung ihrer Stellung zu nutzen. Insbesondere gegen Ende des 19.Jahrhunderts

\footnotetext{
John Plunkett, Queen Victoria. First Media Monarch, Oxford 2002.

Christopher Clark, Kaiser Wilhelm II, London 2000, S. 160.

3 Martin Loiperdinger, Kaiser Wilhelm II. Der erste deutsche Filmstar, in: Thomas KoebNER (Hrsg.), Idole des deutschen Films. Eine Galerie von Schlüsselfiguren, München 1997, S.41-53. Zum komplexen Verhältnis zwischen Wilhelm II. und der Presse jetzt auch: KoHLRAUSCH, Der Monarch, bes. S. 452-456.
} 
ließen ihre Hemmungen nach, in einen direkten Kontakt mit der Presse zu treten. Eine echte Wahl hatten die Monarchen ohnehin nicht. Zeigten sie sich gegenüber den Medien eher reserviert, wie Queen Victoria in den 1860/70er Jahren, so kritisierten die Zeitungen ihre Distanz zur Öffentlichkeit und suchten ihre Nähe.

Diese Medienberichte über die Monarchen lösten wiederum kollektive Handlungen aus. Die weit verbreiteten, anschaulichen und täglich erscheinenden Artikel über ihre öffentlichen Auftritte verstärkten den Zulauf zu derartigen Ereignissen, die einen persönlichen Blick auf den Monarchen versprachen. Von der Taufe über die Krönung bis hin zur Beerdigung entstanden nun regelmäßig Massenaufläufe mit zehntausenden Schaulustigen. Da die mediale Berichterstattung bevorzugt die Menschenmenge um den Monarchen zeigte, suggerierte sie nicht nur seine Beliebtheit, sondern machte auch das populäre Spektakel um ihn herum zu selbst einer sensationellen Attraktion, die das Ansehen des Monarchen steigern konnte. Allerdings verloren die Monarchen zugleich die Kontrolle über ihre Selbstdarstellung. ${ }^{4}$ Ihr öffentliches Auftreten machte sie zu Objekten zahlloser Berichte, die durch die große Nachfrage kaum noch kontrollierbar waren.

Dabei trugen die Medien bereits durch ihre Bilder dazu bei, bürgerliche Erwartungen an den Monarchen zu fördern. So zeigten sie die Monarchen häufig in bürgerlichen Kontexten - etwa im Kreise der Familie oder bei der Kur. ${ }^{5} \mathrm{Ne}-$ ben dem Aufkommen der auflagenstarken Familien- und Sonntagszeitungen (wie der Illustrated London News oder der Gartenlaube) verstärkte die Etablierung der Fotographie diesen bürgerlichen Blick auf die Könige. Denn im Unterschied zum Gemälde bildeten die Fotos die Monarchen häufiger in Alltagssituationen $a b$ und suggerierten eine intime Nähe und Vertrautheit. ${ }^{6}$ Für eine gröBere Nähe zum Monarchen standen aber auch die textlichen Innovationen im Journalismus. Persönliche Augenzeugenberichte oder Interviews vermittelten eine unmittelbare Kommunikation mit den Monarchen. Beides dürfte zugleich die Erwartungen und Maßstäbe mit verändert haben, unter denen die Herrscher bewertet wurden. Die Medialisierung konnte so die Stellung der Monarchen absichern, machte sie aber zugleich auch verletzbarer, wie nicht zuletzt die

4 So auch mit Blick auf die Bilddarstellungen: Johannes Paulmann, Pomp und Politik. Monarchenbegegnungen in Europa zwischen Ancien Régime und Erstem Weltkrieg, Paderborn 2000, S.391f.

5 Vgl. zu dieser bürgerlichen Darstellung: Alexa Geisthövel, Den Monarchen im Blick. Wilhelm I. in der illustrierten Familienpresse, in: Навво Knoch und Daniel Morat (Hrsg.), Kommunikation von Beobachtung. Medienwandel und Gesellschaftsbilder 1880-1960, München 2003, S. 59-80. Vgl. zur Etablierung bürgerlicher Bewertungsmaßstäbe für die Monarchie generell: Monika WiEnfort, Monarchie in der bürgerlichen Gesellschaft. Deutschland und England von 1640 bis 1848, Göttingen 1993, S. 205; Regina Schulte, Der Aufstieg der konstitutionellen Monarchie und das Gedächtnis der Königin, in: Historische Anthropologie 6 (1999), S. 76-103.

6 Franziska Windt, Majestätische Bildflut. Die Kaiser in der Photographie, in: Dies. et al. (Hrsg.), Die Kaiser und die Macht der Medien, S.67-98. 
Skandale zeigten, die ihr moralisches und politisches Verhalten auf den Prüfstein stellten.

Auf welche Weise diese Skandale auftraten, wie die Öffentlichkeit jeweils mit den Königshäusern interagierte und welche Rollenerwartungen sie an den Monarchen richtete, wird jeweils an exemplarischen Skandalen für beide Länder geprüft. Zunächst wird vergleichend untersucht, welche Bedeutung sexuelle Normverstöße für die Monarchen im 19.Jahrhundert haben konnten. Da in Großbritannien bürgerliche Moralanforderungen an den Monarchen eine größere Rolle spielten, erfolgt eine vertiefte Fallanalyse anhand des Baccarat-Skandals von 1891, der die Spielleidenschaft des späteren Edward VII. und damit die Bewertung des Glücksspiels thematisierte. In Deutschland hingegen traten herausragende Skandale vor allem im Kontext der politischen Handlungen von Wilhelm II. auf. Neben der berühmten Daily-Telegraph-Affäre werden dementsprechend weitere Skandale systematisch untersucht, die in Verbindung mit seinem eigenen Führungsanspruch standen und diesen zu begrenzen versuchten - wie etwa der Kotze-, Kladderadatsch- und Caligula-Skandal.

\section{Monarchen und Ehebruch im 19. Jahrhundert}

Die Skandalisierung des Monarchen zählt zu den Formen des politischen Skandals, die sich lange vor dem 19. Jahrhundert etablierten. Neben Empörungen über Formen des Machtmissbrauchs bildete der Spott über sein sexuelles Verhalten vielfach den Ausgangspunkt, wobei die Kritik an seinen Maitressen das Bild des idealen Monarchen entwarf. 7 Zu den bis heute vielleicht berühmtesten Fällen zählt sicherlich die Halsbandaffäre der französischen Königin Marie Antoinette im Vorfeld der französischen Revolution. Das ihr vorgeblich von Kardinal Rohan geschenkte Diamantenhalsband bildete dabei nur den Kulminationspunkt einer Reihe von Skandalisierungen, bei der zahllose Pamphlete der Königin sexuelle Normbrüche, Verschwendung und Verletzung ihrer Mutterpflichten vorgeworfen hatten. ${ }^{8}$ In Westeuropa verstärkten die Presseberichte hierüber eine „sex panic“ (Binhammer), bei der sexuelle Normverstöße und Revolution eng miteinander verbunden wurden. ${ }^{9}$ Bei späteren MonarchieSkandalen im 19. Jahrhundert blieb die Halsbandaffäre in ganz Westeuropa der

7 Vgl. etwa für das frühe 18. Jahrhundert: Jens Ivo ENGELs, Königsbilder. Sprechen, Singen und Schreiben über den französischen König in der ersten Hälfte des achtzehnten Jahrhunderts, Bonn 2000, bes. S. 207-226.

8 Angesichts der umfangreichen Literatur vgl. stellvertretend die Beiträge in: Goodman (Hrsg.), Marie-Antoinette. Zur Visualisierung bes. Lynn Hunt, The Many Bodies of Marie Antoinette: Political Pornography and the Problem of the Feminine in the French Revolution, in: ebd., S. 117-138.

9 Katherine Binhammer, The Sex Panic of the 1790s, in: Journal of the History of SexuALITY 6 (1996), S. 409-435. Binhammer argumentiert hier allerdings, dass es zu einer Verschiebung von einer aktiven zur passiven weiblichen Sexualität gekommen sei. 
Bezugspunkt, an den am häufigsten mahnend erinnert wurde, um die drohenden revolutionären Folgen eines Skandals ins Bewusstsein zu rufen. ${ }^{10}$ In gewisser Weise bildete die Halsbandaffäre ein Narrativ, das immer wieder an die bedrohliche Macht des Skandals erinnerte. Andere Monarchie-Skandale, die für die Zeitgenossen des späten 18. Jahrhunderts ebenfalls spektakulär erschienen, gerieten dagegen eher in Vergessenheit. Dies gilt etwa für den dänischen Skandal um die Absetzung des liberalen monarchischen Beraters Johann Friedrich Struensee, der nach seiner öffentlich angeprangerten Liebesaffäre mit der dänischen Königin wegen „Majestätsbeleidigung“ 1772 hingerichtet wurde. ${ }^{11}$ Bei derartigen Monarchie-Skandalen ging es bereits vor dem 19.Jahrhundert nicht allein um den Ehebruch des Monarchen. Vielmehr verhandelten sie zugleich den Einfluss von Günstlingen und Beratern, monarchische Verhaltensweisen, Fragen der Gerechtigkeit und grundsätzliche Vorstellungen über die Gesellschaftsordnung.

Auch in England kam es Ende des 18. Jahrhunderts zu vielfältigen Versuchen, den Adel wie in Frankreich durch die Enthüllung seiner Dekadenz zu skandalisieren. So diffamierte der radikale Publizist John Wilkes in den 1760er Jahren weniger aus moralischen Überzeugungen die sexuellen Affären von Angehörigen des Königshauses, sondern um politische Reformen zu erreichen. Bezeichnender Weise beantworteten die Royalisten die Pressekampagne wiederum mit Enthüllungen über Wilkes Liebesleben. ${ }^{12}$ Somit setzten beide Seiten die Lauterkeit des Privatlebens zum Maßstab für politische Zuverlässigkeit und Glaubwürdigkeit. Ebenso machte der radikale Journalist Charles Pigott Ende des 18. Jahrhunderts in zahlreichen Pamphleten die sexuellen Normbrüche des Hochadels öffentlich, um ihn als überflüssigen, dekadenten und korrupten Parasiten darzustellen. ${ }^{13}$ Die in den 1790 er Jahren zunehmenden Zeitungsberichte über adlige Scheidungsprozesse verstärkten diesen Eindruck. ${ }^{14}$ Dennoch lösten derartige Veröffentlichungen in Großbritannien eine geringere Empörung als in Frankreich aus. Der Historiker Nicholas Rogers führte dies nicht nur auf die geringere Zensur zurück, sondern auch darauf, dass weniger der Monarch als bereits das Parlament die Nation verkörperte und dessen stärker pluralistische Struktur den Spott abbremste. ${ }^{15}$ Ebenso dürften neben einigen Reformen die konservativen Gegenkampagnen retardierend gewirkt haben. ${ }^{16}$

10 Vgl. etwa die Hinweise im Kontext anderer Skandale in: Times 24.2.1870, S. 8; DAily ChroniCle 10.9.1891; VorwäRTs Nr. 287, 8.12.1896; Kölnische Volkszeitung Nr. 923, 15.10.1907. Christine Keitsch, Der Fall Struensee. Ein Blick in die Skandalpresse des ausgehenden 18. Jahrhunderts, Hamburg 2000.

12 Vgl. zu diesem Wechselspiel: Clark, Scandal, S. 19-52.

13 Vgl. Nicholas Rogers, Pigott's Private Eye. Radicalism and Sexual Scandal in EighteenthCentury England, in: Journal of the Canadian Historical Association 4 (1993), S. 247263.

14 Vgl. Binhammer, The Sex Panic, S. $424 \mathrm{f}$.

15 Rogers, Pigott's Private Eye, S. 258.

16 So das Argument von Clarke, Scandal, S. 113. 
Welche starke Wirkung diese Form der Skandalisierung auch in Großbritannien haben konnte, zeigte sich im frühen 19. Jahrhundert bei der Queen Caroline Affair. Da sie ein wegweisender Monarchie-Skandal für das britische Inselreich war und eine denkbar breite öffentliche Diskussion auslöste, lohnt ein ausführlicher Blick auf den Fall. Immerhin führte der Skandal zu Massenprotesten, die die Stellung der Krone so sehr herausforderten wie vermutlich kein anderes Ereignis im langen 19. Jahrhundert. Der Skandal kam 1820 auf, als der unbeliebte zukünftige König Georg IV. vor seiner Krönung die Scheidung von seiner Frau durchsetzte, von der er längst getrennt lebte, wobei beide seit längerem mit verschiedenen Partnern verkehrten. ${ }^{17} \mathrm{Da}$ sich weder der bisherige Lebenswandel des Kronprinzen noch der vorheriger Monarchen durch Monogamie ausgezeichnet hatte, wird man die Empörung über die Verstoßung der angehenden Königin im hohen Maße mit spezifischen gesellschaftlichen Veränderungen erklären müssen. Vor allem die Revolutionsangst und -hoffnung der Nach-Napoleonischen Ära, das Aufkommen der Radical Press, die zaghafte Formierung von Proto-Sozialisten sowie die wirtschaftliche und politische Krise ermöglichten erst diese breite Empörung über das Eheleben des angehenden Königs.

Die Scheidung löste eine vielfältige Kommunikationsverdichtung aus. Sowohl die Auflagen etablierter Zeitungen wie der Times als auch der neugegründeten radikalen Blätter stiegen im Zuge des Skandals rasant an - von den zahllosen Flugblättern ganz zu schweigen. ${ }^{18}$ Wie viele Zeitgenossen hervorhoben, beschäftigte und empörte der Skandal darüber hinaus alle Ebenen der Öffentlichkeit. „Since I have been in the world I never remembered any question which so exclusively occupied everybody's attention, and so completely absorbed men's thoughts and engrossed conversation“, schrieb etwa Charles Greville in seinem Tagebuch. ${ }^{19}$ Der radikale Publizist William Cobbett betonte, der Fall bewegte „for a time every tongue and pen in England“, und William Hazlitt betonte etwas später: „It was the only question I have ever known that excited a thorough popular feeling. It struck its roots into the heart of the nation; it took possession of every house or cottage in the kingdom. " 20 Nicht allein der Ehebruch elektrisierte die Zeitgenossen somit, sondern bereits das Medienereignis selbst mit seiner grenzübergreifenden breiten öffentlichen Emotionalisierung. Der Hof und

17 Der Ablauf ist bereits in vielfältigen Darstellungen analysiert worden und muss deswegen hier nicht erneut ausgebreitet werden; vgl. zuletzt bes. Flora Fraser, The Unruly Queen. The Life of Queen Caroline, London 1996. Als Quellenedition hilfreich: E. A. SмIтH (Hrsg.), A Queen on Trial. The Affair of Queen Caroline, Dover 1993.

18 Die Auflage der damals auflagenstärksten Zeitung, der Times, erhöhte sich etwa von 7000 auf über 15000 Exemplare; Vermerk Robinson 13.10.1820, abgedr. in: Derek Hudson (Hrsg.), Thomas Barnes of The Times, Cambridge 1943, S. 41.

19 Eintrag 15.10.1820, in: Lytton Strachey und Roger Fulford (Hrsg.), The Greville Memoirs, Bd.1, London 1938, S. 105 f.

20 In: Commonplaces 15.11.1823, zit. nach: T. W. Laqueur, The Queen Caroline Affair. Politics as Art in the Reign of George IV, in: Journal of Modern History 54 (1982), S. 417-466, S.417. Als einen Höhepunkt der Berichterstattung über Scheidungen bewertet den Fall auch: STONE, Road to Divorce, S. 253. 
die Regierung versuchten auf vielfältige Weise, den Skandal zu vermeiden. Zunächst boten sie Caroline vergeblich Geld an, um sie umzustimmen. Um einen Prozess zu verhindern, der auch Georgs Ehebrüche thematisiert hätte, ließ der Thronfolger im House of Lords ein Gesetz einbringen, nach dem das Fremdgehen der Königin Hochverrat sei, was allein Caroline bei der Scheidung die peinigenden öffentlichen Geständnisse abverlangte. Dennoch konnten die loyalen Monarchisten nicht verhindern, dass die Medien und die breitere Öffentlichkeit auf Carolines Krönung beharrten, als sie 1820 nach längerer Abwesenheit aus Italien zurückkehrte und so den Scheidungsskandal auslöste.

An diesem Skandal lassen sich vor allem drei miteinander verbundene Deutungsebenen der britischen Monarchie ausmachen. Erstens trug die Queen Caroline Affair innerhalb der middle classes zur Konstruktion eines monarchischen Ideals bei, das sich durch bürgerliche familiäre Werte auszeichnete und von der Moral des Adels abgrenzte. George IV. hatte nach dieser bürgerlichen Lesart mit seinem Verhalten seine Pflichten als treu sorgender Ehemann und Vater verletzt. Für Caroline wurde dagegen das melodramatische Narrativ einer Frau konstruiert, die das Opfer adliger Untreue war. ${ }^{21}$ Durch diese Abgrenzung förderte der Skandal ein bürgerlich geprägtes monarchisches Rollenmodell, wie es dann später Queen Victoria einlöste. Zugleich stärkte die Abgrenzung vom Lebenswandel der Herrscher die kulturelle Herausbildung der middle classes selbst, wie bereits Zeitgenossen bemerkten. ${ }^{22}$

Der Skandal eröffnete zweitens spezifisch weibliche und proto-feministische Lesarten des Ehebruchs. Radikale Zeitungen veröffentlichten Texte, die Frauen als Besieger der männlichen Tyrannen feierten. So hieß es im Black Dwarf: „Through a WOMAN Rome obtained Liberty. [...] It was a WOMAN that brought down the bloody tyrant, Marat. [...] And a QUEEN will now bring down the corrupt Conspirators against the Peace, Honour, and Life of the INNOCENT." 23 Frauen unterstützten die verhinderte Königin Caroline explizit „in the name of our sex“. Sie schrieben Artikel, die sich gegen die männliche Doppelmoral richteten, sammelten Unterschriften für sie und beteiligten sich an den Straßenprotesten. ${ }^{24}$ Dabei identifizierten sie sich mit der Opferrolle einer verstoßenen Frau, die sie Caroline zuschrieben, und kämpften zugleich gegen

21 Vgl. neben Laqueur, The Queen, S. 439, zur bürgerlichen Konstruktion der middle classes im Kontext des Falles bes.: Leonore Davidoff und Catherine Hall, Family Fortunes. Men and Women of the English Middle-Class, London 2002 (Erstauflage 1987), S. 150-155.

22 Vgl. Dror Wahrman, „Middle-Class“ Domesticity Goes Public: Gender, Class and Politics from Queen Caroline to Queen Victoria, in: Journal of British Studies 32 (1993), S. 396-432, S. 406.

23 The Black Dwarf, 12.7.1820 (H.i.O.), abgedr. in: Smith (Hrsg.), Queen on Trial, S. 100.

24 Vgl. etwa die "Address of the Married Ladies of the Parish of St. Marylebone " in: Times 28.8.1820, S.2, Times 5.9.1820, S.3; „Address from the Ladies in Edinburgh“ in: Times 4. 9.1820; Leserbrief einer Frau („of my own sex“) Times 3. 8.1820. Ähnlich auch die Artikel im Radical Magazine, vgl. die Faksimile-Ausgaben in: Paul Keen (Hrsg.), The Popular Radical Press in Britain 1817-1821, London 2003, S. 291-296 u. 302-305. Vgl. Anna Clark, Queen Caroline and the Sexual Politics of Popular Culture in London 1820, in: Representations 31 (1990), S. 47-68; LaqueUr, The Queen, S. 442-445. 
sie an, wobei sie die Frauen als Verteidiger von Moral und Familienwerten sahen. Dass Carolines Lebenswandel weder dem puritanischen Ideal entsprach noch diese ein hilfloses Opfer war, unterstreicht nur die Projektionskraft der öffentlichen Zuschreibungen.

Drittens förderte der Skandal die Herausbildung einer radikalen popular culture, die Scheidung und Ehebruch als Beleg für den monarchischen Machtmissbrauch deutete. Die Queen erschien in ihrer Interpretation als Opfer und Vorkämpferin des Volkes: „[...] her INTERESTS are the same as the interests of the people!“ (H.i.O.) hieß es etwa im radikalen Black Dwarf. ${ }^{25}$ Der Kampf für die wehrlose Frau verband diese popular culture mit dem Kampf für eine freie unkorrumpierbare Presse. ${ }^{26}$ Radikale Journalisten wie William Cobbett, der sich in seinen Artikeln und in direkten Briefen mit Caroline solidarisierte, zogen Parallelen zwischen der Unterdrückung der Queen und der fehlenden Vertretung der Unterschichten im Parlament. ${ }^{27}$ Cobbetts Engagement ging dabei sogar so weit, dass er im Namen von Caroline einen Brief in der Times veröffentlichte, in dem sich Caroline als weibliches Opfer monarchischer Willkür stilisierte. ${ }^{28}$ Die Empörung der sich im Skandal formierenden Populärkultur zeigte sich vor allem in Spottschriften, Straßenaufläufen und symbolischen Aktionen. So kam es zum öffentlichen Verbrennen von grünen Tüten als dem Symbol für Korruption, weil laut Medienberichten die vermutlich bestochenen Zeugen aus Italien mit Informationen aus einer "green bag“ versorgt worden waren. ${ }^{29}$ Ebenso kam es zu Gewalt in den Straßen und eingeworfenen Fensterscheiben, was bei verschiedenen Zeitgenossen die Angst vor einer bevorstehenden Revolution hervorrief. ${ }^{30}$ Der Skandal entwickelte sich so zu einem generellen Protest gegen die Korruption und Ungerechtigkeit der monarchischen Herrschaft. Insbesondere die Karikaturen zum Skandal forderten gleiches Recht für Monarch und Volk, wobei die Behandlung der Königin die korrupte Willkür des Monarchen verkörperte. ${ }^{31}$ Dies galt nicht nur für die radikalen Medien, sondern auch etwa für bürgerliche Organe wie die Times. Unter Verweis auf die öffentliche Meinung kritisierte sie die Zeugen als gekaufte „Italian devils“ und monierte, dass der Scheidungsprozess nicht die Moral des Prinzen bewerte. ${ }^{32}$

The Black Dwarf 25.10.1820, abgedr. in: Smith (Hrsg.), Queen, S. 129.

26 Vgl. etwa die Erklärung der 1335 Londoner Drucker in: LAQUeUR, The Queen, S. 432.

27 Fraser, Unruly Queen, S. 389.

28 Times 14. 8.1820, S. 2. Dieser Brief, der offiziell nicht direkt an die Times, sondern am 7.8.1820 an den König ging, ohne dass sie eine Antwort erhielt, entwarf vor allem ein Bild der Old Corruption der Monarchie (etwa: „From the very threshold of Your Majesty's mansion the mother of your child was pursued by spies, conspirators and traitors [...]"). Vgl. auch AnTHONY Burton, William Cobbett: Englishman. A Biography, London 1997, S. 193.

29 Vgl. die Berichte über die zahlreichen Sympathiekundgebungen überall im Land in: Times 21.11.1820, S.3.

30 Vgl. zu dieser Revolutionsangst Tagebucheinträge wie von Greville, 9.6.1820, abgedr. in: Strachey und Fulford (Hrsg.), The Greville Memoirs, S. 95.

31 Vgl. bes. die Karikaturen abgedr. in: SмIтH (Hrsg.), Queen, S. 26, 33 u. 47.

32 Times 17.8.1820 und 11.9.1820, S.2. 
Der Skandal um Prinzessin Caroline entwickelte somit jenseits des Ehebruches vielfältige Lesarten, die soziale Dynamiken auslösten. Zugleich konstruierte der Prozess gegen Caroline öffentliche Vorstellungen über das Intimleben des Königshauses, welche sein Ansehen nachhaltig schmälerten. Um ihren permanenten Ehebruch mit dem jungen Italiener Bergami nachzuweisen, sagten im Prozess Zimmermädchen über schmutzige Bettwäsche aus, Matrosen über ihr gemeinsames Schlafzelt auf einem Schiff und englische Reisende über den Zustand ihrer Kleidung. Die Empörung in dem Skandal hatte zwar nicht die Kraft, den angehenden König George IV. zu stürzen. Vielmehr gewann er den Prozess und bestieg den Thron, während Caroline ohne Krönung kurz darauf verstarb. Aber sowohl die Enthüllungen als auch die breite Debatte über den Fall artikulierten mit Nachdruck künftige moralische Erwartungen an die Krone.

Die anfängliche Beliebtheit von Queen Victoria und ihre Verehrung als „Maiden Queen“ lassen sich dementsprechend im hohen Maße aus der Empörung im Queen Caroline-Skandal erklären. Die Queen verkörperte in den Erwartungen ein Gegenmodell zu den männlichen "Georgian Kings“. Dementsprechend zeigten visuelle Darstellungen sie anfangs vor allem als Verkörperung von Tugend und Weiblichkeit, dann als Mutter und Ehefrau. Insbesondere das Aufkommen fotographischer Darstellungen verstärkte die hier bereits angedeutete monarchische Repräsentation im Sinne bürgerlicher Normvorstellungen. ${ }^{33}$

Dennoch verschob die Queen Caroline Affair die Grenzen des Sagbaren nicht so sehr, dass die sexuellen Normbrüche von Queen Victoria in den Medien artikulierbar wurden. Sagbar war im viktorianischen Großbritannien eine Kritik an der politischen Einmischung der Königin, an ihrer zeitweilig ausbleibenden öffentlichen Präsenz und an den hohen Kosten der Monarchie, die vor allem Reynolds's Newspaper zunehmend monierte. ${ }^{34}$ Dagegen erwies sich das in der mündlichen Öffentlichkeit der 1860er Jahre kursierende Gerücht, Queen Victoria sei nach dem Tod ihres Ehemanns Albert eine Affäre mit ihrem Stallmeister John Brown eingegangen, nicht als druckbar. Während in einem amerikanischen Blatt die Meldung erschien, in England würde Victoria überall „Mrs. Brown“ genannt und eine Schweizer Zeitung angeblich bereits ein gemeinsames Kind meldete, hielten sich die britischen Zeitungen mit entsprechenden Andeutungen zurück. ${ }^{35}$ Eine Ausnahme bildeten etwa die Anspielungen des kleinen Satireblattes Tomabawk. Dies zeigte einen leeren Thron, an dem Brown lehnte, und untertitelte in einer anderen Karikatur das berühmte Bild, auf dem Brown das

33 Vgl. hierzu: Plunkett, Queen Victoria.

34 Zur Kritik an der politischen Einmischung von Victoria insbesondere 1853/54 vgl. RICHARD Williams, The Contentious Crown. Public Discussion of the British Monarchy in the Reign of Victoria, Aldershot 1997, S. 99 u. 264; zur Empörung über ihre mangelnde öffentliche Präsenz nach dem Tod ihres Gatten: Antony Taylor, ,Down with the Crown'. British AntiMonarchism and Debates about Royalty since 1790, London 1999, bes. S. 81-88. Erstaunlicher Weise lassen diese Studien die Skandale um die Krone weitgehend außen vor.

Die ausländischen Berichte erwähnt: Williams, The Contentious Crown, S.34. 
Pferd der Königin im Trauergewand hält, mit „All is black that is not Brown“.36 Der Liebhaber wurde damit einerseits dafür verantwortlich gemacht, dass die Königin nicht mehr ihren öffentlichen Aufgaben nachkomme. Andererseits deutet sich das bekannte Narrativ an, der Liebhaber schwänge sich zum eigentlichen Machthaber auf. Auch der Punch deutete das Verhältnis mit vier versteckten Sätzen an, die Browns Tagesablauf im Stile der täglichen Meldungen über Monarchen berichteten. ${ }^{37}$ Zumindest im Spott erschien damit der Liebhaber als der heimliche Herrscher.

Da die Monarchin mit Anspielungen auf ihr Liebesleben weitgehend verschont blieb, verlagerte sich die Forderung nach einer bürgerlichen Lebensführung stärker auf den Thronfolger. Die Liebesaffären des Prince of Wales, des späteren Edward VII., waren zunächst ebenfalls nicht druckbar, obgleich sie als Gerüchte öffentlich kursierten. Am Hof war man sich der Gefährdung durch Medienberichte bewusst. Da der Prinz extrem unvorsichtig mit Kurtisanen verkehrte und ihnen offene Liebesbriefe schrieb, mussten letztere zurückgekauft werden, um das Aufkommen von Skandalen zu verhindern. ${ }^{38}$ Medienkompatibel wurde eine derartige moralische Kritik am Königshaus erst im Rahmen des Mordaunt-Skandals von 1870, als der Prince of Wales in einem Aufsehen erregenden adligen Scheidungsprozess als Zeuge auftreten musste. Hierzu kam es, nachdem die 21jährige Lady Harriett Mordaunt ihrem Mann gestanden hatte, dass er nicht der Vater ihres Kindes sei und sie mit mehreren Hochadligen, unter anderen mit dem Prince of Wales, ein sexuelles Verhältnis gehabt hätte. Die dann eingereichte Scheidung überführte diese Vorwürfe in die Medien, die ihr Geständnis über die Ehebrüche in wörtlicher Rede druckten. ${ }^{39}$

Der Skandal zeigte erneut, dass selbst das Königshaus nicht in der Lage war, die öffentliche Berichterstattung und Empörung zu begrenzen. Dass ein öffentliches Gericht einen Thronfolger als Zeugen vernahm, war bereits Ausdruck dieses Kontrollverlustes. Ebenso war schon das Erscheinen des Prinzen ein Zugeständnis an die bürgerliche Rechtsordnung, die seinen Verzicht auf Privilegien untermauern sollte. Vor Gericht schienen zunächst noch die üblichen Korrekturversuche zu greifen. Indem das Gericht die betrügerische Ehefrau für wahn-

36 Tomahawk Mai und August 1867; Hinweise hierauf bereits in: Tom Cullen, The Empress Brown. The Story of a Royal Friendship, London 1969, S. 104.

37 Punch 7.7.1866, S.4: „Court Circular/Balmoral Tuesday. Mr. John Brown walked on the Slopes. He subsequently partook of a haggis. In the evening Mr. John Brown was placed to listen to a bag-pipe. Mr. John Brown retired early."

38 Theo Aronson, The King in Love. Edward VII's Mistresses, London 1988, S.37. Aus dem reichhaltigen populären Buchmarkt über königlichen Mätressen vgl. hier: STANLEY WEINTRAUB, Edward the Caresser. The Playboy Prince who became Edward VII, New York u. a. 2001.

39 Vgl. etwa Prozessbericht Times 19.2.1870, S.11: „,Charlie, I have been very wicked: I have done very wrong.' I said, Who with?' She said: ,With Lord Cole, Sir F. Johnstone, the Prince of Wales, and others, often, and in open day. “ Zu dem Fall vgl. Elizabeth Hamilton, The Warwickshire Scandal, London 1999. Eher eine Biographie, die auch Zeitungsberichte aufgreift, als eine Studie über die Monarchie in der Öffentlichkeit bietet: KINLEY RoBy, The King, the Press and the People. A Study of Edward VII, London 1975. 
sinnig erklärte, machte sie die Schuldfrage irrelevant und bekräftigte das moralische Ansehen des Königshauses, da es demnach nur von einer Verrückten verunglimpft worden sei. Die Zuschreibung des Wahnsinns sollte zugleich die „normale“ weibliche Sexualität herausstellen, die monogam und zurückhaltend war. Ebenso musste sich der Prinz vor Gericht nicht dem üblichen detaillierten Kreuzverhör unterziehen, sondern nur ein paar Fragen beantworten, bei denen er jeden intimen Verkehr mit der Frau zurückwies. Doch selbst diese Fragen des Gerichtes („Has there ever been any improper familiarity or criminal act between yourself and Lady Mordaunt“) rückten den Ehebruch in den allgemeinen Imaginationsraum und unterwarfen den künftigen Monarchen unter ein staatliches und öffentliches Urteil.

Tatsächlich löste der Prozess auch in diesem Fall einen unkontrollierbaren Skandal aus, der die Monarchie diskreditierte. Allein die öffentlichen Zeugenaussagen und verlesenen Beweisstücke über das Privatleben des Prinzen führten zu einem moralischen Reputationsverlust des Königshauses. So erfuhren die Leser, dass Lady Mordaunts Mann in ihrem Schreibtisch Hotelrechungen, Briefe, Blumen, Verse und ein Taschentuch des verheiraten Prince of Wales fand. Zur Diskreditierung des Prinzen trugen zudem die Aussagen des Hauspersonals bei, das öffentlich von heimlichen Besuchen des Prinzen bei Lady Mordaunt berichtete, obwohl ihr Ehemann dies in seiner Abwesenheit verboten hatte, und dass während dieser Besuche niemand sonst ins Haus durfte. ${ }^{40}$ Wie bei anderen Skandalen erhielten Angehörige von Unterschichten so die Möglichkeit, sich aktiv an der Demontage eines künftigen Monarchen zu beteiligen.

Visuelle Darstellungen, wie auf der Titelseite der Illustrated Police News, zeigten den Prinzen ebenfalls als erwischten Nebenbuhler (vgl. Abb. 10). ${ }^{41} \mathrm{Ob}-$ gleich die Bilder nur die innige Zuneigung zwischen Prinz und Lady Mordaunt präsentierten, verstärkte allein schon das hier abgebildete Bett die erotische und spöttische Suggestionskraft. Nicht nur der suggerierte Ehebruch, sondern bereits das heimliche Eindringen in die Privatwohnung des Mannes war dabei ein eklatanter Verstoß gegen die bürgerlichen Normen.

Die im Prozess veröffentlichten Privatbriefe des Prinzen an Lady Mordaunt verstärkten die Banalisierung des Königshauses zusätzlich. Ihr Inhalt, den alle Zeitungen abdruckten, war zwar wenig amourös und drehte sich vornehmlich um die Jagd, Reisen und das Wetter. Doch bereits dies ließ den Spott aufflammen. Der Times erschien er „simple, gossiping, everyday,“ der Reynolds's Newpaper „very silly, very tautological, and very ungrammatical“. ${ }^{42}$ Reynolds sprach dem Prinzen deshalb generell die Eignung zum künftigen König ab, da die Briefe darüber hinaus eine Abhängigkeit von „sensational pleasures“ zeigten und der Prinz der Nation Schande bereite. ${ }^{43}$ Auch die Straßenöffentlichkeit

\footnotetext{
40 Vgl. etwa Prozessbericht Times 21.2.1870, S. 10.

41 Illustrated Police News 26.2.1870, S. 1 und 5.3.1870, S. 1.

42 Times 24.2.1870, S. 8; Reynolds's Newspaper 27.2.1870, S. 4.

43 Reynolds's Newspaper 6.3.1870, S. 4.
} 


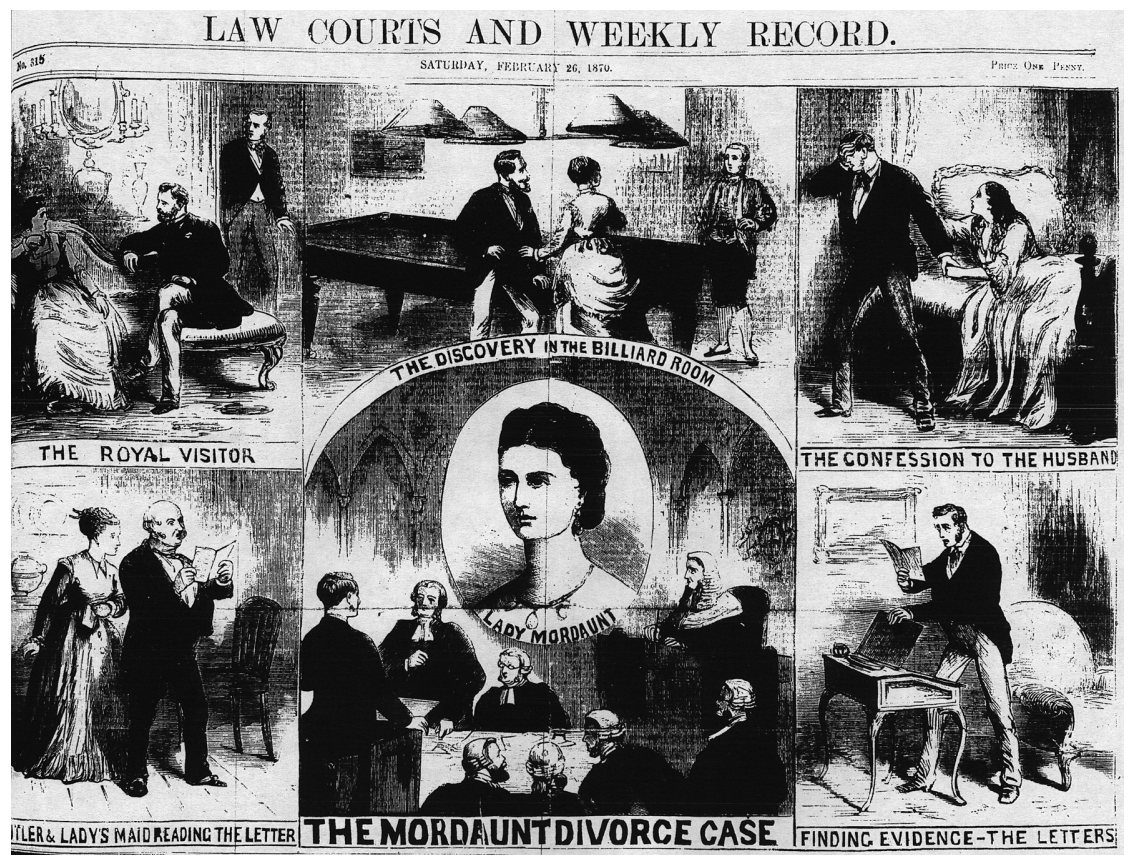

Abb. 10: Der Thronfolger als Ehebrecher in der populären Presse, der durch sein Eindringen in die Privatsphäre das Eheleben zerstört; Quelle: ILLUSTRATED POLICE NEWS 26. 2.1870.

reagierte anscheinend entsprechend. Wie zeitgenössische Berichte andeuten, wurde der Prinz danach auf der Straße verspottet und Schmährufe hinter ihm hergerufen. 44

Ähnlich wie bei der Queen Caroline Affair führte der Skandal zu nachdrücklich formulierten bürgerlichen Erwartungshaltungen an das Könighaus. Die Enthüllungen in dem Prozess aktualisierten Vorwürfe gegen das adlige Sexualleben, die nun auch das Königshaus mit einschlossen. Die Aussagen von Lady Mordaunt (wie „Everyone does it“) verstärkten dabei die Vorstellung, weibliche Adlige würden bürgerliche Normen wie die Monogamie permanent überschreiten. ${ }^{45}$ Welches breite Interesse an derartigen Medienberichten bestand, zeigte sich wie bei der Queen Caroline Affair an den sprunghaft ansteigenden Zeitungsauflagen. Ein kleines Blatt wie The Echo erhöhte seine Auflage auf angeblich 124000 Exemplare. Das belegte, dass die Fähigkeit und das Interesse Zeitungen zu lesen bereits recht groß war, allerdings die Kaufkraft der Unterschichten nur

44 So Havers, Royal Baccarat, S. 20.

45 Reynolds's Newspaper 27.2.1870, S. 3. 
für derartig spektakuläre Berichte ausreichte. ${ }^{46}$ Neben den Zeitungen verkauften Straßenhändler sofort Publikationen mit Titeln wie „The Infidelities of a Prince“ und „Unparalled Revelations.“47

Der Mordaunt Divorce Scandal verstärkte so die um 1870 generell grassierende Monarchiekritik erheblich. Die großen Zeitungen fanden so kritische Worte wie sie in den vorangegangenen fünfzig Jahren wohl nur selten gefallen waren. Selbst in der Times und dem Daily Telegraph war dies deutlich erkennbar. Sie betonten zwar im Sinne des Gerichtes die Unschuld des Prinzen und den Wahnsinn der vermeintlichen Liebhaberin, verurteilten aber scharf seinen Lebenswandel, der angesichts der neuen Massenpresse nicht mehr möglich sei. So formulierte die Times: „He had acted as a young man who does not understand the passion far too many have for scandal, and had given occasion to misconstruction through simple headlessness. "48 Wie bei dem gleichzeitigen Boulton/Park Homosexuellen-Skandal wurde jugendlicher Übermut als Entschuldigung angeführt. Jedoch warnte die Times zugleich, auch Marie Antoinette sei unschuldig gewesen, aber dennoch hätten hinterhältige Indiskretionen zu ihrem Tod und dem Ende der französischen Monarchie geführt. Mit dieser Drohung und der Zuschreibung, dass ein Prinz kein Privatleben habe, verpflichtete sie ihn auf ein künftiges Leben in „domestic purity“. Während die radikalen Zeitungen den Prinzen in die Tradition früherer Könige stellten, betonten auch der Daily Telegraph, dass gerade das moralische Verhalten einstiger Monarchen heute dank einer „modern morality" nicht mehr toleriert würde. ${ }^{49}$ Angesichts dieser „modernen Moral" erschien der Thronfolger wie ein Relikt früherer Unmoral, der durch die öffentliche Verwarnung zu erziehen sei.

Auch die politische Führung deutete den Skandal als ernsthafte Bedrohung für das Königshaus. Öffentlich unterstrich der Prinz zwar mit einer Einladung zum Dinner an das Ehepaar Gladstone seine Verbundenheit mit dem Premierminister. ${ }^{50}$ Intern sprach der Premierminister aber von einem äußerst kritischen Ereignis. Der Königin gegenüber, die ihn um Vermittlung bat, mahnte Gladstone unter Anspielung auf die Queen Caroline Affair warnend zur Zukunft des Throns, „that the revival of circumstances only half a century old tend rapidly to impair its strength and might bring about its overthrow" ${ }^{51}$ Queen Victoria teilte diese Ansicht und schrieb dem Skandal ebenfalls ein gesellschaftsveränderndes Potential zu. So bezeichnete sie das Verhalten ihres Sohnes und der anderen beschuldigten Adligen als einen „amount of imprudence which cannot

6 Vgl. zu diesem : Brown, Victorian News, S. 30.

47 Times 25.2.1870, S. 9.

48 Times 24.2.1870, S. 8; sehr ähnlich: Daily Telegraph 26.2.1870, S. 4.

49 Daily Telegraph 26.2.1870, S. 4.

50 Zur Einladung: Gladstone an Queen Victoria 14.2.1870, abgedr. in: Philipp Guedalla (Hrsg.), The Queen and Mr. Gladstone, Bd.1, London 1933, S. 267.

51 Gladstone an Queen Victoria 23.2.1870, abgedr. in: Philip Magnus, King Edward VII, London 1975 (Erstausgabe 1964), S.144. Gladstones Tagebuch verzeichnet hierzu leider nichts; vgl. Matthew (Hrsg.), The Gladstone Diaries, Bd.7. 
but damage him in the eyes of the middle and lower classes, in their frivolous, selfish and pleasure-seeking lives, do more to increase the spirit of democracy than anything else." 52 Dabei sah die Queen die kritischen Zeitungsartikel über ihren Sohn auch als ein heilsames Mittel, wie sie ihrer Tochter gegenüber erwähnte: „He has however received his warnings now. You read I hope The Times article of the $24^{\text {th }}$ - and a still finer one in The Daily Telegraph of the $26^{\text {th }}$. Have you seen that? B. feels now that these visits to ladies and letter writing are a mistake - to say the least. [...] I hope it will get him to change but it is difficult; still I never give up reminding him of the trial." 53 Die Presse galt selbst der Queen somit als moralische Erziehungsinstanz für den kommenden Monarchen, und nicht etwa umgekehrt.

Dass das Gericht Lady Mordaunt für wahnsinnig erklärte, um das Königshaus zu schützen, verschärfte zusätzlich die Empörung. So zweifelte die Daily News den Wahnsinn der Ehefrau und die Aussagen des Prinzen an. Damit stellte sie explizit eine gerechte Justiz über das Ansehen der Krone. ${ }^{54}$ Am schärfsten fiel erwartungsgemäß der Kommentar der Reynolds's Newspaper aus, die sogar den Ausschluss des Prinzen vom Thron und dem sozialen Leben erwog. Bezeichnender Weise nahm jedoch selbst Reynolds den Fall nicht zum Anlass, die generelle Abschaffung der Krone zu fordern, sondern beschränkte sich auf bürgerliche Normforderungen an den Monarchie. Insofern dürfte der Skandal, pointiert bilanziert, vielleicht sogar mehr dazu beigetragen haben, die Monarchie auf bürgerliche Werte wie Moral, Effizienz und Würde festzulegen, als herausragende ideengeschichtliche Entwürfe wie Walter Bagehots English Constitution (1867). 55

Der Mordaunt-Skandal war zumindest maßgeblich mit dafür verantwortlich, dass die Proteste gegen die viktorianische Monarchie im folgenden Jahr ihr größtes Ausmaß erreichten. Die ständige öffentliche Abwesenheit der Königin und ihre Forderung nach 30000 Pfund für die Hochzeit ihrer Tochter verstärkten den allgemeinen Unmut. ${ }^{56}$ „The Queen is invisible and the Prince of Wales is not respected“, fasste Gladstone 1872 deprimiert die Situation zusammen. ${ }^{57}$ Dennoch blieb es bei diesem kurzen Aufblitzen der Empörung über die Krone. Queen Victoria ging zunehmend auf die öffentlichen Erwartungen ein und

52 Queen Victoria an Lord Chancellor 21.2.1870, abgedr. in: MAgnus, King, S.143.

53 Queen Victoria an Frederick 2.3.1870, abgedr. in: Roger Fulford (Hrsg.), Darling Child: Private Correspondence of Queen Victoria and the Crown Princess of Prussia 1871-1878, London 1976, S.262f.

54 „The interests of royalty, important as they are, are less important than the interests of Justice." Daily News 26.2.1870, S. 4.

55 Zur Bagehots Redefinition der Monarchie vgl. William M. Kunn, Democratic Royalism. The Transformation of the British Monarchy, 1861-1914, London 1996, S. 15-31. Ob man die fünf von Kuhn diskutierten Argumente Bagehots für die Erhaltung der Monarchie als „democratic royalism" bezeichnen sollte, ist allerdings fraglich, da Bagehot vor allem mit der Suggestionskraft der Krone für die Massen argumentiert.

56 Zur historischen Einordnung: TAYLOR, Down, S.81.

57 Abgedr. in: G. E. BuckLE (Hrsg.), Letters of Queen Victoria, Bd.1, London 1926, S. 244. 
erreichte gerade durch ihre Mischung aus stärkerer öffentlicher Präsenz und gleichzeitiger politischer Zurückhaltung seit den 1880er Jahren den Höhepunkt ihrer Beliebtheit. Da die Queen kaum selbstständig eine Medienpräsenz suchte, wird man zugleich davon ausgehen können, dass die öffentliche Sehnsucht nach einer visuell präsenten Monarchin zu ihrer inflationären medialen Verbreitung und Beliebtheit führte. ${ }^{58}$

Der Prince of Wales blieb dagegen zunächst wenig respektiert und änderte sein moralisches Verhalten nach dem Skandal kaum. Vielmehr riskierte er weitere Verhältnisse mit Frauen, die ihn in die Nähe von neuen Skandalen brachten. So wurde er wegen Liebesbriefen erpresst, die eine Geliebte zu veröffentlichen drohte, und 1879 kam es abermals in einem kleinen abseitigen Blatt namens Town Talk zu Andeutungen über eine Affäre. Dabei meldete der junge Journalist Rosenberg, der Prinz sei als co-respondent im Scheidungsprozess des Ehepaar Langtry genannt..$^{59}$ Dieser Fall machte jedoch deutlich, dass sowohl die Gerichte als auch die britischen Medien es ganz überwiegend vermeiden wollten, erneut das Sexualleben des Prinzen öffentlich zu machen. Rosenberg wurde wegen Verleumdung verklagt, zunächst erwähnte die Times aber keine Hinweise auf die Verwicklung des Prinzen. ${ }^{60} \mathrm{Im}$ Prozess und der Urteilsverkündigung wurde der Vorwurf zwar benannt, die harte Strafe von 18 Monaten Haft gegen den Journalisten aber wegen ihrer abschreckenden Wirkung begrüßt. ${ }^{61}$ Selbst Reynolds's Newspaper druckte nur zurückhaltend die Prozessberichterstattung ab. ${ }^{62}$ Gerade wegen der harten Bestrafung war dieser Fall vor allem ein Signal an die Journalisten, dass der Abdruck von entsprechenden Gerüchten auf keinerlei Toleranz des Staates treffen würde. Tatsächlich folgten, soweit ersichtlich, darauf keine entsprechenden Artikel mehr. Zumindest bei diesem Fall zeigte sich damit, dass die Libel Lawes zur Sicherung des Ansehens der Krone eine ähnlich repressive Wirkung entfalten konnten wie die repressive Pressepolitik in Deutschland, die auch nach dem liberalen Reichspressegesetz von 1874 durch die Bestrafung von Majestätsbeleidigung entsprechende Artikel zu unterbinden suchte. Nachdem das Ansehen der Monarchie in zwei großen Sexualitätsskandalen attackiert worden war, verzichtete die Presse mit einem erstaunlichen Konsens auf weitere Enthüllungen.

Insofern lässt sich bilanzieren, dass von den Sex-Skandalen des 18. und 19. Jahrhunderts eben keine direkte Linie zu jenen Skandalen des Königshauses führte, wie sie heute in Großbritannien bekannt sind. Die Politisierung der Printmedien und die Ausbildung der Massenpresse verschoben nur punktuell

58 Diese öffentliche Sehnsucht zeigt vielfach: Plunkett, Queen Victoria. Die zahlreichen Biographien heben die Figur der „Imperial Matriarch“ zwar hervor, deuten sie aber kaum als Ergebnis der Medialisierung; vgl. etwa WaLter L. Arnstein, Queen Victoria, Basingstoke 2003, S. 165-194.

59 Hinweise bei Aronson, Prince, S.115f.

60 Times 16.10.1879, S.11.

61 Times 27.10.1879, S. 4 und 28.10.1879, S. 9.

62 Reynolds's NewsPaper 2.11.1879, S. 2. 
die Grenzen des Schreibbaren, etablierten aber keine permanente Skandalisierung entsprechender Normverstöße. Latent bekannte Gerüchte gelangten nur dann in die Presse, wenn Prozesse eine entsprechende Öffentlichkeit schufen und sich gesellschaftliche Konfliktsituationen mit einer Monarchiekritik vermischten, die sich aus anderen Quellen speiste. Die Marginalisierung jener Journalisten, die entsprechende Gerüchte gelegentlich in die Presse brachten, zeigte hingegen, dass vielfach der Schutz der Krone höher stand als eine verkaufsträchtige Enthüllung.

Im deutschen Kaiserreich spielten dagegen die sexuellen Normbrüche des Hohenzollernhauses keine vergleichbare Rolle. Sicherlich lassen sich im 19. Jahrhundert einzelne Fälle ausmachen, bei denen auch deutsche Königshäuser an moralischen Tugendmaßstäben gemessen wurden. Parallelen zu einem Skandal wie der Queen Caroline Affair wies am ehesten die Lola Montez-Affäre des bayerischen Königs Ludwig I. 1847/48 auf, die sich aus seiner Liaison zwischen dem Monarchen und einer britischen Tänzerin entwickelte. Lola Montez, die sich als eine spanische Tänzerin ausgab, hatte bereits in ganz Europa Skandale ausgelöst, als sie 1846 nach München kam und die Geliebte von Ludwig I. wurde. Wie bei der Queen Caroline Affair entstand hieraus ein Skandal mit breiten öffentlichen Protesten, die schließlich sogar den Rücktritt des Königs einleiteten und die Dynamik der Revolution von 1848 in Bayern verstärkten. Ebenso ging die Empörung über die Affäre mit Vorwürfen gegen monarchische Willkür und Verschwendung einher. Sie bezog sich auf die Einbürgerung und Standeserhebung von Lola Montez, die Schließung der Münchener Universität nach Protesten gegen die Begünstigung Lola Montez' sowie die Entlassung von protestierenden Ministern. ${ }^{63}$ Und ähnlich wie Queen Caroline interagierte auch Lola Montez mit den Medien, um ihre Stellung zu sichern, indem sie sowohl die deutsche als auch die internationale Presse mit Zuschriften versorgte, um auf die öffentlichen Vorwürfe zu antworten. ${ }^{64}$

Zugleich zeigt jedoch ein Blick in die zeitgenössische Presse, dass sich der bayerische Skandal von dem englischen Fall unterschied. So bezog sich die mediale Kritik im geringeren Maße auf den Monarchen als auf seine Liebhaberin, deren Vertreibung als die Lösung des Problems galt. ${ }^{65}$ Weniger dem König als der Geliebten wurde die Usurpation willkürlicher Macht, der Bruch von moralischen Verhaltensweisen und die Auslösung von Unruhen vorgehalten. Offensichtlich sorgte die wesentlich rigidere Zensur für eine (Selbst)Beschränkung, die selbst in dem damals relativ liberalen Bayern zu deutlich tabuisierteren Medienberichten als in England führten. Die politische Skandalisierung des

63 Von den zahlreichen Publikation zu Lola Montez vgl. etwa: Bruce Seymour, Lola Montez. A Life, New York 1996; Ishbel Ross, The Uncrowned Queen. Life of Lola Montez, New York u.a. 1972.

64 Vgl. etwa ihre Zuschriften in: Times 18.3.1847, S. 6 u. 9.4.1847, S. 5.

65 Ausgewertet wurden von mir die Vossische Zeitung und die Augsburger Allgemeine ZeiTUNG für die Zeit der Hauptkonflikte um die Mätresse (Febr. 1847, Febr./März 1848). 
Monarchen verlief stattdessen stärker über die mündliche Öffentlichkeit, über Flugschriften und Zeitungen aus Nachbarländern, deren Kritik moralischen Druck auf den König ausübte. Sie zeigte den Monarchen etwa kaum bekleidet als Lüstling und teuflischen Bock, während Lola als Höllenwesen ebenfalls in die christliche Ikonographie eingeschrieben wurde. ${ }^{66}$

Auch bei der Lola Montez-Affäre kam es zu einer intensiven länderübergreifenden Wahrnehmung des Skandals. Englische Presseberichte bezogen dabei das Verhalten von Ludwig I. auf frühere Skandale und Verhaltensweisen der einstigen „Georgian Kings“, nicht ohne auf deren deutsche Herkunft hinzuweisen. ${ }^{67}$ Damit stellte sich die britische Öffentlichkeit auf eine moralisch höher entwickelte Stufe, da sie angesichts der regierenden Queen Victoria derartige Skandale überwunden glaubte. Insgesamt stand der Lola Montez-Skandal somit trotz der Zensur für einen Kontrollverlust, durch den das private und politische Verhalten des Königs als unzeitgemäß erschien.

Wie sehr sich zwischen 1848 und der Jahrhundertwende die Form der Berichterstattung und die verhandelten Normen veränderten, zeigt ein vergleichender Blick auf den Scheidungsskandal der 37jährigen Kronprinzessin Luise von Sachsen, einer Tochter des Großherzogs Ferdinand IV. von Toskana. Sie hatte 1891 den Prinzen Friedrich August von Sachsen geheiratet, der 1904 den sächsischen Königsthron bestieg. Im Jahr zuvor ließ er sich jedoch von seiner Frau scheiden, nachdem sie beim Ehebruch mit ihrem belgischen Sprachlehrer überrascht worden war. ${ }^{68} \mathrm{Da}$ der Scheidungsprozess im Unterschied zu England unter Ausschluss der Öffentlichkeit stattfand, konnten die Journalisten jedoch weiterhin den Ehebruch selbst nicht derartig detailliert thematisieren wie in Großbritannien. Dennoch publizierten nun alle Zeitungen monatelang umfangreiche Artikel über den Fall, was sowohl das breite Interesse selbst seriöser Zeitungen zeigte als auch erneut die Grenzen der Zensur. ${ }^{69}$

Auch dieser Gesellschaftsskandal eröffnete vielfältige Zuschreibungen über die Stellung der Monarchie innerhalb der Gesellschaft und die Rolle von adligen Frauen. Während 1847/48 Lola Montez noch als verdammungswürdige Verführerin erschien, zeigten nun zumindest einige Artikel Verständnis für die adlige Ehebrecherin. So urteilte der konservative Reichsbote: „So gerecht das Urteil über den schmachvolle Ehebruch der Prinzessin auch ist, so drängt sich einem doch unwillkürlich der Gedanke auf, wie leicht über den von Männern verübten Ehebruch meistens hinweg gegangen wird, und wie unglückliche Frauen, die unter demselben zu leiden haben, ohne Rechtshilfe ihrem Schicksal überlassen

66 Vgl. etwa die Bilder in: Eduard Fuchs, Ein vormärzliches Tanzidyll. Lola Montez in der Karikatur, Berlin o. D. (1904).

67 Vgl. etwa: Times 2.3.1847, S. 5; Times 9.3.1847, S. 6; ein Journalist des Fraser's Magazine sah dagegen Lola Montez als liberale Vorkämpferin; SEYmour, Lola, S. 168.

68 Vgl. von den zahlreichen populärwissenschaftlichen Darstellungen bes.: ERIKA BeSTENREINER, Luise von Toscana. Skandal am Königshof, München 2000.

69 Vgl. etwa: Berliner Tageblatt Nr.81, 14.2.1903, Münchner Neueste Nachrichten Nr.70, 12.2.1903. 
werden.“70 Verschiedene Blätter verteidigten sie zudem als Opfer der „Ultramontanen “ und Jesuiten. ${ }^{71}$ Andere Zeitungen druckten Briefe der Prinzessin, die ihr Leiden und ihre Liebe zu den Sachsen ausdrückten. ${ }^{72}$ Ähnlich wie Caroline und Lola Montez war die Prinzessin damit nicht nur ein „Opfer“ der Medien, sondern bediente sich dieser, um ihre Position zu verteidigen. Die sozialdemokratischen Zeitungen sahen die Prinzessin nicht nur als Musterbeispiel für die Auflösung des höfischen Ehelebens. Sie galt ihnen auch als ein Opfer von Standesherrschaft und Klerikalismus, die nur frei von den Zwängen des Hofes leben wollte und dafür bestraft würde. ${ }^{73}$ Ähnlich interpretierten auch die Arbeiter in den Kneipen den Fall. Laut Spitzelberichten sahen sie den Ehebruch und die Verstoßung als typisch für die Hofgesellschaft an: „das traurige wäre ja bei solchen Leuten, daß sie nie nach ihrem Wunsch heiraten könnten. “74 Trotz anderer Stimmen, die wie Maximilian Harden die Prinzessin als „moderne Frau" karikierten, zeichnete sich damit eine Interpretation ab, die, neben einer moralischer Verdammung des Hochadels, wie bei der Queen Caroline Affair Empathie für die betroffenen Frauen aufbrachte. ${ }^{75}$

Dass die deutschen Monarchen in der zweiten Hälfte des 19. Jahrhunderts kaum in große „Sex-Skandale“ verwickelt waren, lag jedoch sicherlich nicht an ihrer Lebensführung. Die homoerotischen Neigungen des bayrischen Königs Ludwigs II. etwa waren den Zeitgenossen zumindest gerüchteweise bekannt. Dennoch blieben entsprechende Kommentare in den Zeitungen, soweit ersichtlich, selbst im Zuge seiner Entmündigung und seines anschließenden plötzlichen Todes aus. ${ }^{76}$ Angriffspunkte gewährte auch der Lebenswandel des jungen Kronprinzen und späteren Kaisers Wilhelm II. Wie John Röhl gezeigt hat, verkehrte Wilhelm auch nach seiner Heirat noch recht offen mit verschiedenen Prostituierten, mit denen er nicht nur Briefe und Fotos austauschte, sondern anscheinend auch uneheliche Kinder hatte. ${ }^{77}$ Die Berater des Kaisers mussten daher mehrfach hohe Erpressungsgelder zahlen. Bismarcks Sohn Wilhelm, der zu den Unterhändlern zählte, riet zu einem großzügigen Aufkauf, da sie „ungeheuren

70 Reichsbote Nr.37, 13.2.1903.

71 Vgl. etwa Berliner Extrapost 7.2.1903; weitere Meldungen und Zurückweisungen dessen in: Historisches Archiv Köln, 1006 Nr. 189.

72 Berliner Tageblatt Nr. 85, 16.2.1903.

73 Vgl. die zahlreichen Beiträge in: BA/K, ZSg 113-517.

74 Vigilanzbericht Schutzmann Struve 24.12.1902, in: StAH, S 3930-23 Bd. 9.

75 Harden, Zukunft, 5.1.1903, S.1-13, zit. S. 2.

$76 \mathrm{Ob}$ Ludwig II. homosexuell war, ist unter seinen zahlreichen heutigen Biographen nicht nur umstritten, sondern auch weiterhin nur andeutungsweise sagbar; vgl. etwa Hütls Urteil: „Seine zwischenmenschlichen Beziehungen entsprachen nicht der Norm und stempelten ihn zum Außenseiter. Die wechselnden Favoriten, die er auswählte, gaben seit je her Anlaß zu entsprechenden Vermutungen. “ Ludwig HüTtL, Ludwig II., München 1986, S.388. Keine Belege für die praktizierte Homosexualität sieht: Christopher McIntosh, The Swan King. Ludwig II of Bavaria, New York 2003 (Erstauflage 1982), S. 157.

77 So John C. G. RöHL, Wilhelm II. Die Jugend des Kaisers 1859-1888, München 1993, S.46567; DERs., Wilhelm II. Der Aufbau der persönlichen Monarchie, München 2001, S. 232-237. 
Skandal“ hervorrufen könnten. ${ }^{78}$ Herbert Bismarck verteidigte diese Skandalabwehr seinem Vater gegenüber mit dem Hinweis auf die veränderte mediale Stellung des Monarchen:

Nach meiner Auffassung ist die Sache nur ein pudendum. Heutzutage machen solche Sachen nur mehr Lärm als früher, weil die Presse viel verbreiteter u. gemeiner ist, als früher, u. weil der Deutsche Kaiser mehr en vue ist, als irgend ein anderer Mensch oder Monarch, u. von übelsten Elementen, die die verworfenste Presse haben - Franzosen, Jesuiten, Socialisten, Juden - auf das Bitterste gehaßt wird. ${ }^{79}$

Die Annahme, die „Sensationspresse“ und die politischen Gegner könnten durch solche Informationen die Monarchie stürzen oder beschädigen, führte somit zu verstärkten Sicherheitsmaßnahmen, um das Privatleben des Monarchen den bürgerlichen Konventionen entsprechend erscheinen zu lassen. Zugleich spielten diese Aufkäufe den Bismarcks belastendes Material in die Hand, dass bei einer Eskalation des Konfliktes mit dem Kaiser durchaus eine letzte Waffe sein konnte.

Trotz, oder vielleicht gerade wegen seiner eigenen früheren Normbrüche sorgte sich Wilhelm II. energisch um das moralisch korrekte Verhalten seiner Verwandtschaft. Verschiedentlich maßregelte er sie mit scharfen Briefen, um Skandale zu verhindern. ${ }^{80}$ Drangen dennoch entsprechende Meldungen in die Presse, wie bei der Liebesaffäre von Prinz Joachim Albrecht von Preußen mit einer verheirateten Frau, erteilte er Sanktionen. So musste der Prinz zur moralischen Erziehung beim Krieg in Südwest-Afrika teilnehmen. Zudem wurden ihm symbolische Gesten verweigert, wie der Handschlag beim Hoffest. ${ }^{81}$ Tatsächlich hoben die bürgerlichen Presseberichte über Wilhelm II. immer wieder seine moralische Vorbildlichkeit hervor, während monarchiekritische Blätter selbst im Kontext der Eulenburg-Affäre von Andeutungen über sexuelle Verfehlungen absahen. Anzunehmen ist, dass nicht allein die drohenden Verurteilungen und Zensurmaßnahmen von derartigen Deutungen abhielten. Vielmehr gab gerade sein politisches Engagement genügend Anlass für Kritik und Empörung. Gerade weil Wilhelm als politische Instanz auftrat, brauchte er in geringerem Maße an moralischen Ansprüchen gemessen werden.

\section{Der Prinz als GlüCKSSPieler}

Auch die Skandale des britischen Königshauses drehten sich im ausgehenden 19. Jahrhundert kaum noch um sexuelle Verfehlungen. Dennoch stand die mo-

78 W. von Bismarck an H. von Bismarck, zit. nach RöHL, Wilhelm II. Der Aufbau, S. 233.

79 H. von Bismarck an O. von Bismarck 25.11.1888, zit. nach ebd. S. 235.

80 Einige Beispiele hierfür in: Lothar Machtan, Wilhelm II. als oberster Sittenrichter: Das Privatleben der Fürsten und die Imagepolitik des letzten deutschen Kaisers, in: ZfG 54 (2006), S. 5-19.

81 Vgl. die Einträge hierzu im Tagebuch Zedlitz-Trützschler, Zwölf Jahre, S. 164 u. $190 f$. 
ralische Lebensführung weiterhin im Mittelpunkt der Aufmerksamkeit. Während Queen Victoria nun, nicht zuletzt aufgrund ihres Alters, wieder uneingeschränkt als moralisches Vorbild galt, bot der Lebenswandel des Prince of Wales weiter Anlässe für kritische Reflexionen. Hierzu zählte insbesondere seine Spiel- und Wettleidenschaft. Sie mündete 1891 in den Baccarat Scandal, dem sicherlich bedeutendsten britischen Monarchie-Skandal im ausgehenden 19. Jahrhundert. Auch dieser Skandal trug bürgerliche Erwartungen an die Monarchie und den Adel heran und verhandelte zugleich generelle Normen - in diesem Fall die Zulässigkeit von Glücksspielen.

Die Kritik an der Spielleidenschaft des Prinzen war nicht neu. Sie zählte bereits seit längerem zu den festen Topoi der radikalliberalen Presse. So berichtete die auflagenstarke Reynolds's Newspaper schon im Zuge der Monarchiekrise 1870/71, der Prinz würde im Bad Homburger Casino jenes Geld am Roulettetisch verspielen, das die englische Arbeiterklasse in ihrem Schweiß erarbeitet hätte, während der Prinz selbst niemals einen Penny erwirtschafte. ${ }^{82}$ Selbst wenn man in Deutschland offen zu Glücksspielen auffordere, müsse der Prinz auch im Ausland ein Vorbild für die englische Gesellschaft sein. Anderenfalls tauge er kaum als Thronfolger. Zugleich verwies das Blatt auf die harten Strafen, die normale Bürger für das Glückspielen erhielten. Die grundsätzliche Kritik an der Spielleidenschaft des Thronfolgers bezog sich somit auf die Verschwendung, Ausbeutung und Doppelmoral, auf eine Zweiklassenjustiz und einen fehlenden bürgerlichen Arbeitsethos. Ebenso spielte der linksliberale Star auf die Baccaratleidenschaft des Prinzen an, als es 1889 um die Bewilligung von 40000 Pfund ging: „What guarantee have we that the money will not go to Monte Carlo or the gambling table?" 83 , fragte er und sprach von 11000 Pfund, die der Prinz gerade bei einem Baccaratspiel mit Baron Hirsch gewonnen habe. Der sogenannte Baccarat-Skandal von 1891 knüpfte insofern an eine bestehende Kritik an, die jedoch bisher noch nicht zu einem Skandal geführt hatte.

Voraussetzung für die wirkungsmächtige Empörung war zunächst - wie bei den Ehebruchsskandalen - eine Verschiebung der öffentlichen Bewertung des Glückspiels, die in den 1880 er Jahren einsetzte. Da es sich bei Baccarat um ein reines Glückspiel handelt, war es unter Geldeinsatz prinzipiell illegitim. Die bürgerliche Presse sah in dem Kartenspiel, wie bei den meisten moralischen Normbrüchen, spöttisch ein französisches Laster. ${ }^{84}$ Ähnlich wie in Sexualfragen nahmen seit Mitte der 1880er Jahre die Versuche zu, Glücksspiele zu kontrollieren und einzudämmen. Weil der Gaming Act von 1845 nur ungenau die illegitimen Spielpraktiken festschrieb, bestanden wie bei anderen Normbrüchen Spielräume, die durch Präzedenzfälle auszuloten waren. So urteilte ein Richter 1884, nachdem die Polizei eine vornehme Spielstätte namens Park Club ausgehoben hatte, „while baccarat is at common law a lawful game, it can become unlawful

82 Reynolds's Newspaper 24.9.1871, S. 5.

83 STAR 20.7.1889, S.1.

84 Vgl. noch vor dem Skandal: Times 11.6.1890, S. 10. 
if [...] it is played: (i) (per Hawkins J.) to excess (ii) so as to injure public morals (iii) in a house kept for the purpose of playing it [...]. "85 Da der Ermessensraum selbst nach diesem Urteil groß blieb, fielen die Strafen unterschiedlich aus. Die zeitgenössische Kritik der späten 1880er Jahre wies deshalb wie bei den sexuellen Normverstößen auf die geringen Strafen für Spieler aus den Oberschichten hin, wo das Glückspiel zunehmend verbreitet sei. ${ }^{86}$ Damit verlagerte sich auch hier der kritische Blick vom armen Londoner East-End auf das reiche WestEnd. 1889 machte die Polizei erneut verschiedene Glücksspielstätten aus. Die ausführlichen Presseberichte dürften mit dazu beigetragen haben, dass sich 1890 die National Anti-Gambling League gründete, die gegen das Glücksspiel und das in England weitverbreitete Wetten allgemein vorging. ${ }^{87} \mathrm{Um} 1890$ war somit das Narrativ des reichen Spielers, der ungestraft große Einsätze verspielte, im öffentlichen Diskurs recht präsent.

Ausgelöst wurde auch der Baccarat-Skandal nicht durch eine investigative Presserecherche, sondern durch einen Gerichtsprozess, der sich aus Streitigkeiten innerhalb des hohen Adels entfaltete. Ein langjähriger Freund und Spielpartner des Prince of Wales, Sir William Gordon-Cumming, leitete ihn im Februar 1891 ein. Der Baron und Oberstleutnant in den Scots Guards hatte mit dem Prince of Wales und anderen Adligen im September 1890 bei einer Einladung auf dem Schloss Tranby Croft Baccarat gespielt. Nachdem er an zwei Abenden vor allem vom Prince of Wales 225 Pfund gewonnen hatte, beschuldigten seine Mitspieler ihn des Falschspieles. Sie nötigten ihn, eine Erklärung zu unterschreiben, in der er sich zu völliger Abstinenz beim Glücksspiel verpflichtete, wofür die Mitspieler stillschweigen wollten. Wie die Beteiligten später aussagten, machten sie dies „to avoid an open row and scandal." 88 Tatsächlich führte genau diese Verpflichtung erst zum Skandal, da Gordon-Cumming einige Zeit später hierin eine Verleumdung sah, von der er sich nun zur Rettung seiner Ehre durch einen Prozess freisprechen wollte. ${ }^{89}$ Gerade der Versuch, ein Geheimnis mit Nachdruck zu schützen, führte somit auch bei diesem Skandal zu dessen Veröffentlichung.

Wie bei allen Skandalen leitete bereits die Prozessankündigung im Februar 1890 Presseberichte, Parlamentsanfragen und öffentliche Diskussionen ein, die jedoch erst mit dem Prozess vier Monate später ihre volle Dynamik erhielten. Da der Reputationsverlust für die Krone absehbar war, weil der Prinz als einer

85 Zit. nach: DAvid Miers, Regulating Commercial Gambling. Past, Present and Future, Oxford 2004, S. 67.

86 Vgl. zeitgenössisch zu den Gerüchten über die „West End Clubs“ etwa: G. STUdTField, Modern Gambling and Gambling Laws, in: The Nineteenth Century 26 (1889), S. 840-860.

87 Lediglich auf die recht bedeutungslose Anti-Gambling League, nicht auf Skandale bezogen: David C. Itzkowitz, The (other) Great Evil: Gambling, Scandal, and the National AntiGambling League, in: GarRigan (Hrsg.), Victorian Scandals, S. 235-256.

88 Prozessprotokoll nach: DaILY News 2.6.1891, S.2.

89 Zum Ereignisablauf, allerdings ohne eine weitere historische Einordnung, vgl. ausführlich aus der "Classic Crime Series“: Michael Havers et al., The Royal Baccarat Scandal, London 1977; zudem: Magnus, Edward VII, S. 279-289; RoвY, King, S. 229-259. 
der wichtigsten Zeugen erscheinen sollte, versuchte das Königshaus einzugreifen. Allerdings zeigte sich erneut der Kontrollverlust der Krone. Vertraute des Prinzen versuchten vergeblich, den vermeintlichen Falschspieler Gordon-Cumming von seiner Klage abzuhalten. Als das nicht gelang, erbaten sie, ebenfalls vergeblich, Premierminister Salisbury solle gegenüber dem Gericht eingreifen. Der Premierminister hielt sich jedoch zurück - vermutlich gerade wegen seiner Erfahrung im Cleveland Street Scandal kurz zuvor, bei dem Salisbury durch sein Eingreifen selbst in den Mittelpunkt des Skandals gerückt war. ${ }^{90}$ Eine weitere Taktik war, Gerüchte über den Prozessverlauf in den Medien zu verbreiten. So sprach der Anwalt der Adligen in einem Zeitungsartikel frühzeitig den Kronprinzen von aller Schuld frei. Eine andere Strategie verfolgten liberale Blätter, die aus „well-informed circles“ berichteten, der Prinz müsse vor Gericht nicht ins Kreuzverhör. ${ }^{91}$ Die so suggerierte Zweiklassenjustiz sollte gerade ein Kreuzverhör unausweichlich machen.

Die Zeugenaussagen im Prozess machten wiederum zahlreiche Details über das Privatleben des zukünftigen Monarchen öffentlich, die gerade durch ihre Banalität für Spott sorgten. Das zentrale Bild des Skandals, in dem die Empörung in den Artikeln, Karikaturen und persönlichen Reflexionen kulminierte, war die Annahme, der Prinz führe stets sein eigenes Baccaratspiel bei sich. Offensichtlich hatte der Prinz bei der Einladung in Tranby Croft die Gastgeber, die mit Baccarat wenig vertraut waren, sofort zum Spiel aufgefordert, seine eigenen Spielsteine herausgeholt und die wichtige Rolle der Bank übernommen. Dieses Bild bildete das Grundmotiv der öffentlichen Vorwürfe: „It was played with his counters, specially taken down for the purpose“, monierte die Times, und die Pall Mall Gazette beklagte „a set carried about by him wherever he goes“. Auf der Straße rief man dem Prinzen nach: „Have you brought your counters?“92 Auf diese Weise etablierte sich die Vorstellung eines spielsüchtigen Thronfolgers, der jederzeit seine Spielsteine bereit hielt, genau wie, so die Daily News, ein Mohammedaner seinen Gebetsteppich oder, so ein Abgeordneter, ein Trinker seiner Flasche. ${ }^{93}$

In dem Skandal wurden wiederum verschiedene Normen ausgehandelt. Zum einen ging es um die offene Frage, inwieweit Glücksspiele generell zulässig seien. Dabei kam es zunächst zu einer bemerkenswerten Umdeutung. Im Parlament antwortete etwa der konservative Innenminister Henry Matthews auf entsprechende Anfragen - nicht zuletzt um den Prinzen zu schützen -, das Glücksspiel sei in einem Privathaus erlaubt. ${ }^{94}$ Sowohl die zahlreichen Nachfragen der

\footnotetext{
Vgl. Kap. II. 4. Zur Anfrage bereits: Magnus, Edward VII, S. 287.

Pall Mall Gazette 17.2.1891; Echo 17.3.1891, nach Times 25.3.1890, S. 3.

92 Pall Mall Gazette 4.6.1891; Times 10.6.1891, S.9. Eine Sammlung von Karikaturen findet sich in: Review of Reviews Juli 1891, bes. S.16-22.

93 Daily News 5.6.1891, S.2.

94 „I am advised that it is not an offence against the Gaming laws to play baccarat in a private house." 13.2.1891, Hansard's Parliamentary Debates, 3rd Series, Bd.350, Sp.613; vgl. auch seine Antwort: 26.2.1891, ebd., Sp.1697.
} 
Journalisten beim Innenministerium als auch die internen Vermerke des Ministeriums zeigen, dass dies als erstaunliche Neuinterpretation galt. ${ }^{95}$ Die Forderung nach einem schärferen Vorgehen gegen das Glücksspiel, das der Abgeordnete Morton vor allem mit der Oberschicht verband, lehnte der Innenminister $\mathrm{ab}$ und bezeichnete dies als einen lächerlichen Eingriff in die Privatsphäre, da Agenten der Justiz und Polizei nicht in Privathäusern verfolgen könnten, ob Familien um einige Pennies Baccarat spielten. „Such an investigation of the amusements of every private family would be a most intolerable tyranny, and the country would not bear it. "96 Ebenso hielt der konservative Premierminister Salisbury intern fest, dass er selbst zwar Geldspiele ablehne, sie aber toleriere solange sich die Spieler dies leisten könnten. ${ }^{97}$ Damit verschob das Verhalten des Prinzen sowohl Rechtsinterpretationen als auch soziale Normen.

Diese Umbewertung des Glücksspiels zeigte sich auch in der Urteilsbegründung des Richters. Er äußerte Verständnis für den Prinzen, da man dem einfachen Mann, der sich nach einem harten Arbeitstag ein wenig Vergnügen gönne, dies auch nicht verübeln würde. ${ }^{98}$ Die meisten Zeitungen vertraten mit Blick auf das Glückspiel im allgemeinen eine ähnliche Deutung. Selbst die moralistische Pall Mall Gazette betonte, das Spielen von Baccarat sei generell kein schweres Vergehen. ${ }^{99}$ Ebenso bewertete W. T. Stead in der Review of Reviews das Spielen als etwas, was der Prinz zur Entspannung benötige. ${ }^{100}$ Somit führte der Skandal überraschender Weise eher zu einer Lockerung der Normen, indem Glücksspiele als ein zwar nicht wünschenswertes, aber tolerierbares Privatvergnügen umgedeutet wurden. Kaum Beanstandung fanden zudem die Wetten beim Pferderennen, mit denen sich der Prinz wie gewöhnlich auch an dem besagten Wochenende in Tranby Croft vergnügt hatte. Die Geistlichen und nonkonformistischen Gruppen, die aus dem Fall die öffentliche Forderung nach einem generellen Verzicht auf Glücks- und Wettspiele ableiteten, wurden zwar in den Zeitungen zitiert, blieben jedoch in der Minderheit. ${ }^{101}$

Diese insgesamt liberale Deutung des Glücksspieles wurde allerdings mit Blick auf den Prinzen eingeschränkt. Fast die gesamte Presse empörte sich über das Verhalten des Thronfolgers. Der Skandal festigte und präzisierte dabei die normativen Anforderungen an sein Leben und seine Aufgaben. So stellte die Times fest, dass der Prinz im Unterschied zu normalen Bürgern kein Anrecht

95 Vgl. etwa den internen Vermerk der verwunderten Mitarbeiter, der Minister habe bisher angewiesen, "the police must not countenance baccarat even in social clubs or private houses." 14.7.1891, in: TNA, HO 45/9726/ A 52553.

96 17.3.1891, Hansard's Parliamentary Debates, 3rd Series, Bd.351, Sp. 1286.

97 Salisbury an Cadogan o. D. (um 6.6.1891) und 19.6.1913, in: HLRO, Cadogan Papers, RC 65 u. 81.

98 Gerichtsaussagen nach Prozessbericht nach: Daily News 10.6.1891, S. 2.

99 Pall Mall Gazette 10.6.1891, S.1 und 15.6.1891, S.1. Ähnlich etwa: Standard 10.6.1891.

100 Review of Reviews Juli 1891, S. 23-34.

$101 \mathrm{Vgl}$. die öffentlichen Stellungnahmen von unterschiedlichen Kirchenvertretern bes. in: Times 10.6., 12.6. und 15.6.1891, S.6; Reynolds's Newspaper 14.6.1891, S. 5; Pall Mall Gazette 15.6.1891, S. 1 und 5. 
auf ein Privatleben habe, sondern stets der Öffentlichkeit verantwortlich sei. ${ }^{102}$ Da ihm die Zeitungen die Aufgabe zuschrieben, ein moralisches Vorbild zu sein, erschien sein Zeitvertreib mit Glücksspielen als völlig unzulässig. Die liberale Daily News formulierte dementsprechend:

The Prince of Wales is bound to a pure, a simple, and a cleanly life as rigorously as if the obligations were set down in some constitutional pact. He is not here to command our armies, or even to initiate great measures of policy, but, in some sort, to show, in the higher station, how life in every station should be lived. Woe to the Monarchy when it can not perform what may fairly be called its last surviving use. ${ }^{103}$

Stärker als beim Mordaunt-Skandal artikulierten die Zeitungen somit die Drohung, der Prinz würde durch sein Verhalten zur Abschaffung der Monarchie beitragen. Noch deutlicher forderte der irenfreundliche liberale Star, das englische Königshaus müsse des Landes Wert sein, da es sonst, wie eine nicht-geachtete Flagge, keinen weiteren Sinn habe. ${ }^{104}$ Dem zukünftigen Monarchen wurde damit erneut auferlegt, durch sein privates und öffentliches Leben bürgerliche Werte nach außen zu repräsentieren - oder auf den Thron zu verzichten.

Die Zeitungen selbst waren sich ihrer exzeptionellen Form der Monarchiekritik bewusst. „Never perhaps during the present reign has there been such an outspoken criticism of one so near the Throne“, resümierte die Pall Mall Gazette ihre ausführliche Presseschau. ${ }^{105}$ Der Verweis auf die Halsbandaffäre unterstrich in anderen Blättern die drohenden Konsequenzen. ${ }^{106}$ Lediglich W. T. Stead zog aus dem Skandal einen geradezu konträren Schluss. Er argumentierte, gerade weil der Kronprinz keine politischen Aufgaben habe, würde er sich derartigen Zerstreuungen hingeben. Daher müsse man ihm mehr Verantwortung geben. ${ }^{107}$ Steads Argument ließ sich vielleicht jedoch eher umgekehrt erweitern: Gerade weil die Krone sich politisch zurückhielt, fand im Unterschied zu Deutschland der Lebensstil des Prinzen eine derartig hohe öffentliche Aufmerksamkeit.

Über das Glückspiel hinaus diskreditierte der Skandal den Hochadel insgesamt, weil er zu einer minutiösen exemplarischen Veröffentlichung ihres Alltags führte. Das Wochenende auf dem Schloss Tranby Croft bestand, wie die Zeugenaussagen deutlich machten, vornehmlich aus Essen, Glückspiel mit hohem Geldeinsatz und dem Besuch von Pferderennen mit entsprechenden Wetten, obwohl zeitgleich der Schwager eines Mitspielers verstorben war. Ebenso spotteten die liberalen Zeitungen über die unbürgerlichen Lebenswege der hochadligen Mitspieler, die etwa das College nach einem Jahr abgebrochen hatten, nur einen Monat in der väterlichen Firma gearbeitet hatten und dann berufslos

\footnotetext{
102 Times 10.6.1891, S. 9.

103 Daily News 10.6.1891, S. 4 (H.i.O.).

104 STAR 10.6.1891, S.1.

105 Pall Mall Gazette 10.6.1891, S.6.

106 Daily Chronicle 10.9.1891.

107 Review of Reviews Juli 1891, S. 23-34, bes. S. 26.
} 
blieben. ${ }^{108}$ Entscheidend für die Bewertung des Prinzen und der beteiligten Adligen war zudem, dass es sich bei ihnen auch um Inhaber hoher militärischer Ränge handelte. Indem sie das Geldspiel und sogar das Falschspiel deckten, verstießen sie gegen Militärgesetze, die eine sofortige Meldung verlangten. Während der vermeintliche Falschspieler Gordon-Cumming daraufhin von der Queen aus der Armee ausgeschlossen wurde, konnte der Prinz seinen militärischen Rang behalten, was vor allem die Reynolds's Newspaper als Zeichen der Doppelmoral kritisierte. ${ }^{109}$ Damit stellte der Skandal erneut die Forderung auf, dass Gesetze gleichermaßen selbst für das Königshaus zu gelten hätte.

In dem Skandal entflammte zudem eine Kritik an den Kosten der Monarchie. Da der Prinz in seiner Rolle als „Bank“ jeweils um bis zu 100 Pfund spielte also mehr als den Monatslohn eines bürgerlichen Einkommens - sah die Öffentlichkeit an einem konkreten Beispiel, wie leichtfertig der Thronfolger mit Geld umging. Die Gerüchte über die hohen Schulden des Prinzen, die in vielen Zeitungen im Zuge des Skandals erneut kursierten, ergänzten diesen Verstoß gegen bürgerliche Leitvorstellungen von Sparsamkeit und solider Wirtschaft. So sprach Reynolds's Newspaper von 500000 Pfund Schulden, die durch derartige Vergnügungen entstanden seien, obgleich er seit seiner Volljährigkeit allein über zwei Millionen Pfund vom Steuerzahler bekommen habe. ${ }^{110}$ Der Fall belebte so den schon vorher angelegten und besonders 1870/71 aufgeflammten Vorwurf, das Königshaus sei ein verschwenderischer Kostgänger der Steuerzahler. Die Reynolds's Newspaper setzte den Prinzen in eine Traditionslinie mit dem unmoralischen und verschwenderischen Leben früherer Könige, insbesondere mit „Queen Carolines“ Gemahl Georg IV., der sich auch durch eine entsprechende Sinneslust ausgezeichnet habe. ${ }^{111}$ Der Thronfolger erschien damit wie ein Anachronismus in einer modernen bürgerlichen Gesellschaft. Queen Victoria galt dagegen selbst in der Reynolds's Newspaper als Gegenbild und Garantin der Monarchie.

Anschaulich wurde diese Kritik am Prinzen in den Karikaturen. Allerdings blieben die visuellen Darstellungen des Skandals in den englischen Zeitungen wesentlich zurückhaltender als die der internationalen Presse. So beschränkte sich das Satireblatt Punch sogar nur auf die Verspottung der Zuschauerinnen, die es mit Operngläsern drängelnd darstellte, und erwies sich damit einmal mehr als wesentlich unkritischer als sein bis heute bewahrter Ruf. ${ }^{112}$ Die amerikanischen, französischen und deutschen Blätter zeichneten den Prinzen dagegen als Spieler, Trinker, Schuldenmacher oder Mann mit schlechter Gesellschaft, wobei sie ihn fast immer als kleinen Jungen neben der großen übermächtigen Mutter darstellten. Die Übernahme dieser ausländischen Karikaturen in auf-

\footnotetext{
108 Daily News 24.6.1891, S.2.

109 Reynolds's Newspaper 14.6.1891, S. 1.

110 ReYnolds's NewsPaper 17.5.1891, S.1.

111 Reynolds's Newspaper 7.6.1891, S.1.

112 Punch 6.6.1891.
} 

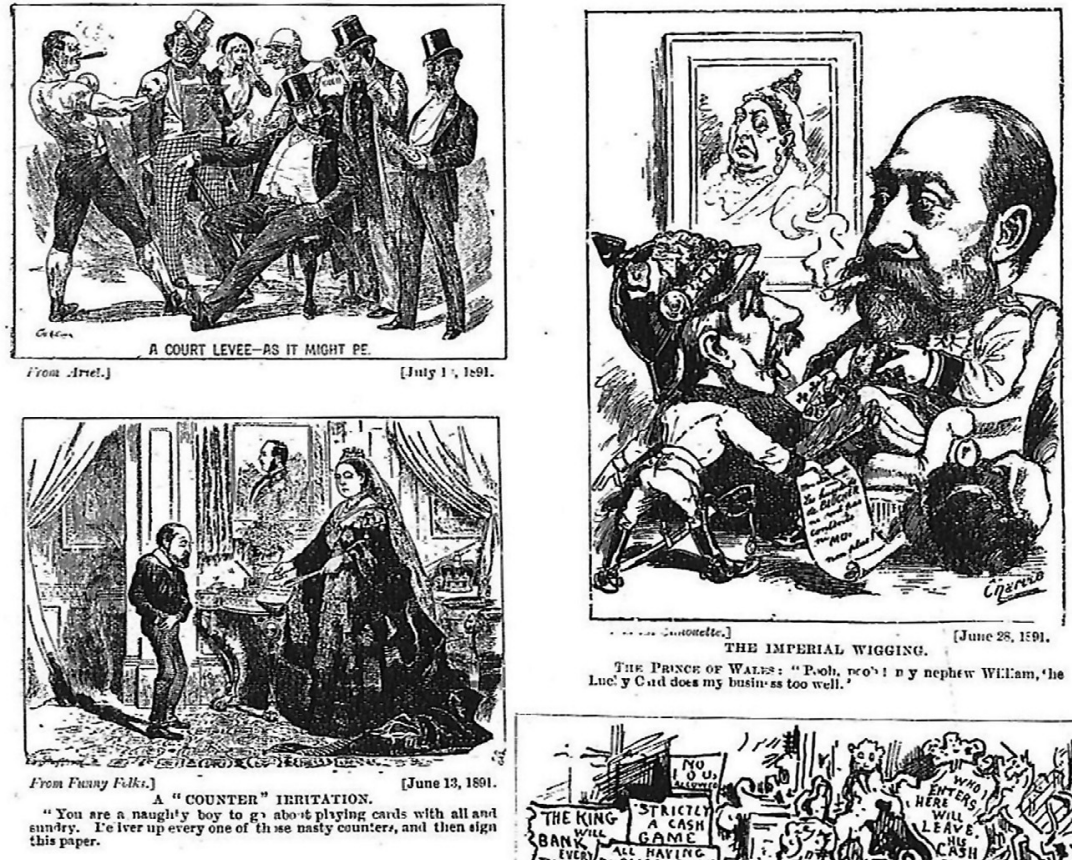

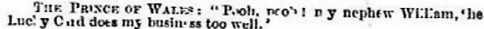

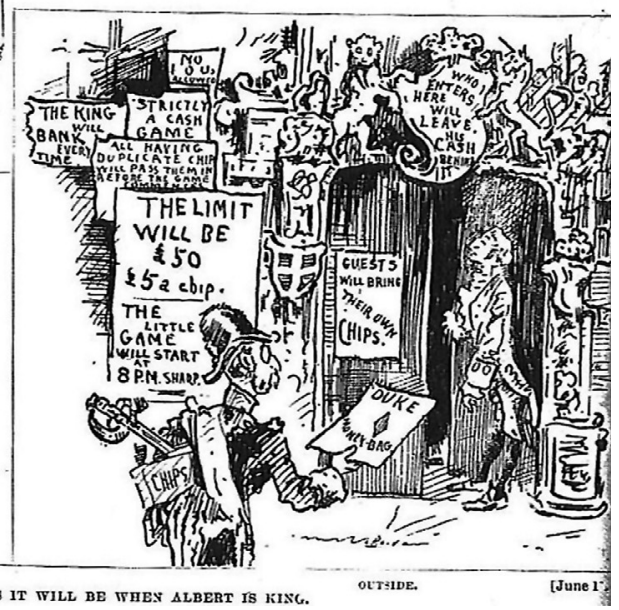

Abb. 11: Der Thronfolger als unreifer Spieler, der sich in schlechte Gesellschaft begibt. Der Spott der internationalen Presse kam, wie hier in diesen Karikaturen, wieder in die britische Öffentlichkeit zurück, um durch sie den Prinzen zu erziehen. Quelle: REVIEW OF REVIEWS Juli 1891.

lagenstarke englische Blätter, wie die Review of Reviews, überführte diese spöttischen Deutungen des Thronfolgers freilich wieder in die britische Öffentlichkeit (vgl. Abb. 11). ${ }^{113}$

113 Vgl. die Zusammenstellung in: Review of Reviews Juli 1891, bes. S. 16-22. 
Der Prozess selbst wurde allein schon durch die physische Anwesenheit des Prinzen zur Sensation. Im Gericht erhielten die Journalisten trotz des enormen Andranges erneut gute Zugangsbedingungen, was selbst bei diesem Skandal das im Vergleich zu Deutschland gute Verhältnis zwischen Staat und Presse unterstrich. ${ }^{114}$ Unter den dicht gedrängten Zuschauern vermerkten die Zeitungsberichte nicht nur wie gewöhnlich die zahlreichen Frauen, sondern auch viele Adlige, was die Möglichkeiten vergrößerte, diese exotisierte Gesellschaftsgruppe zu beobachten. Insbesondere der Kronprinz wurde durch seine tagelange Anwesenheit auf der Zeugenbank zu einem Beobachtungsobjekt, bei dem Journalisten und Zuschauer jede seiner Bewegungen festhielten. Genau wie das Verhör nahm dies dem angehenden König die Aura der Unnahbarkeit und des Außergewöhnlichen. Obgleich das Gericht den Prinzen deutlich zurückhaltender befragte und Gordon-Cumming seine Verleumdungsklage trotz fehlender Beweise über sein Falschspiel verlor, banalisierte allein die Prozessteilnahme den Thronfolger. Der Prinz nahm diese Rolle jedoch bereitwillig an und verzichtete auf angebotene Privilegien wie das Sitzen bei der Aussage. Damit vollzog er eine wichtige symbolische Handlung, die der öffentlichen Forderung nach der Gleichheit vor Gericht entgegen kam und ihn für die Zeitungen „like any other man" erscheinen ließ.115

Nach dem Prozess wurde zwischen der politischen Führung und dem Königshaus diskutiert, wie der Prinz wieder an Reputation gewinnen könne. Schließlich schloss sich auch die Queen dem Urteil der Zeitungen an, dass die Monarchie insgesamt in Gefahr sei, wenn der Prinz derartig verspottet würde. Der liberale Oppositionsführer Gladstone und die Times unterstützten das Ansinnen der Queen, der Prinz solle in einem öffentlichen Schreiben an den Erzbischof von Canterbury das Glücksspiel verdammen. ${ }^{116}$ Premierminister Salisbury sprach sich jedoch gegen eine öffentliche Entschuldigung aus, da dies von der Wirkung her unberechenbar sei und den Prestigeverlust verstärken könne. ${ }^{117}$ Schließlich lehnte der Prinz eine solche Erklärung ebenfalls ab, weil sie wie ein Schuldeingeständnis wirken würde, schrieb aber in einer privaten Erklärung an den Erzbischof, dass er das "gambling“ ablehne, nicht aber Pferderennen. ${ }^{118}$ Eine indirekte öffentliche Entschuldigung gab er jedoch über den Kriegsminister Edward Stanhope im Parlament, als dieser im Unterhaus gefragt wurde, wie er sich zu den militärischen Regelverletzungen verhalte. Der Kriegsminister

114 Dies erwähnten die Zeitungen mehrfach lobend: DAILy News 2.6.1891, S. 2; Times 10.6.1891, S. 12.

115 Pall Mall GazetTe 2.7.1891.

116 Queen Victoria an Cadogan 17.6.1891, in: HLRO, Cadogan Papers, RC 78/3.

117 Salisbury an Cadogan o. D. (um 6.6.1891) und 19.6.1913, in: HLRO, Cadogan Papers, RC 65 u. 81. Cadogan an Salisbury 10.6., 12.6. u. 17.6.1891, in: NL Salisbury, Hatfield House.

118 In dem Entwurf hieß es: „I have a horror of gambling and should always do my utmost to discourage others who have an inclination for it, as I consider that gambling, like intemperance, is one of the greatest curses that a country can be afflicted with." Abgedr. in: Magnus, Edward VII, S. 289. 
richtete von Seiten des Prinzen aus, es sei ein Fehler gewesen, nicht gleich das Fehlverhalten von Gordon-Cumming zu melden. Dies sei aber verständlich, weil jeder so gehandelt hätte, wenn ein enger Freund wegen „dishonourable conduct" angeklagt wäre. ${ }^{119}$ Der Prinz erschien damit wieder in der Rolle des gewöhnlichen Bürgers, aber eben nicht als Vorbild. Die indirekte öffentliche Entschuldigung war zwar eine Art Schuldeingeständnis, zugleich ein Zugeständnis, um eine Rehabilitierung einzuleiten.

Um das zukünftige öffentliche Bild des Prinzen zu verbessern, suchte die politische Führung auch bei diesem Skandal den Austausch mit dem damals wichtigsten Journalisten, mit W. T. Stead, dem nunmehrigen Herausgeber der Review of Reviews. Gladstone, der mit Verärgerung den Prozess verfolgt hatte, wandte sich danach gleich an den Journalisten. ${ }^{120}$ Auch der engste Vertraute des Prinzen, Lord Knollys, bot Stead ein Treffen an. ${ }^{121}$ Umgekehrt engagierte sich Stead eigenständig, um für den Prinzen eine stärker politische Rolle zu finden, die ihn von seinem unmoralischen Müßiggang befreien sollte. Wie sehr sich der Journalist mittlerweile als omnipotenter Staatsmann verstand, verrieten seine geradezu kollegial formulierten Ratschläge an Gladstone über die Lenkung des „somewhat lethargic Prince in the direction that we wish to take him “. ${ }^{122} \mathrm{Um}$ das moralische Ansehen des Prinzen unmittelbar zu heben, schlug Stead etwa dessen Teilnahme bei einem Treffen des nonkonformistischen International Congregational Council vor, der gerade in London zusammen kam, was natürlich keine Zustimmung fand. ${ }^{123}$ Steads Korrespondenz zeigt erneut, wie sehr der Journalist die Nähe und Abstimmung mit den Mächtigen suchte. So schickte er die Manuskriptfassung seines großen abschließenden Artikels über den Skandal vorher an den Vertrauten des Prinzen und an Gladstone. Deren Kritik oder Kommentare nahm er zumindest teilweise auf. ${ }^{124}$ Gleichzeitig betonte Stead weiterhin die Rolle des unabhängigen Journalisten. Sein Artikel enthielt, trotz seines vergleichsweise wohlwollenden und konstruktiven Grundtons, weiterhin kritische Passagen. Umso mehr ärgerte er sich, dass er angeblich als „whitewasher" der Krone verstanden wurde. ${ }^{125}$ Ein derartig enger Austausch zwischen einem unabhängigen kritischen Journalisten und dem Königshaus wäre in Deutschland sicherlich undenkbar gewesen, auch wenn ein deutscher Starjournalist wie Maximilian Harden ebenfalls die Aufmerksamkeit der Krone und den Austausch mit hohen Politikern suchte.

Der Monarchie-Skandal stellte normative Forderungen an den angehenden Monarchen. Seinen Lebensstil änderte er jedoch kaum. Vielmehr spielte er bis

119 15.6.1891, Hansard's Parliamentary Debates, 3rd Series, Bd.354, Sp. 393 f.

120 Vgl. Tagebucheintrag 19.6.1891, in: Matthew (Hrsg.), Gladstone Diaries, Bd. 12, S. 390.

121 Knollys an Stead 29.6. und 3.7.1891, in: CAC, Sted 1-44.

122 Stead an Gladstone 2.7.1885, in: BL, Ms Add. Gladstone Papers 44303:454.

123 Stead an Knollys 16.7.1891, in: CAC, Sted 1/44.

124 Gladstone an Stead 25.6.1891, in: BL, Ms Add. Gladstone Papers 44303:447; Knollys an Stead 28.6.1891, in: CAC, Sted 1/44.

125 Stead an Gladstone, o. D. (Juli 1891), in: BL, Ms Add. Gladstone Papers 44303:463. 
zu seinem Tod 1910 weiterhin Glücksspiele. Dennoch blieben Nachfolgeskandale aus. Der Fall zog zwar wie alle Skandale kleinere ähnliche Fälle über adlige Baccarat-Spieler nach sich, aber das Königshaus blieb, soweit ersichtlich, außen vor. ${ }^{126}$ Man kann dies erneut damit erklären, dass sich die Medien nach dem Skandal bemühten, nicht die Monarchie als Institution zu gefährden, zumal der Thronwechsel immer absehbarer wurde. Ebenso bemühte sich Queen Victoria und die Staatsführung verstärkt, die Veröffentlichung von derartigen Meldungen zu vermeiden. Als kurz nach dem Prozess Gerüchte aufkamen, der Prinz habe erneut Baccarat gespielt, verlangten ihre Vertrauten etwa mit scharfen Briefen Rechtfertigungen vom Prinzen. ${ }^{127}$ Ebenso setzte sich Premierminister Salisbury 1892 persönlich dafür ein, adlige Ehebrecherinnen davon abzuhalten, den Prinzen öffentlich mit ihren Fällen in Verbindung zu bringen, da gerade aus Prozessen Monarchie-Skandale zu entstehen drohten. ${ }^{128}$

Ein weiterer Grund für das Ausbleiben von weiteren Skandalen um Prinz Edward war die wachsende Beliebtheit des angehenden Königs. Der Skandal hatte zwar zur Herabsetzung seiner Würde beigetragen und den Respekt gegenüber der Krone gemindert. Seine persönliche Anwesenheit vor Gericht und seine Wett- und Spielleidenschaft gaben dem Prinzen jedoch auch volkstümliche Züge. Angesichts der hohen öffentlichen Nachfrage nach dem Königshaus erschien die permanente Anwesenheit von Edward VII. auf den Rennbahnen als Volksverbundenheit. Dabei profitierte Edward von dem steigenden Ansehen der Monarchie, das sich aus der wachsenden Beliebtheit von Queen Victoria in den 1890er Jahren ergab und sich insbesondere in den Feiern zum Diamond Jubilee 1897 zeigte. Bei seiner Thronbesteigung 1901 blieben schließlich kritische Stimmen ganz aus. Selbst die stets kritische Reynolds's Nerespaper kommentierte eher optimistisch, dass der König seine wilden Jahre hinter sich habe. ${ }^{129}$ Bereits kurze Zeit später meldete sie zwar wieder, Edward VII. würde wegen seines Kartenspiels seine offiziellen Termine vergessen, löste mit diesen Berichten aber keine breite Empörung mehr aus. ${ }^{130}$ Gerade die weitere Entwicklung zeigte somit, dass die Reaktionen im Baccarat-Skandal vor allem eine Warnung an das Königshaus waren, dass die Öffentlichkeit bestimmte Ansprüche an dessen Lebensstil hatte. Eine ernsthafte strukturelle Kritik, die auf die Abschaffung der Monarchie hätte zulaufen können, stand nicht dahinter. Mit dem Lebenswandel des Thronfolgers hatte die Öffentlichkeit somit vor allem diskutiert, welche moralische Lebensführung für die Gesellschaft wünschenswert sei.

Für die deutsche Presse hatte der Skandal bezeichnender Weise eine gewisse Vorbildfunktion. Zwar betonten selbst die bürgerlichen Blätter mit spöttischer

126 So berichteten die Zeitungen im Jahr darauf über einige hohe Adlige, die betrügerisch Baccarat gespielt hätten; Times 21.10.1892, S. 8.

127 Brodirck an Cadogan 16.6.1891, in: HLRO, Cadogan Papers, RC 75.

$128 \mathrm{Zu}$ dem hier angedeuteten Beresford-Fall vgl. die Hinweise in: Aronson, The King, S. 196; Roberts, Salisbury, S. 559; Magnus, Edward VII, S. 292.

129 Rову, The King, S. 279.

130 Reynolds's NewsPaper, 15.2.1903, S.1. 
Abgrenzung, dass der englische Prinz im Unterschied zum deutschen Kaiser als der „erste Lebemann im Reich“ gelte und der Fall sich in eine Reihe von zahllosen Skandalen über den hohen englischen Adel einreihe. Aber dennoch bemerkte die liberale Presse voller Bewunderung, dass die konstitutionelle Monarchie so gefestigt sei, dass man dort selbst die Königin wegen Ehebruchs vor Gericht stellen könne, wie man unter Anspielung auf die Queen CarolineAffäre erinnerte. ${ }^{131}$ Insofern galt für sie selbst der Skandal, der den Prinzen als Lebemann lächerlich machte, indirekt doch als etwas Vorbildliches, da er Rechtsgleichheit und die Freiheit der öffentlichen Meinung verdeutlichte. Zugleich schufen die Skandale um Edward VII. Stereotype, die bei Konflikten mit Großbritannien aktualisiert werden konnten. Bereits die Spannungen, die im Kontext des Burenkrieges gegenüber England auftraten, führten dazu, dass die deutschen Karikaturen Edward VII. vehement als Lebemann und Glücksspieler verspotteten. ${ }^{132}$ Das durch den Skandal verbreitete Image des Monarchen schuf somit Zuschreibungen, die bei Bedarf pars pro toto zur Abwertung von ganz Großbritannien dienen konnte.

\section{Skandale als Grenzen des persönlichen Regiments}

In Deutschland kam es kurz darauf ebenfalls zu einer Häufung von MonarchieSkandalen. Diese unterschieden sich jedoch von den englischen Fällen. Während in Großbritannien moralische Fragen für Empörung sorgten, gab in Deutschland vor allem das politische Verhalten von Wilhelm II. den Anstoß. Die stärkere Machtstellung der deutschen Monarchen, die im Unterschied zu Großbritannien noch nicht mit demokratisch gewählten Regierungen kooperieren mussten, begünstigte diesen Unterschied. Auch die bürgerlichen Zuschreibungen dürften eine Rolle gespielt haben. Folgt man Monika Wienforts Studien, so entwickelten sie sich bereits seit dem späten 18. Jahrhundert in unterschiedliche Richtungen: Während den englischen Monarchen eine moralische Tugendbewährung abverlangt wurde, sahen die Deutschen den Monarchen stärker als einen Staatsbürger, womit sie den Herrscher eher in der politischen Sphäre im engeren Sinne verorteten. ${ }^{133}$

Das verdichtete Aufkommen von Monarchie-Skandalen, die die politische Stellung des Monarchen thematisierten, wurde selbstverständlich durch das Auftreten von Wilhelm II. forciert. Nachdem Kaiser Wilhelm I. sich trotz seiner starken Stellung im Verfassungsgefüge politisch eher zurückgehalten hatte und Bismarck das Tagesgeschäft überließ, zeigte Wilhelm II. bekanntlich schnell

131 Zit. Vossische Zeitung Nr. 262, 9.6.1891, S.1; Vossische Zeitung Nr. 264, 10.6.1891, S.1. Die meisten Berichte zu dem Baccarat-Skandal fanden sich in der „Kreuzzeitung“, die sich dabei aber kaum Wertungen machte.

132 Vgl. Simplicissismus Bd. 4 Nr. 42 (1899/1900); Geppert, Pressekriege, S. 135 f.

133 So Wienfort, Monarchie, S. 149, 170 u. 205. 
weitergehende Ambitionen. An dieser Stelle muss nicht erneut die Debatte aufgerollt werden, ob es sich bei ihm nur um einen bramabasierenden schwachen „Schattenkaiser" handelte oder, wie insbesondere John Röhl argumentierte, um eine „persönliche Monarchie“, in der der Kaiser ein Machtzentrum bildete. ${ }^{134}$ Zweifelsohne setzte Wilhelm allein durch seine öffentlichen Auftritte, seine deutlich artikulierte polarisierende Weltanschauung und seine Personalpolitik Akzente. Eine erste öffentliche Empörung entstand besonders bei der Entlassung Bismarcks und bei einzelnen politischen Richtungsänderungen, die als „neuer Kurs“ firmierten. Sein „persönliches Regiment" beruhte dabei nicht nur auf seinem eigenständigen Eingreifen, sondern ebenso auf persönlichen Beratern und Günstlingen, die zunehmend für das skandalöse Auftreten des Kaisers verantwortlich gemacht wurden. ${ }^{135}$

Zunächst galt der Verweis auf die „Jugendlichkeit“ und „Impulsivität“ des Kaisers noch als Entschuldigung. Bereits Anfang der 1890er führten jedoch insbesondere seine Reden und Selbstinszenierungen zu einem gewissen Unmut, der durch die Vorwürfe der Bismarck-Anhänger stärker politische Formen annahm. Insbesondere der Journalist Maximilian Harden trat hierbei als akzentuierter Kritiker hervor. Sein viel beachteter Sieg in einem Majestätsbeleidigungsprozess im Juni 1893 zeigte, dass auch die juristischen Grenzen des Sagbaren in Bewegung gerieten. Harden wurde nicht nur wegen „seiner besten Absichten“ freigesprochen, sondern auch weil man Ehrfurcht gegenüber dem Monarchen dadurch zeige, dass man „auch ihm gegenüber die Wahrheit hochhält.“136 Im Jahr 1894, als sich der kaiserliche Machtanspruch besonders deutlich artikulierte, kulminierten daher nicht zufällig mehrere scheinbar unverbundene Skandale, die alle auf unterschiedliche Weise das Ansehen des Kaisers oder zumindest seines Umfeldes diskreditierten: Der Caligula-Skandal hinterfragte die persönliche Kompetenz des Monarchen, die Kladderadatsch-Affäre die seiner politischen Freunde und der Kotze-Skandal das moralische Verhalten des Hofes und damit der engsten Umgebung des Monarchen. Gerade ihr zeitgleiches, ineinander verschränktes Auftreten und ihre unterschiedlichen Stoßrichtungen dürften dazu geführt haben, dass in Deutschland die Kritik am Kaiser und seinem Umfeld artikulierbarer wurde.

Da die Skandale um Wilhelm II. bereits relativ gut erforscht sind, kann an ihnen gleich ihre Struktur und das Zusammenspiel von Medien und Politik ausgemacht werden. Von ihrem Ablauf her wiesen diese drei Skandale zahlreiche Gemeinsamkeiten auf. Sie entstanden allesamt nicht aus einer direkten journalis-

134 Vgl. zu diesen gegensätzlichen Positionen bes.: WeHLER, Deutsche Gesellschaftsgeschichte, Bd.3, S.1001; RöHL, Wilhelm II. Der Aufbau, S.15f. Eine Herrschaft per „Königsritual“, öffentlicher Sinnstiftung und „kaiserlichem Apparat“ sieht: Nicolaus SOMbart, Wilhelm II. Sündenbock und Herr der Mitte, Berlin 1996. S. 86, 103 u. 109.

135 Neben Röhls Biographie weiterhin grundlegend hierfür: HulL, The Entourage.

136 Urteil zit. nach: H. F. Young, Maximilian Harden. Censor Germaniae. Ein Publizist im Widerstreit 1892 bis 1927, Münster 1971, S. 69 Insgesamt ohne nennenswerte Befunde: NeumanN und Neumann, Maximilian Harden, S. 95. 
tischen Kritik an einzelnen Handlungen des Kaisers, seiner Ratgeber oder des Hofes. Vielmehr entwickelten sie alle aus versteckt artikulierten Vorwürfen, die ein skandalöses Verhalten umkreisten, das offensichtlich nicht direkt öffentlich sagbar war. Die Journalisten griffen allerdings diesen verdeckt artikulierten Unmut auf und beförderten ihn ebenfalls mit Techniken der Camouflage als gezielte Kaiserkritik in die Öffentlichkeit. So entfaltete sich der Caligula-Skandal aus einer satirisch angelegten Schrift des Historikers Ludwig Quidde, der in einer schmalen Broschüre scheinbar das Leben des wahnsinnigen römischen Kaisers beschrieb, tatsächlich jedoch den deutschen Kaiser meinte. ${ }^{137}$ Diese Form der Skandalisierung stand damit noch ganz in der Tradition der versteckten Monarchenkritik in Form von Satiren oder Parabeln, wie sie sich gerade in Deutschland durch die harten Zensurbestimmungen der Karlsbader Beschlüsse im Vormärz entwickelt und lange gehalten hatte. Nicht minder verschlüsselt und poetisch geformt setzte die Kladderadatsch-Affäre ein. Das nationalliberale Satireblatt Kladderadatsch richtete seit dem 3. Dezember 1893 regelmäßige Angriffe gegen drei prominente Reichsbeamte, die dem Kaiser nahe standen und maßgeblich die Außenpolitik, Personalfragen und die Öffentlichkeitsarbeit prägten (Holstein, Kiderlen-Waechter und Philipp von Eulenburg). ${ }^{138}$ Allerdings nannte es die Angegriffenen nur mit Kosenamen (Austernfreund, Spätzle, Troubador) und schrieb nur in verschlüsselten Versen und Märchenformen über deren Intrigen, die aber für alle politischen Eliten leicht zu enträtseln waren. Die sprachspielerischen Formulierungen ähnelten freilich ebenfalls weniger den englischen Artikeln als jener versteckten Monarchenkritik des Vormärzes. Ihre Brisanz gewannen diese Texte aus der angedeuteten detaillierten Kenntnis der Hinterzimmerpolitik, die auf einen Informanten aus dem Auswärtigen Amt hinwiesen.

Ebenfalls mit spielerischen Verschlüsselungen setzte der Kotze-Skandal ein, obgleich er als intriganter Spott innerhalb des Hochadels begann. Seit Anfang 1891 hatten zahlreiche Angehörige des preußischen Hofes insgesamt einige hundert anonyme Briefe erhalten, die ihnen mit äußerst derben Formulierungen insbesondere persönliche sexuelle Normbrüche vorwarfen. Beigelegt waren oft pornographische Fotos, Fotomontagen oder Zeichnungen der Adligen. So lautete einer der Briefe an Hofmarschall Freiherr von Reischach: „Im Bett ist nicht viel los/der Prinzen Schwänze sind klein, und Lokes Loch ist riesengroß/Ein Kürbis geht hinein“, versehen mit gezeichneten Penis-Bilder, die mit Namen

137 Vgl. zur Affäre selbst: KarL Holl et al., Caligula - Wilhelm II. und der Caesarenwahnsinn. Antikenrezeption und wilhelminische Politik am Beispiel des „Caligula“ von Ludwig Quidde, Bremen 2001, S. 89-116 u. 153-160; Ludwig Quidde, Caligula. Eine Studie über römischen Cäsarenwahn. Mit einer Einleitung von Hans-Ulrich Wehler, Frankfurt 1977; KoHLRAUsch, Der Monarch, S.118-154.

138 Vgl. Helmuth Rogge, Die Kladderadatschaffäre. Ein Beitrag zur inneren Geschichte des Wilhelminischen Reichs, in: HZ 195 (1962), S. 90-130, S. 90f. Hinweise auch in: ForsBaCH, Alfred von Kiderlen-Wächter, S.127f. 
Adligen des Hofes versehen waren. ${ }^{139}$ Der Kaiser selbst erhielt zwar keine Briefe, wohl aber seine engeren Verwandten, wie seine Mutter und seine Schwester, und sein persönliches Umfeld am Hof. Ähnlich wie bei der KladderadatschAffäre war schnell deutlich, dass der Briefschreiber ein „Insider" war und aus dem engeren Hofadel um Wilhelm II. kommen musste, da er detaillierte Kenntnisse über geheime Liebesaffären, Ausflüge des Hofes oder die Einrichtung der Privatzimmer hatte. Seit Juli 1894 wurde die Existenz dieser Briefe schließlich auch in der Öffentlichkeit bekannt, bis heute aber nicht der Autor. Da zunächst der Zeremonienmeister Leberecht von Kotze verdächtigt wurde, erhielt der Skandal seinen Namen.

Die verschlüsselte Struktur der Vorwürfe förderte bei allen drei Skandalen die breite öffentliche Kommunikation über sie. Bei Quiddes Schrift konnten die Leser diskutieren, welche der herausgestellten Eigenschaften besonders auf den deutschen Kaiser anspielten. Der Kladderadatsch-Skandal löste ein öffentliches Rätselraten über die genannten Spitznamen aus, und in der politischen Führung ein Rätseln über mögliche Hintermänner. Der Kotze-Skandal führte schließlich $\mathrm{zu}$ einem bis heute andauernden Spekulieren über den Autor der denunziatorischen Briefe. Dabei vermutete die Studie von Tobias Bringmann die Schwester des Kaisers, Charlotte von Meiningen, als Autorin, John Röhl dagegen Herzog Ernst Günther zusammen mit „Theaterweibern“. 140 Wer auch immer der anonyme Briefschreiber war - er spielte gezielt mit der Öffentlichkeit, um die Aufmerksamkeit auf die Beschuldigten und sich selbst zu richten. So übermittelte er dem Chefredakteur des Berliner Tageblatts, Theodor Wolff, bereits Anfang 1894 Informationen und bot ein Treffen an. ${ }^{141}$ Dann richtete er direkt anonyme Briefe an das Kleine Journal, das diese abdruckte. Die öffentliche Suche nach dem Briefschreiber verlief dabei, ähnlich wie im Dreyfus-Skandal, über die abgedruckte Handschrift, wodurch sich jeder Leser als Detektiv an der Aufdeckung beteiligen konnte. ${ }^{142}$

139 Anonymer Brief an Reischach 25.1.1893, in: GStA, HA I, Rep. 89, Nr.3307/10, S.73. Der erste Brief war an Graf Hohenau 15.2.1891, in: GStA, HA I, Rep. 89, Nr.3307/10. Eine Abschrift von ca. 40 der Briefe in: GStA, HA I, Rep. 89, Nr.3307/3, ein dutzend weitere in: ebd., Nr. 3307/4. Vgl. zu dieser Affäre auch: Tobias C. Bringmann, Reichstag und Zweikampf. Die Duellfrage als innenpolitischer Konflikt des deutschen Kaiserreiches 1871-1918, Freiburg 1997, S. 152-201; RÖHL, Wilhelm II.: Der Aufbau, S. 741-755.

140 RöHL, Wilhelm II, Bd.2, S.753; BRIngmann, Reichstag, S. 209. Direkte Belege fehlen. Röhl stützt sich auf eine Aussage des dubiosen Kommissar Tausch; Bringmanns Argumenten wäre hinzuzufügen, dass in den Briefen die zahlreichen Verweise auf „Emporkömmlinge“ auf einen Autor schließen lassen, der selbst in der Adelshierarchie denkbar weit oben steht. Die Sprache und die Art der Bilder in den Beschimpfungen lassen meiner Meinung nach ebenfalls den Schluss zu, dass eine Frau einen Großteil der Briefe verfasste.

141 Schreiben an Wolff in: GStA, HA I, Rep. 89, Nr. 3307/5; Wolff an Gräfin Hohenau 30.6.1894, in: ebd.

142 Zuerst wurde die Handschrift im Kotzefall veröffentlicht in: Das Kleine Journal Nr.249, 28.6.1894. Vgl. die Schriftgutachten, die eine weibliche Handschrift ausmachten, in: GStA, HA I, Rep. 89 , Nr.3307/6. 
Gemeinsam war den drei Skandalen zudem, dass ihre öffentliche Dynamik eben nicht aus der Monarchiekritik der politischen Linken entstand. Vielmehr brachten konservative Eliten die Fälle in die breitere Öffentlichkeit - sei es aus Verbitterung über Bismarcks Entlassung, über den „neuen Kurs“ oder über den Charakter des Kaisers und Hofes insgesamt. So überführte beim Caligula-Skandal erst eine scheinbar empörte Rezension der konservativen „Kreuzzeitung“ Quiddes versteckte Kaiserkritik in die breite Öffentlichkeit. Auf der Titelseite verurteilte sie zwar Quiddes „krankhafte Sucht “ zur Analogienbildung, benannte jedoch diese Analogien so deutlich, dass die Monarchenkritik nicht mehr zu übersehen war. ${ }^{143}$ Erst dies machte die Medienöffentlichkeit auf die CaligulaBroschüre aufmerksam, was Quiddes Satire schnell zu einer Auflage von einigen 100000 Exemplaren verhalf. Ebenso löste bei der Kladderadatsch-Affäre ein nationalliberales Blatt den Skandal aus, wobei die Informationen für die Artikel von konservativen Bismarckanhängern wie Maximilian Harden und aus dem Auswärtigen Amt stammten, insbesondere vom Leiter der Rechtsabteilung Ernst von Bothmer. ${ }^{144}$ Auch der Kotze-Skandal entbrannte gerade nicht aus einer sozialdemokratischen Adelskritik, sondern aus dem Adel heraus. Dass selbst konservative Kreise eine derartige Form der Kritik am Monarchen und seinen Umfeld lancierten, vergrößerte die Aufmerksamkeit auf die Vorwürfe beträchtlich. Von sozialdemokratischer Seite hätte man derartiges vielleicht erwartet. Eine Skandalisierung von konservativer Seite zeigte hingegen, wie brüchig das Fundament der Staatsführung wurde.

Bemerkenswerter Weise sah das Umfeld des Kaisers kaum Möglichkeiten, nach den Regeln der klassischen Zensur und durch Prozesse einzugreifen, da gerade dies die Dynamik der Skandale verstärkt hätte. So hätte im Falle Quiddes ein Prozess dezidiert prüfen müssen, ob und inwieweit die Caligula zugeschriebenen Eigenschaften auch auf Wilhelm II. zuträfen, was den Kaiser leicht in Misskredit gebracht hätte. Tatsächlich kam es zu keinem Verfahren wegen der Schrift. ${ }^{145}$ Bei der Kladderadatsch-Affäre äußerte der verspottete Kaiserfreund Eulenburg ähnliche Bedenken gegen einen Prozess gegenüber Wilhelm II.: „Man weiß eben, daß ein Prozeß, der zwei Jahre dauern würde, alle möglichen speziellen Diener als Zeugen vorrufen würde, große Unruhe erzeugen und Eurer Majestät Schaden zufügen würde [...] wenn ein Prozeß so sensationeller Art entstünde, daß ihn der demokratisch-fortschrittliche Richterstand unter einem schwachen Justizminister $\mathrm{zu}$ einer Art Panamaskandal frisieren könnte."146 Beim Kotze-Skandal verlor schließlich der Kaiser inmitten der gegenseitigen Beschuldigungen die Nerven und ließ seinen Zeremonienmeister

143 Neue Preussische Zeitung Nr. 226, 18. Mai 1894, Morgen.

144 RogGe, Die Kladderadatschaffäre, S. 116.

145 Erst 1896 wurde Quidde wegen einer beiläufigen anderen Äußerung wegen Majestätsbeleidigung verurteilt; vgl. HoLl et al., Caligula, S.26.

146 Eulenburg an Wilhelm II. 13.3.1894, bereits abgedr. in: RogGE, Die Kladderadatschaffäre, S. 106. 
Leberecht von Kotze verhaften und vor ein geheim tagendes Militärgericht stellen. Dies hatte jedoch zur Folge, dass dadurch die Presse erst auf die brieflichen Verleumdungen aufmerksam wurde und sich zugleich über den Willkürakt des Kaisers empörte, der einfach eine offensichtlich unschuldige Person vor ein nicht-öffentliches Gericht stellen ließ. Nach Kotzes Freilassung lehnte der Staatsanwalt eine strafrechtliche Verfolgung aus Angst vor einem „tendenziösen Skandalprozeß“ ab. ${ }^{147}$ Auch bei der beabsichtigen Privatklage Kotzes ging die Staatsanwaltschaft davon aus, dass auf diese Weise nur „ein Sensationsprozeß ersten Ranges bezweckt sei, in welchen die gesamte Hofgesellschaft zur Vernehmung herangezogen werden soll“. ${ }^{148}$ Die Furcht, eine juristische Verfolgung könne den Skandal nur ausweiten, schuf somit der Kritik an Kaiser und Hof neue Spielräume.

Die medialen Skandalisierungen waren bereits in diesem Stadium eine massive Herausforderung der Macht. Gerade weil eine juristische Verfolgung wenig opportun erschien, reagierten die öffentlich Angegriffenen trotz ihrer hohen Stellung äußerst verunsichert. In der Kladderadatsch-Affäre verfiel etwa Friedrich von Holstein, gewöhnlich als die mächtige graue Eminenz der Außenpolitik bezeichnet, in völlige Hilflosigkeit. Er fand kaum noch Schlaf und erwog seinen Rückzug aus der Politik, wie zahlreiche seiner Briefe zeigen. So klagte er gegenüber Eulenburg: „Unsere Schutzlosigkeit, ohne Polizei, ohne Gerichte, ohne geeignetes Verständnis für unsere Lage an höchster Stelle, läßt mich wünschen, möglichst bald zur Ruhe zu kommen. [...] Die Gerichte geben sich her zum Resonanzboden derjenigen Verleumdungen, die in keiner Zeitung würden gesagt werden können. " ${ }^{149}$ Nicht minder empfindlich reagierte der Kaiserfreund Eulenburg auf den Spott in der Presse, obgleich auch er zumindest in den 1890er zu den einflussreichsten Hintergrundpolitikern zählte. Er spornte den Kaiser jedoch zu einem schärferen Vorgehen gegen die Presse an, indem er ihm entsprechende Artikel schickte und die Schuld auf Reichskanzler Caprivi lenkte: „Napoleon und Bismarck wußten solche Dinge nach 24 Stunden zu regeln. Die Polizei bestach entweder einen Redakteur oder setzte Daumenschrauben an. Jetzt läßt sich der Reichskanzler ruhig verspotten, Euere Majestät werden hineingezogen [...]. “150 Dass ein derartig repressives Vorgehen gegen Journalisten angesichts des neuen Medienmarktes kontraproduktiv sein musste, war jedoch offensichtlich.

147 Oberstaatsanwalt Drescher an Justizminister Schönstedt 29.5.1895, in: GStA, HA I Rep. 84a Nr. 58193; Oberstaatsanwalt Drescher an Kotze 9.5.1895, in: ebd.

148 „Information für die Bearbeitung der von Schrader-von Kotze'schen Angelegenheit“, Oberstaatsanwalt Drescher 10.7.1895, in: GStA, HA I Rep. 84a Nr. 58193.

149 Holstein an Eulenburg 19.3.1894, abgedr. in: RöHL (Hrsg.), Eulenburgs politische Korrespondenz, Bd.2, S.1255. Ähnlich etwa: Holstein an Eulenburg 28.12.1893, 10.1.1894 u. 7.2.1894, abgedr. in: ebd., S.1172, 1183 u. S. 1214.

150 Eulenburg an Wilhelm II. 23.1.1894, abgedruckt in: RöHL, Eulenburgs politische Korrespondenz, S. 1194. Ähnlich auch: Eulenburg an Wilhelm II. 1.2.1894, 5.2.1894 u. 9.3.1894, abgedr in: ebd., S. 1203,1210 u. 1244. 
Da Gerichtsprozesse aus Angst vor der Öffentlichkeit risikovoll erschienen, reagierte das Kaiserumfeld mit einem anderen Mittel, das eine Konfliktlösung ohne eine öffentliche Aussprache versprach: dem Duell. Das Duell lässt sich dabei eben nicht nur als Mittel verstehen, um die männliche Ehre herzustellen, sondern auch als Schutz vor öffentlichen Zeugenaussagen, wenn Einblicke in das Privatleben oder arkane politische Handlungen drohten. So forderte der verspottete Vortragende Rat des Auswärtigen Amtes, Kiderlen-Wächter, anscheinend auf Drängen des Kaisers den Redakteur des Kladderadatsch, Wilhelm Polstorff, zum Duell heraus und verletzte den Journalisten schwer. ${ }^{151}$ Ebenso führte Leberecht von Kotze in dem nach ihm benannten Hofskandal verschiedene Duelle, um seine Ehre wieder herzustellen, bei denen er unter anderen den Zeremonienmeister Karl Freiherr von Schrader erschoss. ${ }^{152}$ Auch hier unterstützte der Kaiser diese Form der Konfliktlösung und trat sogar öffentlich für eine Tolerierung der Duelle ein. ${ }^{153}$

Die Versuche, die Skandale per Duell mit dem Erschießen von Journalisten und vermeintlichen Verleumdern zu lösen, gaben ihnen wiederum eine neue Dynamik. Denn nun empörte sich die Öffentlichkeit mehrheitlich über diese als unzeitgemäß empfundene Form der Konfliktbewältigung. Die Zeitungen sahen darin einen Verstoß gegen Gesetze und kirchliche Gebote. ${ }^{154}$ Auch in den Kneipen diskutierten die Gäste den Skandal jetzt empört mit Blick auf die Duelle und klagten laut Spitzelbericht, dass „die Kämpfer für Religion, Sitte und Ordnung“ morden würden, ohne bestraft zu werden. ${ }^{155}$ Im Reichstag führten die Duelle ebenfalls zu einer massiven Empörung, die in eine breit unterstützte Interpellation des Zentrumspolitikers Karl Bachem und eine Resolution des nationalliberalen Eduard Abt mündeten, die schärfere Gesetze gegen Duelle forderten. Hier argumentierten die Abgeordneten gerade damit, dass sich jetzt auch die konservative Presse gegen die Duelle ausgesprochen habe und damit die gesamte Öffentlichkeit hinter der Forderung stehe. ${ }^{156}$ Als Vorbild dafür, dass solche Skandale auch ohne Duelle lösbar seien, sahen die Abgeordneten England an, wo ja tatsächlich die hier diskutierten Skandale allesamt ohne Duell, sondern vornehmlich mit Beleidigungsklagen verhandelt wurden. ${ }^{157}$

151 Vgl. RöHL, Wilhelm II.: Der Aufbau, S. 670; Forsвach, Kiderlen-Wächter, S. 137.

$152 \mathrm{Zu}$ diesen Duellen vgl. auch: BRIngmann, Reichstag, S.178-201. Vgl. auch, allerdings ohne Hinweise auf diese öffentlich besonders wirkungsmächtigen Duelle: UTE Frevert, Ehrenmänner. Das Duell in der bürgerlichen Gesellschaft, München 1991.

153 Vgl. Wilhelm II. an Hohenlohe 15.11.1896, in: BA/K, N 1007-1604; Wilhelm II. an Hohenlohe 20.4.1897, in: BA/K, N 1007-1606.

154 Vgl. etwa Berliner Tageblatt Nr.189, 14.4.1895; ein gewisses Verständnis für die Duelle äußerte dagegen das in Adelskreisen beliebte Kleine Journal 11.4.1896. Durch die Duelle wanderte der Skandal auch wieder in die internationale Presse, vgl. Times 16.4.1895, S.3.

155 Vgl. Vigilanzberichte Schutzmann Graumann 14.3.1896 u. 18.3.1896, in: StAH, S 3930-23 Bd.3.

156 Vgl. die Debatte in: RT 20.4.1896, IX. Legislatur-Periode, IV. Sess., 1895-97, 72. Sitzung, Bd. 145, S. 1797-1802.

157 RT 21.4.1896, IX. Legislatur-Periode, IV. Sess., 1895-97, 73. Sitzung, Bd. 145, S. 1819. 
Damit trugen die Skandale dazu bei, Duelle als Form der Konfliktbewältigung zu desavouieren. Aufgrund der Proteste musste der Justizminister Schönstedt im Reichstag bekräftigen, die Duellanten vor Gericht zu stellen. ${ }^{158}$ Ebenso setzte in der politischen Führung eine Reformdiskussion ein, die erneut den engen Zusammenhang zwischen den Duellen und der Angst vor „Skandalprozessen“ zeigte. Im Staatsministerium wurde argumentiert,

daß das Duellwesen dadurch gefördert werde, daß es für einen Angehörigen der gebildeten Klassen heut zu Tage nahezu unmöglich sei, den Weg einer Beleidigungsklage zu beschreiten, da - abgesehen von der Geringfügigkeit der von den Gerichten verhängten Strafen - durch das übliche Strafverfahren thatsächlich der Beleidigungskläger zum Angeklagten werden, sich gegen alle Verleumdungen rechtfertigen und dem Verleumder den Gegenbeweis liefern müsse. ${ }^{159}$

Deshalb sollten in Zukunft Duelle nur dann stärker bestraft werden, wenn zugleich die Prozessordnung geändert würde, was auch Bachem in seiner Interpellation den Konservativen zugestand. Dabei forderten die Minister, dass neben schärferen Strafen bei Beleidigung „nicht mehr gerichtlich die ganze Vergangenheit der Beteiligten durchforscht wird. " 160 Auch wenn die daraus resultierende Kabinettsordre vom 1.Januar 1897 keine direkte Strafverschärfung bescherte, ${ }^{161}$ setzte die Öffentlichkeit durch die Empörung im Skandal der Duellpraxis neue Grenzen. Kaiser Wilhelm II., der weiterhin bei Skandalen zu Duellen anstiftete, mochte das anders sehen. In der Öffentlichkeit stellte das Duell nun weniger die Ehre her, sondern minderte sie vielmehr, indem es den Skandal verstärkte.

Konsequenzen hatten die Skandale zunächst für die Beteiligten. Die CaligulaSchrift des Historikers Ludwig Quidde beendete seine akademische Karriere. Kiderlen-Wächter erlitt einen langährigen Karriereeinbruch durch die Kladderadatsch-Angriffe, und Kotze, obgleich anscheinend nicht maßgeblich für die Briefe verantwortlich, verlor seine Hofstellung als Zeremonienmeister. ${ }^{162}$ Eulenburg und Holstein behielten zwar ihre einflussreichen Stellungen, wurden nun aber kritischer beäugt. Eulenburg, der 1894 gerüchteweise auch als nächster Reichskanzler gehandelt wurde, sah sich selbst gegenüber dem Kaiser wegen des Kladderadatsch-Skandals als so angeschlagen an, dass er nicht einmal einen Ministerposten übernehmen wollte: „Es müßte also erst Gras über diesen PreßSkandal wachsen, - was ja nicht ausbleiben wird, - ehe ich überhaupt in Frage komme."163 Zudem führten die öffentlichen Verdächtigungen zu einem verstärkten Misstrauen, das insbesondere Spannungen im Auswärtigen Amt förderte.

158 RT 9.5.1895, IX. Legislatur-Periode, III. Sess., 1894/95, 88. Sitz., S. 2180.

159 Staatsministerial-Sitzungsprotokoll 18.4.1896, in: GStA, HA I Rep. 90 A Nr. 3579.

160 Sitzung Staatsministerium 6.10.1897, Punkt 3, S. 283.

161 Vgl. zu der Kabinettsordre: BRIngmann, Reichstag, S. $282 \mathrm{f}$.

162 Kiderlen wurde zunächst Gesandter in Hamburg und Kopenhagen, der Bruch mit dem Kaiser erfolgte erst nach 1899; FonsBACH, Kiderlen-Wächter, S. 162.

163 Aufzeichnung Eulenburg für Wilhelm II., 2.3.1894, abgedruckt in: RöHL, Eulenburgs politische Korrespondenz, S. 1258. 
Die weiteren politischen Folgen waren doppelter Natur. Zum einen bemühte sich das Kaiserumfeld um eine gewisse Aussöhnung mit dem Bismarck-Lager. Zum anderen setzte die Justiz zwar nicht in den konkreten Skandalen, wohl aber generell auf eine schärfere Strafverfolgung öffentlicher Kaiserkritik. So erreichte 1894 die Zahl der Verurteilungen wegen Majestätsbeleidigungen ihren Höhepunkt. ${ }^{164}$ Auch die im selben Jahr aufgebrachte Umsturzvorlage stand mit den Skandalen in Verbindung. Sich politisch stärker zurückzuhalten, war sicherlich ebenfalls keine Konsequenz, die Wilhelm II. aus den Skandalen zog. Vielmehr vergrößerte sich in den folgenden drei Jahren sein Einfluss.

Die wichtigste Folge aller drei Skandale war, dass sie eine kritische öffentliche Auseinandersetzung mit dem Kaiser, seinem Hof und seinen Beratern förderten. Sie brachen Tabus und leiteten Artikel und Gespräche über das Verhalten von Wilhelm II. ein, über die Macht seiner Berater und das moralische Verhalten seines Umfeldes. Alle drei Skandale konstruierten ein Narrativ des dekadenten Verfalls der Monarchie und brachten Analogien zum Niedergang Roms auf. Dieser Rombezug reichte vom Wahnsinn des Monarchen über die Verschwörung einer Kamarilla bis hin zur sexuellen Degeneration und der intriganten Selbstzerstörung des Adels. Während derartige Deutungen bisher eher bei der Sozialdemokratie verbreitet waren, etablierten sie sich so auch im bürgerlichen Lager. Zugleich zeigten die Skandale, wie begrenzt die Andeutungen in direkte Forderungen an den Monarchen umgemünzt werden konnten. Eine explizite Diskussion, inwieweit etwa die Analogie zu Caligula auf Wilhelm II. tatsächlich zutraf, blieb in den Zeitungen weitgehend aus. ${ }^{165}$ Dennoch waren die Berichte eine Warnung an den Monarchen: Sie machten deutlich, dass das engste Umfeld des Kaisers kein Arkanbereich war, sondern dass insbesondere Rivalitäten nach Bismarcks Entlassung zu Indiskretionen und damit zu Skandalen führen konnten. Auch wenn der Kaiser sich im Zuge der Skandale von 1894 vorerst nicht wandelte, so veränderten sie doch die Zuschreibungen und die Anforderungen gegenüber dem Thron.

\section{Der unmündige Kaiser: Wilhelm II. Als Redner und INTERVIEWPARTNER}

Die frühen Skandale um Wilhelm II. hatten sich noch eher indirekt gegen Wilhelms Regierungsstil und persönliches Umfeld gerichtet. Seit der Jahrhundertwende traten nun zunehmend Monarchie-Skandale auf, die sich häufiger an konkreten Äußerungen und Verhaltensweisen des Kaisers entzündeten. Die zunehmende Empörung, die insbesondere seine Reden durch ihren aggressiven, polemischen oder größenwahnsinnigen Gestus auslösten, ist bis heute gut bekannt. Angesichts der vielfältigen Studien über Wilhelm II. sind seine Reden

164 Statistiken zur Majestätsbeleidigung in: RöHL, Wilhelm II.: Der Aufbau, S. 625.

165 So auch Holl et al., Caligula, S. 160. 
freilich bislang erstaunlich wenig untersucht worden. ${ }^{166}$ Pointiert ließe sich argumentieren, dass die Reden des Kaisers eigentlich im hohen Maße der medialisierten Gesellschaft entsprachen. Sie waren so zugespitzt und schillernd, dass sie eine hohe Aufmerksamkeit erreichten. Ebenso bargen sie Überraschungen, die Journalisten anzogen, und sie setzten die Agenda für Debatten. ${ }^{167}$ Insofern hatte die Vossische Zeitung nicht ganz unrecht, dass der Kaiser „der hingebendste indirekte und direkte Mitarbeiter der Presse ist, ein Journalist höherer Ordnung. "168 Zugleich bildete aber gerade die mediale Fixierung der Worte sein Problem. Die Reden, die vor Ort oft Begeisterung fanden, lebten vom freien Vortrag, der körperlichen und stimmlichen Anwesenheit des Kaisers und dem patriotischen Gemeinschaftserlebnis, wobei angesichts fehlender Übertragungsmöglichkeiten gerade bei größeren Veranstaltungen unter freiem Himmel nicht jedes Wort die Zuhörer verständlich erreichte. Erst die Übertragung in das gedruckte Wort der Zeitungen machte sie zum Diskussionspunkt, was bei dem improvisierten Redeakt selbst nicht vorgesehen war. ${ }^{169}$ Insofern kam der Modus der medialen Darstellung dem Kaiser nicht unbedingt entgegen, sondern bildete den Ausgangspunkt für Skandale.

Das wichtigste Beispiel für einen Skandal, der durch eine Rede ausgelöst wurde, ist sicherlich die bekannte „Hunnenrede“ vom 27. Juli 1900. Der Kaiser hatte die deutschen Soldaten mit den Worten zum Boxeraufstand verabschiedet, sie sollten ohne Gnade und ohne Gefangene „wie vor tausend Jahren die Hunnen unter ihrem König Etzel“ kämpfen. ${ }^{170}$ Man würde es sich jedoch zu einfach machen, derartige Reden lediglich als Maßlosigkeit oder Wahn des Kaisers zu interpretieren. Entscheidender ist auch hier die Frage, wie die Regierung und die (Medien-) Öffentlichkeit mit diesen Worten umgingen. Unter dieser Perspektive, und nicht allein von ihrem Inhalt her, bildet die Hunnenrede tatsächlich einen gewissen Wendepunkt, da sie zu einer breiten Empörung und damit zu einem Skandal führte, der grundsätzlich die Mündigkeit des Monarchen hinterfragte.

An dem Skandal lässt sich zunächst ausmachen, wie Regierung und Presse um eine freie Berichterstattung über den Kaiser rangen. Dass in der überregionalen Presse am nächsten Tag nur eine stark abgeschwächte Redefassung des Auswär-

166 Wer an der Abfassung der Reden beteiligt war, wie der Kaiser improvisierte oder welche öffentliche Wirkung er jeweils auslöste, ist bisher nur für ganz wenige Ausnahmereden bekannt; zum Veröffentlichungsmodus: STÖвеR, Pressepolitik, S. 192-201. Gute Beobachtungen zu seinen öffentlichen Auftritten auch in: CLARK, Wilhelm II, S. 160-172.

167 Vgl. Kohlrausch, Monarch, S.78.

168 Vossische Zeitung 8.11.1908, morgens, S.1.

169 Vgl. Clark, Wilhelm II, S. 168.

170 Wortlaut laut Presseberichten, etwa Vossische Zeitung 28.7.1900, S.1. Vgl. auch: Bernd Sösemann, Die sog. Hunnenrede Wilhelms II. Textkritische und interpretatorische Bemerkungen zur Ansprache des Kaisers vom 27.Juli 1900 in Bremerhaven, in: HZ 222 (1976), S.342-358; DERS., „Pardon wird nicht gegeben; Gefangene nicht gemacht“. Zeugnisse und Wirkungen einer rhetorischen Mobilmachung, in: Hans Wilderotter und Klaus Pohl (Hrsg.), Der letzte Kaiser. Wilhelm II. im Exil, Gütersloh 1991, S.79-94. 
tigen Amtes erschien, wurde bisher in Anlehnung an Bülows Memoiren als Gentlemen-Agreement zwischen Außenministerium und Journalisten gedeutet. ${ }^{171}$ Tatsächlich schränkte die Regierung anscheinend schon vorher die Berichterstattung ein. So erhielten die Journalisten nur Zutritt zur Rede, nachdem sie mit ihrer Unterschrift eine vom Auswärtigen Amt ausgestellte Erklärung unterschrieben hatten, nichts von der Kaiserrede zu veröffentlichen, was nicht vorher dem Auswärtigen Amt vorgelegen habe. ${ }^{172}$ Als ein Journalist der Frankfurter Zeitung anschließend dennoch einen Redetext an seine Redaktion telegraphieren wollte, der dem Wortlaut nahe kam, wurde die Meldung auf Bülows Weisung hin vom Telegrafenamt zurückgehalten, obgleich dies eine gesetzeswidrige Einschränkung der Kommunikationsfreiheit war. ${ }^{173}$ Diese repressive Strategie, die den Kaiser von vorneherein als freien Redner entmündigte, schien zunächst aufzugehen. Am folgenden Tag druckten die Zeitungen die korrigierte Version des Auswärtigen Amtes ab. Um auf die Redeeindrücke der Anwesenden einzugehen, verbreitete die Regierung sogar noch eine zweite Version im Reichs-Anzeiger, die etwas direkter, wenn auch ebenfalls entschärfend, Passagen aus der Rede enthielt. Zudem veröffentlichte die Reichsleitung einige Tage später eine weitere, eher zurückhaltende Kaiserrede vor Matrosen, die zwar ebenfalls zum Kampf anspornte, aber das Beten für den Sieg in den Mittelpunkt stellte. ${ }^{174}$

Gleichzeitig entfaltete sich der Skandal jedoch aus der Ausbildung eines eigenständig recherchierenden Journalismus, der dieses Schutzschild um den Monarchen durchbrach. Zeitungen aus dem regionalen Umfeld, wie die Nordwestdeutsche Zeitung, die Nenesten Nachrichten und das Hamburger Fremdenblatt, druckten abweichende Versionen der Rede, die dank ihrer eigenen Korrespondentenmitschriften dem Wortlaut wohl am nächsten kamen. ${ }^{175}$ Dies unterstrich abermals den Kontrollverlust der Regierung gegenüber der Presse, die sich eben nicht mehr über die Nachrichtenagentur WTB, über offiziöse Blätter wie den Reichs- und Staatsanzeiger und der Norddeutscher Allgemeinen Zeitung oder durch persönliche Loyalitätsabsicherungen des Pressebüros beeinflussen ließ. Die Figur des anwesenden Reporters triumphierte vielmehr über die offiziöse Meldung.

Bezeichnend für den entstehenden Skandal war, dass sich die Empörung zunächst erneut weniger gegen den Kaiser richtete. Vielmehr begann er mit Spott über die Reichsleitung, die für die verschiedenen Versionen der Kaiserrede verantwortlich gemacht wurde. So begnügte sich der Vorwärts zunächst damit, die

171 Hier baute die Literatur auf: Bernhard von BüLow, Denkwürdigkeiten, Bd. 1: Vom Staatssekretariat bis zur Marokko-Krise, Berlin 1930, S. 359.

172 Vossische Zeitung Nr. 355, 1.8.1900, S.1.

173 Vgl. Vorwärts 1.8.1900; Frankfurter Zeitung 28.7.1900 (Abendblatt) u. 30.7.1900 (Morgenblatt).

174 Der Text der Seepredigt ging zuerst an: Neue Preussische Zeitung Nr. 356, 2. 8. 1900, S. 1.

175 In der Presse sprach man daher sogar von vier Versionen der Rede. Vossische Zeitung Nr.355, 1.8.1900, S. 1. 
unterschiedlichen Versionen nebeneinander zu stellen, um damit die Hilflosigkeit der Regierung im Umgang mit den Kaiserreden vorzuführen. ${ }^{176} \mathrm{Um}$ das Sensationelle an diesem Vorgang zu unterstreichen, wählte man typographisch eine der größten Überschriften („Drei Lesarten!“), die das SPD-Blatt bisher gedruckt hatte. Damit wurde der Monarch, wie in der früheren Camouflage, nur über seine schlechten Berater kritisiert. Das Nebeneinander der Reden kleidete die Kaiserkritik abermals in ein Rätsel, das die Dynamik der Kommunikation stärkte. Journalisten und Leser konnten nun spekulieren, welche Passagen tatsächlich vom Kaiser stammten und wie diese eigentlich zu verstehen seien.

In der zweiten Phase des Skandals, als der martialische Inhalt debattiert wurde, hielten zumindest die Zeitungen rechts vom Zentrum die Rede für angemessen. Allerdings belegen interne Aufzeichnungen den Unmut, der auch bei der konservativen Elite bestand. ${ }^{177}$ Insgesamt verschob die Rede das Kaiserbild. Die Sozialdemokraten pathologisierten Wilhelm II. nun vehementer als zuvor, indem sie zahlreiche andere Auszüge seiner Reden präsentierten, in denen der Kaiser zur blutigen Vergeltung aufgerufen hatte. ${ }^{178}$ Den Liberalen, die dem Anspruch auf Vergeltung zustimmten, erschien der Kaiser als eine fehlbare Figur, der man explizit Irrtümer und Fehleinschätzungen nachweisen konnte. Dass die Chinesen brutal wie noch kein Volk in der Geschichte gehandelt hätten, wurde ebenso zurückgewiesen wie die Zulässigkeit einer blutigen Rache. ${ }^{179}$ Die Konservativen hingegen kritisierten den Kaiser zwar nicht offen, düpierten ihn aber zumindest dadurch, dass sie unter offensichtlichen Verrenkungen die problematischen Sätze umdeuteten. ${ }^{180}$ Wilhelm II. erschien damit als ein Monarch, dessen Reden nur durch die Zensur und Nachinterpretation publizierbar waren. Besonders deutliche Worte fand abermals Maximilian Harden, der den Kaiser als eine der Realität entrückte Figur beschrieb, dessen Reden und Allmachtsvorstellungen für die „monarchische Krise“ verantwortlich seien. ${ }^{181}$ Andere bürgerliche Blätter kamen zu dem Schluss, wenn der Monarch als Politiker auftrete, müsse er sich auch mit den "Stacheln der öffentlichen Kritik zurechtfinden. “182 Der Skandal legitimierte damit grundsätzlich eine kritische Auseinandersetzung mit dem Monarchen.

Die „Hunnenrede“ verschob die Grenzen des Sagbaren so sehr, dass es zu einer Reichstagsdebatte über den Kaiser kam, obwohl seine Person eigentlich im

176 VORWÄRTs 29.7.1900, S.1. Vgl. als Kritik an der „Unsicherheit“ der offiziösen Berichterstattung von rechts: Neue Preussische Zeitung Nr.351, 30.7.1900, S.1.

177 Selbst Generalfeldmarschall Waldersee, dem der Kaiser schon vor der Rede den Oberbefehl für die Niederschlagung des Aufstandes in China anbot, sah die Rede kritisch; Eintrag 5.7.1900 (Datum fehlerhaft, gemeint war wohl 5.8., F.B.), in: MeIsner (Hrsg.), Denkwürdigkeiten, S. 448 .

178 VORWÄRTS 31.7.1900, S.3.

179 Vossische Zeitung Nr. 355, 28.7.1900, S. 1.

180 Vgl. etwa Neue Preussische Zeitung Nr.349, 28.7.1900, S.1.

181 Harden, Der Kampf mit dem Drachen, in: Die Zukunft 11.8.1900.

182 Nation 11.8.1900, S. 627, zit. nach: FäLschle, Rivalität, S. 200. 
Parlament als nicht verhandelbar galt. Der Monarch, so August Bebels Hauptvorwurf im Reichstag, habe mit seinen Rache-Äußerungen direkt zu brutalen Tötungen aufgerufen, die dann tatsächlich umgesetzt worden seien, was zutiefst unchristlich sei. ${ }^{183}$ Wie bei seiner Kolonialkritik versuchte Bebel durch Verweise auf christliche Grundsätze Teile des Zentrums und der Konservativen zu gewinnen. Die SPD-Presse flankierte dies mit detaillierten quellennahen Berichten über das brutale Vorgehen der Soldaten in China, für das sie den Kaiser persönlich verantwortlich machte. ${ }^{184}$ Der Linksliberale Eugen Richter schloss sich im Reichstag Bebels Kritik an. Er sprach sich generell für eine Debatte über die Kaiserreden im Reichstag aus, da der Kaiser fortlaufend politische Stellungnahmen mache, Parteien des Reichstages angreife und öffentliche Kritik hervorrufe. Deshalb verlangte er eine direkte Kontrolle der Kaiserreden durch Absprachen mit den Ministern. ${ }^{185}$ Obgleich Reichskanzler Bülow daraufhin die Redefreiheit des Kaisers verteidigte, entschuldigte er den Kaiser damit, dieser habe erst kurz zuvor von den Morden gehört und als Soldat, nicht als Diplomat gesprochen. ${ }^{186}$ Selbst diese wenig überzeugende Verteidigung verfestigte das Bild eines unmündigen Kaisers, der durch die Regierung und die Öffentlichkeit kontrolliert werden müsse.

Der Skandal um die „Hunnenrede“ hatte zwar nicht zur Folge, dass der Kaiser seinen Ton mäßigte. Jedoch führte die medial ausgelöste Empörung, die der Monarch bei einigen folgenden Reden erneut anstieß, immerhin dazu, dass selbst konservative monarchietreue Eliten eine Begrenzung seiner öffentlichen Auftritte forderten. So entfachten die überzogenen Reden, die der Kaiser nach Krupps Tod Ende 1902 in Essen, Breslau und Görlitz hielt, nicht nur einen breiten Unmut in der Presse. Sie leitete auch eine Resolution der Fraktionsführer der Konservativen, Nationalliberalen und des Zentrums ein, die gegenüber dem Reichskanzler ihre Besorgnis über die Kaiserreden ausdrückte und aus Angst vor Angriffen von links auf mehr Zurückhaltung im Sinne der Verfassung baten. ${ }^{187}$ Die Skandale um die Reden machten somit das eigenmächtige politische Auftreten des Kaisers zu einem sanktionierbaren Normbruch.

Wilhelm selbst betonte immer wieder, dass er der Presse und der öffentlichen Meinung keine größere Bedeutung beimessen würde, sondern nach eigenem Ermessen entscheide. Wie verschiedene Zeitgenossen bemerkten, las er selbst vornehmlich nur das konservativ orientierte Massenblatt Berliner Lokal-Anzeiger. Ansonsten informierte er sich überwiegend über mündliche Berichte und

183 Vgl. die Rede 19.11.1900 in: RT X. Leg., II. Sess., Bd.179, S.29. Vgl. auch: WielandT und KASCHER, Die Reichstagsdebatten.

184 Dabei stützte sich der Vorwärts nicht nur auf Soldatenberichte, sondern auch auf bürgerliche Journalisten wie den Kriegsberichterstatter des Berliner Lokal-Anzeigers, Missionare und Professoren; so: Rechtsanwälte des Vorwärts 11.6.1901, in: BAB/L, NY 4060-58.

185 Rede 20.11.1900 in: RT X. Leg., II. Sess., Bd.179, S. 53 f.

186 Ebd., S. 63 u. 23.11.1900, S. 125.

187 Das Schreiben der Fraktionsführer vom 20.1.1903 ist abgedr. in: Huber, Deutsche Verfassungsgeschichte, Bd. 4, S. 439. 
Zeitungsausschnitte, die das Auswärtige Amt für ihn bereitstellte. 188 Trotz dieser gewissen Ignoranz war auch seine Herrschaft durchaus auf komplexe Weise mit der Tagespresse verbunden. Der Kaiser kommunizierte mit der Regierung über seine oft sehr emotionalen Reaktionen beim Lesen der Ausschnitte, die er mit kurzen schriftlichen Kommentaren versah. Da die Auswahl der Zeitungsausschnitte und die Reaktion auf sie das Wissen und Denken des Monarchen zeigte, verlangte Reichskanzler Bülow vom Literarischen Büro nicht nur eine Mitteilung darüber, welche Artikel der Kaiser bekomme, sondern auch die Dokumentation seiner Randnotizen. ${ }^{189}$ Hierzu zählten Unterstreichungen und Ausrufezeichen, Ausrufe (wie „gut!“ oder „bravo!“) und kurze Anweisungen (wie „Dementi!“), die allesamt verdeutlichen, wie sehr der Kaiser die öffentliche Meinung rezipierte und auf sie zu reagieren verlangte. Diese Anmerkungen wurden oft sogar in abgetippter Form der Reichskanzlei vorgelegt. ${ }^{190}$ Entgegen Wilhelms Selbststilisierung bildete die Presse damit einen wesentlichen Anstoß für seine politische Kommunikation, mit der er Reaktionen auf die Pressemeldungen einforderte oder sich einer bestimmten vorgeschlagenen Meinung anschloss.

Zugleich suchte der Kaiser zunehmend die direkte Kommunikation mit den Medien - bis hin zum Interview. Zahlreiche Gesamtdarstellungen zum Kaiserreich haben zu Recht die Daily-Telegraph-Affäre als einen Höhepunkt der Kritik am „persönlichen Regiment" bewertet, bei der sich die Empörung gegenüber den unüberlegten Äußerungen des Kaisers entlud und die mangelhafte Regierungsorganisation enthüllte. ${ }^{191}$ Die internationale Empörung entzündete sich dabei vor allem an vier Behauptungen, die der Kaiser in einem Interview äußerte, das der Daily Telegraph am 28. Oktober 1908 publizierte: Erstens die Aussage, er gehöre zu einer englandfreundlichen Minderheit in Deutschland, wodurch er, entgegen seinen Intentionen, leichtfertig die englische Angst vor der deutschen Aufrüstung stärkte; zweitens, er habe ein russisch-französisches Vorgehen gegen England im Burenkrieg nicht nur abgelehnt, sondern auch Queen Victoria mitgeteilt, womit er sich als eigenständiger Außenpolitiker im europäischen Bündnis präsentierte; drittens, durch seinen Schlachtplan sei der Burenkrieg gewonnen worden, was eine denkbar große Anmaßung war; und viertens, der deutsche Flottenbau würde sich nicht gegen England, sondern gegen die Fernost-Staaten richten, was insbesondere eine Provokation gegenüber Japan war. ${ }^{192}$

188 Vgl. etwa: von Holstein an Eulenburg 12.12.1889, abgedr. in: RöHL (Hrsg.), Eulenburgs politische Korrespondenz, Bd.1, S.385f.; Eintrag ZedliTz-TrÜTZsCHLER 29.1.1905, in: DERs., Zwölf Jahre, S. 106; öffentlich dazu: Germania Nr.128, 7.6.1907. Vgl. auch: STöber, Pressepolitik, S. 180 u. 189.

189 Bülow an Minister des Inneren 25.10.1901, in: BAB/L, R 43 1567-10.

190 Vgl. etwa die von Wilhelm II. kommentierten Artikel in Bülows Nachlass, in: BA/K, 1016-35.

191 Vgl. etwa: Hans-Peter Ullmann, Das Deutsche Kaiserreich 1871-1918, Frankfurt a. M. 1995, S. 169; UllRich, Nervöse Großmacht, S.219; HubER, Deutsche Verfassungsgeschichte, Bd. 4, S. 303; Mommsen, War der Kaiser an allem Schuld?, S. 143.

192 Daily Telegraph 28.10.1908, S.11; ein Faksimile-Abdruck der Zeitungsseite in: BüLow, Denkwürdigkeiten, Bd.2, Berlin 1930, S. 352. 
Zudem sorgte für Empörung, dass Bülow, dem das Interview vorab zur Durchsicht vorlag, es angeblich nicht durchsah. Dementsprechend ging auch die historische Forschung insbesondere der Frage nach, ob Bülow tatsächlich die Korrektur des Interviews überging. So argumentierte Peter Winzen jüngst, Bülow habe den Text gekannt, was plausibel erscheint, obgleich ein eindeutiger Quellenbeleg auch bei Winzens Darstellung weiterhin fehlt. ${ }^{193}$ Eine weitere Lesart bot Martin Kohlrausch an, der den Skandal zusammen mit der Eulenburg-Affäre als Ausdruck einer Desillusionierung über den Monarchen bewertete, wodurch radikalerer Führerforderungen aufgekommen seien. ${ }^{194}$

Blick man dagegen zunächst vor allem auf die Medialisierungsprozesse der Zeit, so bietet sich eine etwas andere Perspektive an. Nicht allein die bekannte Sprunghaftigkeit des Kaisers, sondern auch die Etablierung der medialen Kommunikationsform des „Interviews“ bildet dann einen wichtigen Ausgangspunkt für den Skandal. Dabei lässt sich argumentieren, dass der Daily Telegraph-Artikel auch deshalb eine derartige Wirkung entfachte, weil der Kaiser mit einer in Großbritannien bereits etablierten Medientechnik experimentierte, deren Logik für ihn ähnliche Ambivalenzen aufwies wie der Abdruck seiner Reden. ${ }^{195}$

Mediengeschichtlich gesehen waren Interviews zu diesem Zeitpunkt in Deutschland noch eine gewisse Neuheit. In den USA und Großbritannien hatten sie sich dagegen schon im letzten Drittel des 19. Jahrhunderts etabliert. Der Oxford Dictionary verwendete den Begriff bereits 1867 im Pressekontext und schon wenige Jahre später erschienen Interviews mit prominenten Personen wie dem Papst oder mit Bismarck in der englischen Presse, so dass das Gespräch von Wilhelm II. durchaus prominente Vorläufer hatte. ${ }^{196}$ Etabliert und systematisiert wurde das Interview in Großbritannien vor allem seit 1883 durch den Starjournalisten W. T. Stead in der Pall Mall Gazette. ${ }^{197}$ Steads Innovation war, dass er Prominente in deren privaten Räumen aufsuchte und neben dem Gespräch in Reportageform auch Person und Umgebung beschrieb. Durch das Interview veränderte sich damit nicht nur das Format des Artikels, sondern auch die Repräsentation des Politischen. Politik wurde auf diese Weise weitaus stärker personalisiert, und das Individuum konnte von allen Institutionen losgelöst in mündlicher Rede Position beziehen, was dem Kommunikationsverhalten von Wilhelm II. stark entgegen kam.

193 Winzen, Das Kaiserreich, bes. S.34. In Winzens Einleitung zu seiner Quellenedition findet sich auch die maßgebliche Rekonstruktion des Ereignisablaufes. Dass Bülow es nicht vorher las, meinen: Lerman, The Chancellor, S. 221; Fesser, Reichskanzler, S. $132 \mathrm{f}$.

194 Kohlrausch, Der Monarch, S.261f. u. 296.

195 Stärker mit der neuen Macht der Presse gegenüber dem Parlament interpretiert die Affäre auch: Platthaus, Novemberrevolution, S. $150 \mathrm{f}$. sowie generell: Kohlrausch, Der Monarch.

196 Brown, Victorian News, S. 160.

197 Schults, Crusader, S.61f. Nicht haltbar ist jedoch, angesichts verschiedener Vorläufer, die oft formulierte Annahme, Stead habe das Interview eingeführt; vgl. etwa zu wichtigen Vorläufer wie Yates: Joel H. Wiener, Edmund Yates: The Gossip as Editor, in: Ders. (Hrsg.) Innovators, S. 259-274, S. 260 u. 265; Richard SAlmon, A Simulacrum of Power. Intimacy and Abstraction in the Rhetoric of New Journalism, in: BRAKE et al. (Hrsg.), Encounters, S. 27-39. 
Diese frühen Interviews sollten bereits in der spätviktorianischen Presse politische Handlungen und gesellschaftliche Debatten auslösen. So leitete 1884 Steads Interview mit General Gordon Großbritanniens militärische Expedition im Sudan ein. Steads Interview mit Admiral Lord Cooper über die Schwächen der Navy führte noch im gleichen Jahr zusammen mit seiner anschließenden Pressekampagne dazu, dass die Navy ausgebaut wurde. ${ }^{198}$ Ebenso bediente sich Steads berühmte Serie über die Londoner Kinderprostitution im Jahr darauf zahlloser Interviews, um das Alter für legalen Geschlechtsverkehr von 14 auf 16 anzuheben. Für die Leser des Daily Telegraph-Interviews mit Wilhelm II. war somit bereits bekannt, dass per Interview auch direkt Politik gestaltet werden konnte und sollte. Sein Interview-Partner, der damalige Militär-Attaché in Frankreich Edward James Montagu Stuart-Wortley verstand sich dementsprechend auch als diplomatischer Vermittler zwischen den Nationen.

Zudem stand das Interview generell für eine soziale Aufwertung der Journalisten, die so stellvertretend für ihre Leser mit Politikern in einen unmittelbaren Austausch treten konnten. Bemerkenswert ist, dass bei angelsächsischen Journalisten und Publizisten dieser Zugang bereits bis zum Kaiser reichen konnte. Der amerikanische Journalist William Bayard Hale, der im Sommer 1908 mit dem Kaiser ein Interview führte, hatte vom deutschen Botschafter eine Empfehlung erhalten. Stuart-Wortley, dessen Gespräch mit dem Kaiser im Daily Telegraph erschien, war hingegen kein Journalist, sondern ein adliger Offizier, den der Kaiser bei seinem Englandbesuch 1907 näher kennen gelernt hatte und daraufhin zu einem weiteren Gespräch im September 1908 als Gast bei einem Manöver in Saarbrücken einlud.

In Deutschland war das Interview als Format jedoch um 1900 noch wenig bekannt. Die Lexika der Zeit vermerkten immerhin schon den Begriff „Interviewer“, worunter sie einen Besucher verstanden, der meist ein Journalist sei und berühmte Persönlichkeiten „ausfrage“ ${ }^{199}$ Gebräuchlicher in der Korrespondenz zwischen Journalisten und Politikern waren jedoch in Deutschland Begriffe wie „Audienz“ oder „empfangen“.200 Im Unterschied zum englischen Wort „Interview“ verwies dies auf eine „Vorlassung“ im Sinne einer gewährten Gnade, weniger auf den Vorgang des Fragens. Zudem war es in Deutschland üblich, dass die Journalisten, die empfangen wurden, die Einschätzungen des Befragten unter Hinweis auf eine „offizielle Quelle“ in ihre Texte einbauten, nicht dagegen als transparentes Frage-Antwort-Spiel präsentierten.

198 Joseph Baylen, Politics and New Journalism: Lord Esher's Use of the Pall Mall Gazette, in: Wiener (Hrsg.), Papers for the Millions, S. 114.

199 Vgl. die Ausgaben von Brockhaus' Konversations-Lexikon (1898) und Meyers Grosses Konversations-Lexikon (1906), das auch auf die englische und amerikanische Vorbildfunktion verweist.

200 Vgl. die Begriffe in Anschreiben von Journalisten wie: Redaktion BZ am Mittag an Bülow 16.10.1907, in: BA/K, N 1016-185-43; Hartmann an Bülow 13.10.1907, in: BA/K, N 1016$185-13$. 
Für gewöhnlich bewarben sich Journalisten bei Politikern um Gespräche, indem sie lobende Artikel aus Ihrer Zeitung beilegten, die sie jüngst geschrieben hatten. Im Unterschied zu Großbritannien unterstrichen die Journalisten häufig gleich, dass sie nicht als unabhängige Gesprächspartner kamen. So bot der Leiter des Hamburger Fremdenblattes dem Reichskanzler bei einer Interviewanfrage 1907 an, dass es sich nicht „um ein blosses [sic] journalistisches Interview, sondern um einen politischen Schachzug im Interesse der Sache“ handeln würde, um Bülows Politik zu propagieren; eine Antwort erhielt er zunächst trotzdem nicht. ${ }^{201}$ Eine andere charakteristische Strategie, um eine „Audienz“ zu bekommen, wählte ein Redakteur der Neuen Freien Presse, der bei einem neuen Minister einen Termin mit der Versicherung erfragte, keine „Frage politischer Natur vorzulegen“. ${ }^{202}$ In der Reichskanzlei und den Ministerien überprüfte man, was und für welche Zeitungen die Journalisten bisher geschrieben hatten, wobei bereits frühere Artikel für ein ungenehmes Blatt ein Ausschlusskriterium waren. ${ }^{203}$

Um 1907 gewann das Interview in Deutschland deutlich an Bedeutung. So zeigen die Archivüberlieferungen einen unverkennbaren Anstieg der InterviewAnfragen. Der neu designierte Staatssekretär des Kolonialamtes, Bernhard Dernburg, erhielt 1907 etwa gleich dutzende Anfragen, und auch bei Kanzler Bülow nahm in diesem Jahr die Zahl der überlieferten Interviewwünsche und Interviews zu. ${ }^{204}$ Ebenso hat bereits die Analyse des Eulenburg-Moltke-Skandals gezeigt, dass 1907/08 sogar ein Staatsanwalt und Journalisten wie Harden als Interviewpartner auftraten. ${ }^{205}$ Gleichzeitig kam es zu wechselseitigen Besuchen deutscher und britischer Journalisten bei den Staatsführungen beider Länder, wobei im Mai 1907 mehrere dutzend britische Journalisten vom Kanzler, Ministern und sogar vom Kaiser empfangen wurden. ${ }^{206}$ Dieser Austausch dürfte den Siegeszug des Interviews weiter gefördert haben und ist als eine Brücke für die Kaiser-Interviews 1908 anzusehen. Um 1907/08 nutzte auch Reichskanzler Bülow Interviews verstärkt als Mittel der politischen Agitation und Selbstdarstellung. Er reagierte so auch auf die Krisenstimmung, die insbesondere in der Außenpolitik seit 1906 dominierte. So regte Bülow etwa im Mai 1908 ein Interview mit den Hamburger Nachrichten an, um etwas Emotionales über sich in der Presse zu bringen. ${ }^{207}$ Ebenso flankierte er seine Außenpolitik gegenüber Großbritannien per Interview, als er im August 1908 in Norderney mit einem englischen Journalisten ein ausführliches Gespräch für den britischen

201 Paul Raché (Leiter Hamburger Fremdenblatts) an Bülow 13.9.1907, in: BA/K, N 1016-18547; zumindest fragte er vier Wochen später noch einmal nach.

202 Adolf Bondy/Neue Freie Presse an Dernburg, 4.12.1906, in: BA/K, N 1130-1.

203 Hierzu zählte etwa die eher konservative Daily Mail; Hartmann an Bülow 13.10.1907, in: BA/K, N 1016-185-13.

204 Vgl. zu Dernburg die Anfragen ab: 4.12.1906ff., in: BA/K, N 1130-13.

205 Vgl. Kap. II. 7.

206 Vgl. hierzu jetzt ausführlich: Geppert, Pressekriege, S. 358-382.

207 Bülow an Hammann 1.5.1908, in: BAB/L, N 2106/14: $12 \mathrm{f}$. 
Standard machte, das frühere aggressive Äußerungen des Kaisers ein wenig einzudämmen suchte. Hierbei betonte er bereits, dass diplomatische Krisen oft daraus entstehen würden, dass die Presse Dinge aus ihrem Zusammenhang reiße. In Deutschland würde niemand an einen Angriff an England denken, eher müsse Deutschland Angst vor einem englischen Angriff haben. ${ }^{208}$

Die Interviews, die der Kaiser im November 1907 und Sommer 1908 machte, sind folglich im Kontext dieser Pressepolitik per Interview zu verstehen, die insbesondere den Engländern die Angst vor der deutschen Flottenaufrüstung nehmen sollte. Dementsprechend ermutigte Bülow den Kaiser zu dem im Daily Telegraph gedruckten Interview, das mit seinem Werben um Englands Vertrauen ganz auf Bülows Linie lag. Die Interviews standen somit in gewisser Weise für eine Transformation der Außenpolitik, die statt über diplomatische Absprachen über die Presse verlief. Da der Kaiser den Text, den der englische Interviewer Edward James Stuart-Wortley aus zwei Gesprächen zusammengestellt hatte, persönlich zur Korrektur vorgelegt bekam, kann nicht von einer Überrumpelung durch die Presse gesprochen werden. Ein weiteres Kaiser-Interview mit dem amerikanischen Journalisten William Bayard Hale, den das Auswärtige Amt empfohlen hatte, ergänzte diese verstärkte Diplomatie durch direkte Pressekommunikation.

Die Form des Daily Telegraph-Interviews wies zahlreiche Ähnlichkeiten zu den Reden Wilhelm II. auf und entsprach somit durchaus seinen öffentlichen Kommunikationsvorlieben. Von den Formulierungen her blieben die Aussagen äußerst umgangssprachlich und salopp - etwa wenn er den Engländern vorhielt, völlig grundlos vor Deutschland Angst zu haben („You English are mad, mad, mad as March hares“). ${ }^{209}$ Ähnlich wie in seinen Reden gab der Stil der wörtlichen Wiedergabe Gelegenheit, Bedrohungen farbig auszumalen und sich zugleich selbst als Friedensbringer zu präsentieren. Die Zeitungsleser konnten so den Eindruck haben, der Kaiser würde unmittelbar mit ihnen sprechen. Dabei konnte sich der Kaiser durch die Interviewform selbst als entscheidender politischer Akteur herausstellen, der sein Land außenpolitisch lenkte. Das Wort „Ich“ hatte hier, wie in seinen Telegrammen oder Reden, einen zentralen Stellenwert. Diese Unmittelbarkeit des kaiserlichen Sprechens, die durch die spezifische Struktur des Interviews bedingt war, dürfte wesentlich mit dazu beigetragen haben, dass unter den zahllosen problematischen kaiserlichen Handlungen gerade das Interview eine derartige Wirkung entfaltete.

Die mediale Verschriftlichung der Gespräche brachte allerdings ähnliche Probleme mit sich wie die der Reden des Kaisers. So wählte er auch im Interview recht spontan Formulierungen, um seinem unmittelbaren Gegenüber zu gefallen. Während er im Daily Telegraph-Interview seine Liebe zu England pries, betonte Wilhelm II. in dem nahezu zeitgleichen Interview mit dem amerika-

208 Das Interview führte Sydney Whitman, in: STANDARD 13.9.1908; WTB an Bülow 14.9. (1908), in: BA/K, N 1016-185-73. Dass das Daily Telegraph-Interview des Kaisers im Kontext von Bülows Interviewpolitik zu sehen ist, zeigte jüngst auch: GEPPERT, Pressekriege, S. $262 \mathrm{f}$.

209 Alle folgenden Zitate aus dem Interview nach: DaILy Telegraph 28.10.1908, S. 11. 
nischen Publizisten Hale seine Freundschaft zu den USA und monierte die Bedrohung durch England. ${ }^{210}$ Dass Kanzler und Kaiser jeweils glaubten, über ein Interview die nationale Stimmung eines Landes beeinflussen zu können, geht dagegen aus ihren Formulierungen recht deutlich hervor. Eine mittlerweile etablierte transnationale Öffentlichkeit, die diese Aussagen in wenigen Stunden weltweit per Telegraph miteinander verglich und auf den Prüfstein stellte, hatte der Kaiser dagegen während der Interviews anscheinend nicht vor Augen.

Im Vergleich zur Rede schien das Interview zwar wesentlich kontrollierbarer, da seine Freigabe eine Korrektur durch den Kaiser und anschließend durch das Auswärtige Amt beziehungsweise den Kanzler voraussetzte. Tatsächlich zeigte sich aber, dass Interviews ähnlich schnell mediale Eigendynamiken entwickeln konnten wie die Reden. Wie bei der Hunnenrede machte allein die Geschwindigkeit der medialen Übermittlung eine Pressekontrolle kaum möglich. In diesem Fall präsentierte die BZ am Mittag schon wenige Stunden nach dem englischen Erscheinen eine deutsche Version des Interviews, bevor eine offizielle Erklärung über das WTB ausgegeben werden konnte. ${ }^{211}$ Beim Hale-Interview gelang es dem Auswärtigen Amt zwar, unter Mühen die gesamte gedruckte Auflage des Century Magazine, immerhin rund 150000 Stück, vor der Auslieferung aufzukaufen und einstampfen zu lassen, aber dennoch drangen in den folgenden Wochen einzelne Auszüge in die Zeitungen. Zudem erfuhr die deutsche Öffentlichkeit sofort mitten in der Daily Telegraph-Affäre von dieser Maßnahme, was Kaiser und Regierung erneut diskreditierte. ${ }^{212}$

Dass Wilhelm II., die Mitarbeiter des Auswärtigen Amtes und vermutlich auch Bülow die problematischen Stellen der Artikel nicht realisierten, lag sicherlich nicht nur an ihrem mangelnden diplomatischen Gespür. Zugleich dürften sie, wie in ihrer bisherigen Außenpolitik üblich, die Interviews als einen Testballon angesehen haben, um den deutschen Großmachtanspruch zu untermauern und die Flottenaufrüstung zu legitimieren. Insofern stand das Interview eher in einer Tradition von öffentlichen Vorstößen wie der Krüger-Depesche und der Tanger-Landung. Sie alle wurden zwar von ihrer medialen Performanz her allein dem Kaiser zugeschrieben wurden, waren aber tatsächlich oft kollektive Produkte der außenpolitischen Führung - sei es als kalkulierter Affront, sei es als Ausdruck diplomatischer Inkompetenz. ${ }^{213}$

210 Vgl. Ralph R. Menning und Carol Bresnahan Menning, „Baseless Allegations“. Wilhelm II and the Hale Interview of 1908, in: CEH 16 (1983), S.368-397.

211 BZ am MitTag 28.10.1908.

212 Dass ein zweites Interview in letzter Minute verhindert wurde, war in der Presse gleich bekannt; vgl. Vossische Zeitung 7.11.1908, S.1 u. 9.11., S.2. Vgl. zur Unterdrückung auch: Bünz an Bülow 6.11.1908, abgedr. in: Winzen, Kaiserreich, S.176-178; dazu auch: Winzen, Kaiserreich, S. 86; Menning und Menning, „Baseless Allegations“.

213 In diesem Sinne ist hier der pointierten Argumentation von Wolfgang J. Mommsen zuzustimmen, der die Akteure um den Kaiser herum hervorhebt: Mommsen, War der Kaiser an allem Schuld, passim. 
Obgleich sich die öffentliche Empörung zunächst vor allem gegen das unprofessionelle Verhalten des Kanzlers und des Auswärtigen Amtes richtete, prägte der Skandal zugleich die kollektiven Vorstellungen über den Kaiser. Stärker als zuvor etablierte er das Bild des unmündigen Monarchen, der weder in der Lage noch befugt war, alleine öffentlich zu sprechen. Denn unabhängig von den Inhalten des Interviews lernten die Zeitungsleser aus Bülows Rechtfertigungen, dass die Kontrolle und Überarbeitung der kaiserlichen Äußerungen in der politischen Praxis nicht nur vorgesehen, sondern auch dringend nötig war. Dass der Kaiser ohne ein zuverlässiges Lektorat aus dem Auswärtigen Amt schweren Schaden anrichte, untergrub jenen Souveränitätsanspruch, den er öffentlich bis hin zum Gottesgnadentum pflegte. Während sich in der Eulenburg-Affäre kurz zuvor die Empörung noch gegen die schlechten Ratgeber des Kaisers gerichtet hatte, erschien der Kaiser bei einem Medienformat wie dem Interview ganz alleine für den skandalösen Inhalt verantwortlich. Die Forderung nach einem Ende des „persönlichen Regiments“, die von allen Seiten artikuliert wurde, stand daher im Mittelpunkt der rasant anwachsenden Kritik.

Zudem erschien der Kaiser im Zuge des Skandals wie ein Opportunist, der sich jedoch nicht an den heimischen Volksstimmungen orientierte, sondern am Herkunftsland seiner Interviewpartner. Dass er etwa im Daily Telegraph-Interview mit seinem Schlachtplan für den englischen Sieg im Burenkrieg prahlte, sorgte allein schon deshalb für Empörung, weil die deutsche Bevölkerung mehrheitlich auf Seiten der Buren gestanden hatte. Insofern ging es nicht einmal darum, ob seine Prahlereien über den siegreichen Feldzug der Wahrheit entsprachen, sondern um die Anbiederung an das Empire. Die liberale Öffentlichkeit artikulierte nun eine generelle Unzufriedenheit mit den öffentlichen Auftritten des Kaisers in den letzten zwanzig Jahren. So hätten seine Reisen, seine Reden und seine Vielgeschäftigkeit dem Volk viele „Unannehmlichkeiten“ gebracht. ${ }^{214}$ Während der Kaiser in der Medienöffentlichkeit für eine Politik der „Sprunghaftigkeit“ verantwortlich gemacht wurde, bildeten „Stetigkeit“, „Ruhe“ und „Einheitlichkeit“ die positiven Leitbegriffe einer zukünftigen Politik. Ebenso störte man sich daran, dass der Kaiser während des Skandals eben nicht direkt auf die öffentliche Kritik reagierte, sondern fernab auf der Jagd in Donaueschingen weilte. Auf diese Weise entstand das Bild eines Monarchen, der sich nicht um die öffentliche Meinung und um die Folgen seiner Äußerungen kümmerte. Was vormals eine anerkannte Repräsentationspflicht war, galt jetzt als Flucht vor der Öffentlichkeit.

Ähnlich wie bei den frühen Skandalen um den Monarchen erreichte der Skandal seine Schlagkraft dadurch, dass die Empörung gegen den Kaiser von links bis hin zu den Konservativen und Nationalliberalen reichte und sogar von ihnen ausging. Selbst Reichskanzler Bülow zählte indirekt zu den Kaiserkritikern, als er in seiner Rechtfertigung in der Norddeutschen Allgemeinen Zeitung und im

214 Vossische Zeitung Nr. 521, 5.11.1908, S. 1, 4.11.1908, S.1. 
Reichstag unterstrich, er hätte den Text nicht zugelassen. ${ }^{215}$ Auffällig war bereits, wie schnell auch das konservative Milieu die Macht der emotionalen Medienwirkung thematisierte. Die Zeitungen, Tagebucheinträge und Berichte geben davon vielfältige Zeugnisse. So sprach die „Kreuzzeitung“ von der „immer noch anwachsenden Erregung im Volke“216, und der badische Gesandte von Berckheim hielt fest, „auch das große Publikum ist hier in allen seinen Schichten tief erregt, und zwar richtet sich der allgemeine Unwille mehr oder minder verblümt gegen die Person des Monarchen." ${ }^{217}$ In den Hamburger Kneipen vermerkten die Polizeispitzel schon zwei Tage nach Abdruck des Interviews Spott über den Monarchen („Diese Schmach werde er nie mehr gut machen“), womit sie das Interview sogleich als einen Wendepunkt fixierten. Andere Kneipengäste sahen es unter taktischen Gesichtspunkten als guten Stoff für die sozialdemokratischen Reichstagsabgeordneten. ${ }^{218}$

Gerade weil die Empörung durch die ganze Gesellschaft ging, standen besonders die Konservativen vor dem Problem, ihren Unmut über Wilhelm II. zu artikulieren, ohne sich in eine monarchiekritische Phalanx bis hin zur SPD einzureihen. Um einer gemeinsamen Erklärung vorzubeugen, preschte der Parteivorstand der Deutsch-Konservativen Partei deshalb bereits eine Woche nach dem Interview mit einer Resolution vor, die dem Kaiser mehr Zurückhaltung abverlangte, da er das Reich in eine schwierige Lage brächte. ${ }^{219}$ Nicht minder resolut fiel Ernst Bassermanns Erklärung der Nationalliberalen im Reichstag aus, die Öffentlichkeit protestiere einmütig „gegen das Eingreifen Seiner Majestät des Kaisers in die offizielle Politik Deutschlands (lebhafte Zustimmung bei den Nationalliberalen und links) gegen das, was man im Lande das persönliche Regiment nennt".220 Gerade wenn man diese nun sogar im Reichstag formulierte breite Kritik mit jener vergleicht, die in den Skandalen 1894 noch in Form von verschlüsselten Satiren gemacht wurde, wird die immense Verschiebung der Sagbarkeitsgrenzen in nur einem Jahrzehnt deutlich.

Diese Verschiebung im Monarchendiskurs entging auch den Zeitgenossen nicht. Maximilian Harden druckte stolz seine Kaiserkritik von 1892 ab, die ihn damals vor Gericht brachte, um aufzuzeigen, dass nun selbst die offiziösen Blätter kritischer schreiben würden als er damals. ${ }^{221}$ Sein eigener Artikel zu der Interview-Affäre 1908 war sicherlich der schärfste aus dem bürgerlichen Lager.

215 Bülow im RT 10.11.1908, 158. Sitz., S.5395-5397; auch kommentiert abgedr. in: WINZEN, Kaiserreich, S. 197-204.

216 Neue Preussische Zeitung 3.11.1908, abends, S.1.

217 Berckheim an Marschall 2.11.1908, abgedr. in: Winzen, Kaiserreich, S. 14.

218 Polizeibericht Schutzmann Noroschat, 1.11.1906, in: StAH, S 3930-30 Bd. 2.

219 Erklärung des Vorstandes der Deutschkonservativen Partei (DKP) 5.11.1908, abgedr. in: Winzen, Kaiserreich, S. $172 \mathrm{f}$.

220 Erklärung des Parteivorstandes der DKP 5.11.1908, abgedr. in: HubER, Deutsche Verfassungsgeschichte, Bd. 4, S. 440.

221 Harden verwies auf seine Kritik von 1892 in der ZuKunft 15.10.1892 u. 31.12.1892. 
Der Kaiser erschien in seinen unmissverständlichen Formulierungen als gefährlicher Schmarotzer:

Wilhelm der Zweite, der vierzig Jahre nach der Revolution auf den Zollerthron kam und im Reich kein Monarch ist, hat der Nation nie Nützliches geleistet und für seinen Willen dennoch höchste Geltung verlangt. Nun sieht er die Ernte. Wenn ihm, nach allem Geschehenen, möglich dünkt, wird er die Krone auf seinem Haupt behalten. Doch niemals wieder darf an seinem Willen das Schicksal des Deutschen Reiches, deutscher Menschheit hängen. ${ }^{222}$

Aus diesem Grunde forderte er, dass der Kronprinz frühzeitig den Thron übernehmen sollte. Noch bemerkenswerter als der Inhalt war, wie Regierung und Kaiser mit einem derartigen Artikel umgingen. Reichskanzler Bülow setzte sich, wie beim zeitgleichen dritten Moltke-Harden-Prozess, für Harden ein und überzeugte den Kaiser, gegen den Journalisten keinen Prozess wegen Majestätsbeleidigung einleiten zu lassen. Denn selbst bei einer Verurteilung, die nicht wahrscheinlich sei, „würde der Prozeß unendlich viel Staub aufwühlen und insbesondere dem Angeklagten die (von ihm wahrscheinlich erhoffte) Gelegenheit bieten, die ganzen Vorgänge der letzten Zeit für sich zu verwerten und zu giften."223 Harden, der über den offiziösen Journalisten Zimmermann von dieser Fürsprache hörte, bedankte sich entsprechend beim Kanzler. ${ }^{224}$ Der Skandal führte folglich mit dazu, dass es wegen Majestätsbeleidigungen kaum noch zu Prozessen und Verurteilungen kam. Die Kritik am Kaiser wurde durch die Wucht des Skandals vergleichsweise legitim.

Ähnlich wie bei den Skandalen um die englischen Monarchen herrschte nach der ersten Empörung dennoch die Vorstellung vor, den Kaiser gerade durch die breite Entrüstung in der Presse erziehen zu können. So wie der Prince of Wales bei seinen Skandalen gezielt bestimmte Artikel zur moralischen Besserung vorgelegt bekommen hatte, so hoffte auch Friedrich von Holstein weiterhin, dass man den Kaiser durch die Vorlage kritischer Artikel zur Vernunft bringen und lenken könne. Schon am Tag der deutschen Publikation empfahl er dem Reichskanzler: „Die Sache ist unbequem, kann aber vielleicht den Nutzen haben, daß S.M. etwas vorsichtiger wird?? [...] Für S.M. ist dies eine harte Lektion. Aber wird sie nützen? Er bekommt doch reichlich fremdländische Ausschnitte?" 225 Eine Woche später fragte er Bülow erneut, was der Kaiser zu lesen bekomme und regte an: „Der Artikel von Naumann würde ihm gut tun.“226 Derartige Formulierungen ließen die kritische Presse als eine Art Medizin für einen kranken Kaiser erscheinen. Auch Bülow nutzte die problematischen Interviews als Erziehungsmittel, wenn er ihm etwa ein letztes Exemplar des eingestampften

222 Zukunft 21.11.1908, S.296.

223 Bülow an Wilhelm II. 21.11.1908, in: BA/K, N 1016-112-100. Die Argumente lieferte dabei: Zimmermann an Bülow 19.11.1908, in: BA/K, 1016-32-113.

224 Zimmermann an Bülow 21.11.1908, in: BA/K, 1016-32-132.

225 Holstein an Bülow 29.10.1908, abgedr. in: Rogge, Holstein und Harden, S.363. Den Erziehungsansatz betont bereits KoHLRAUSCH, sieht aber stärker sein Scheitern; DERs., Monarch, S. 286.

226 Holstein an Bülow 6.11.1908, abgedr. in: Rogge, Holstein und Harden, S. 377. 
Hale-Interviews mit den Worten zuschickte: „Eure Majestät bitte ich niemanden auf der Welt diesen Auszug zu zeigen und ihn mir zurückzuschicken, damit ich ihn vernichten kann. "227 Der Kaiser bekam damit vorgeführt, dass seine Worte weder für die Öffentlichkeit noch für spätere Historiker geeignet seien, sondern sein Ansehen durch die Vernichtung seiner Interviews geschützt werden müsse.

Als folgenlos wird man den Skandal sicherlich nicht bezeichnen können, auch wenn verfassungsrechtlich keine direkte Veränderung eintrat. Der Skandal veränderte vielmehr die faktische Stellung des Kaisers und das Sprechen über ihn. Durch Bülow ließ er sich sogar zu einer Erklärung bewegen, in der er künftig mehr Zurückhaltung gelobte. ${ }^{228}$ Tatsächlich führte der Skandal dazu, dass sich der Monarch in der politischen Praxis stärker gegenüber der Regierung, dem Reichstag und der Öffentlichkeit zurücknahm. Durch die breite öffentliche Empörung war Wilhelm II. zunächst auch psychisch so verletzt, dass er die folgenden Reden vom Blatt ablas. ${ }^{229}$ Auf der personellen Ebene hatte der Skandal zur Konsequenz, dass nicht nur Außenstaatssekretär Wilhelm von Schoen kurze Zeit später zurücktrat, sondern auch Bülow an Ansehen verlor, so dass seine 1909 erfolgte Absetzung eine Frage der Zeit wurde, nachdem er schon während des Skandals dem Kaiser seinen Rücktritt angeboten hatte. Bereits die Tatsache, dass der Skandal den gleichzeitigen Urlaub von Kanzler, Außenstaatssekretär, Pressechef und anderer wichtiger Repräsentanten zeigte, erweckte den Anschein von mangelnder Koordinationsfähigkeit und fauler Arbeitsscheu. Ein Hamburger Kneipenbesucher kommentierte dies laut Spitzelbericht etwa mit den Worten: „Dem Bülow wird das Herz auch in die Hose fallen wenn er seine Faulheit erörtern soll. [Ein] Reichskanzler der das ganze Reich blamiert muß fort." 230

Vor allem eröffnete der Skandal eine Debatte über eine Parlamentarisierung. Sowohl die Linksliberalen als auch die SPD verlangten eine dem Reichstag verantwortliche Regierung, die SPD sogar ein Anklagerecht des Reichstages gegenüber dem Kanzler. ${ }^{231}$ Die Reformforderungen bezogen sich direkt auf das Versagen der Reichsleitung, die Kaiserrede ordnungsgemäß zu redigieren. Der Skandal führte darüber hinaus im ganzen Land zu verschiedenen Protestversammlungen mit Resolutionen, die eine Parlamentarisierung forderten. ${ }^{232}$ Auch wenn diese Vorstöße chancenlos waren, verstärkte der Skandal zumindest den

227 Bülow an Wilhelm II. 21.11.1908, in: BA/K, N 1016-112-97.

228 Die von Bülow vorher angefertigte Erklärung für den Reichsanzeiger ist abgedr. in: WINZEN, Kaiserreich, S. 247.

229 Aufzeichnung Zedlitz-Trützschler 26.11.1908ff., in: DERs., Zwölf Jahre, S. 194-201.

230 Polizeibericht Schutzmann Noroschat, 10.11.1906, in: StAH, S 3930-30 Bd. 2.

231 Vgl. etwa Rede Singer RT 10.11.1908, 158. Sitz., S. 5389-5392, und die Reichstagsdebatte am 2.12.1908, etwa Ernst Müller-Meiningen 174. Sitz., S.5904-5910; Vossische ZEITUNG 10.11.1908, S. 1 u. 18.11.1908, Nr.543, S.1. Anders argumentiert Platthaus, die Affäre sei nicht in parlamentarische Reformforderungen gemündet; PlatTHaUs, Novemberrevolution, S. 150.

232 SALdern, Arbeiter-Reformismus, S. 65. 
öffentlich artikulierten Anspruch auf eine Parlamentarisierung der Monarchie. Die Rechte des Reichstages wurden zumindest über seine Geschäftsordnung erweitert. $^{233}$

Mit den Kaiser-Interviews ließen sich die Zeitungsauflagen leicht steigern. Dennoch erwiesen sich selbst die stark kommerziell orientierten englischen Zeitungen als recht verantwortungsbewusst. Gerade bei dem Hale-Interview zeigte sich, dass sich auch die britischen Zeitungen bewusst zurückhielten, um eine außenpolitische Krise zu vermeiden. Die englischen Massenblätter von Northcliffe lehnten den Druck ebenso ab wie die amerikanischen Zeitungen, obgleich aus dem Interview heraus ein auflagenstarker Skandal zu erwarten gewesen wäre, der die Daily Telegraph-Affäre noch in den Schatten gestellt hätte. Stattdessen suchten die britischen und die deutschen Journalisten intern den Kontakt zu den Regierungen, um eine diskrete Beilegung zu finden, so dass am Ende nur verzögert Auszüge an die Öffentlichkeit kamen. ${ }^{234}$ Die Versicherung des Kaisers, er werde sich künftig zurückhalten, dämpfte sich die monarchiekritische Stimmung. Selbst Harden nahm nach der reumütigen Erklärung des Kaisers den Monarchen wieder in Schutz und verteidigte ihn bei seinen zahlreichen Vorträgen. ${ }^{235}$

Die Kritik am Kaiser und die Frage, ob die Macht des Monarchen durch eine Verfassungsreform eingeschränkt werden sollte, blieben weiterhin in der öffentlichen Debatte virulent. Selbst den runden 50sten Kaisergeburtstag, den Wilhelm II. am 27. Januar feierte, nahmen die liberalen Zeitungen zum Anlass für derartige Reflexionen - während früher an diesem Tag stets ergebene Glückwünsche und Festberichte dominiert hatten. So forderte das Berliner Tageblatt in seinem Kommentar eine genauere Klärung der kaiserlichen Position in der Reichsverfassung und mehr Sparsamkeit bei Festen und Militärausgaben. ${ }^{236}$ Den kritischsten Geburtstagsgruß unter den bürgerlichen Blättern richtete sicherlich die nationalliberale Rheinisch-Westfälische Zeitung an den Kaiser: „seine Arbeitsmethode sei verfehlt gewesen, sein Wirken ohne Erfolg geblieben, seine Erwartung nicht in Erfüllung gegangen. "237 Eher subtilen Spott zeigte die Berliner Illustrirte Zeitung, die statt der Feierbilder vom 50. Geburtstag vor allem Kinderfotos von ihm abdruckte und ein Kostümbild im Schottenrock von ihm in der Mitte (vgl. Abb. 11). ${ }^{238}$ Damit zementierten sie fotographisch jenes Bild des unmündigen Monarchen, das die Skandale zuvor etabliert hatten.

\footnotetext{
233 RitTER, Der Reichstag, S. 915.

234 Winzen, Kaiserreich, S. 70-73.

235 Zimmermann an Bülow 21.11.1908, in: BA/K, 1016-32-124.

236 Berliner Tageblatt 27.1.1909, S. 1.

237 Zit. in: Berliner Tageblatt 27.1.1909, Abend.

238 Berliner Illustrirte Zeitung 24.1.1909, S. 3.
} 


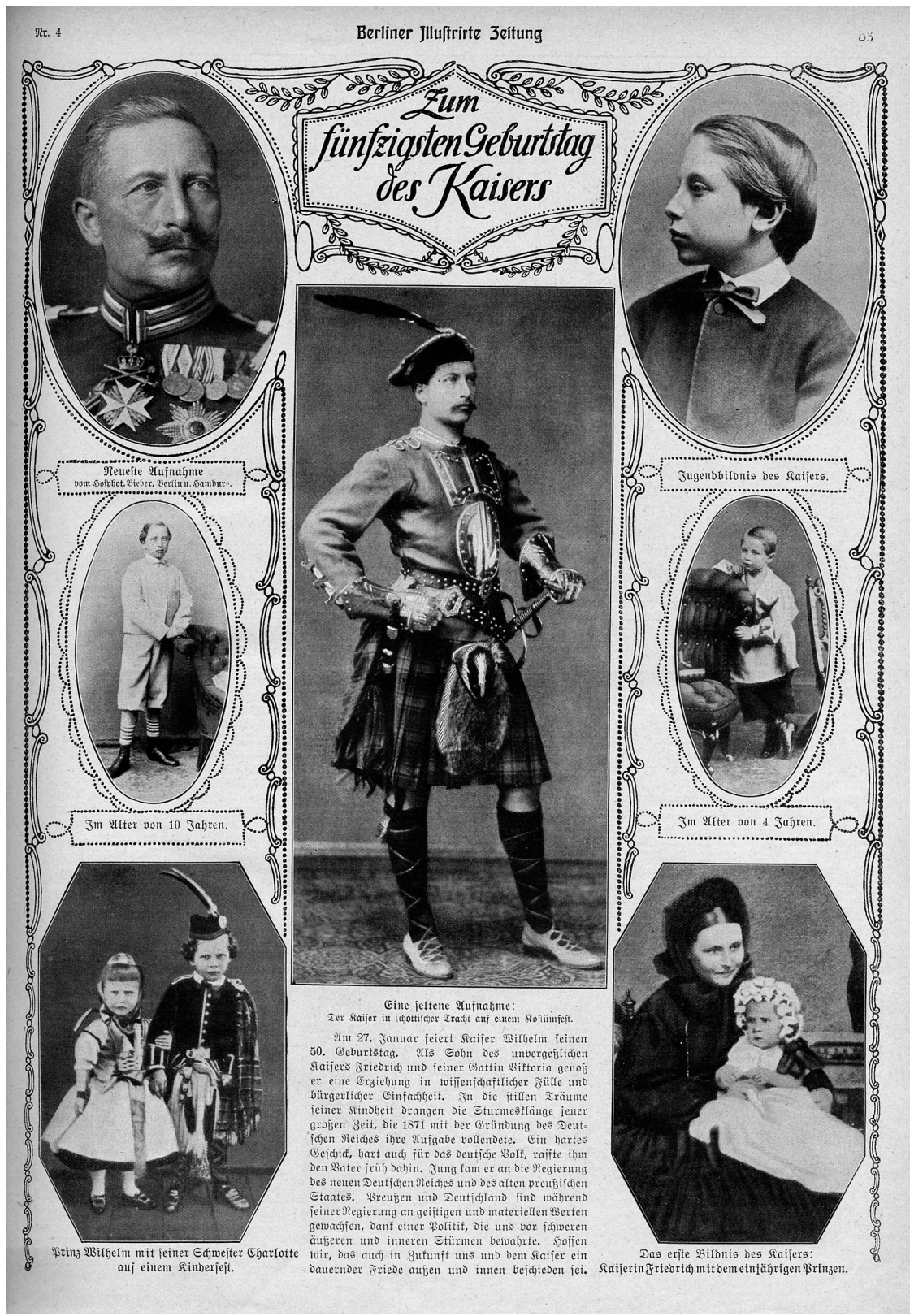

Abb. 12: Der unmündige Monarch im Bild. Nach der Daily-Telegraph-Affäre zeigt die Berliner Illustrirte Zeitung (Nr.4 27.1.1909, S.3) Wilhelm II. zu seinem fünfzigsten Geburtstag vor allem als Kind und als Rockträger in schottischer Verkleidung. 


\section{ZWISCHENFAZIT}

Mit Edward VII. und Wilhelm II. bestiegen im ausgehenden 19. Jahrhundert zwei Monarchen den Thron, die die Öffentlichkeit nicht scheuten und schon früh einer gesteigerten medialen Beobachtung ausgesetzt waren. Wie die Analyse der deutschen und britischen Monarchie-Skandale jedoch zeigte, trafen sie frühzeitig auf recht unterschiedliche öffentliche Erwartungen an die Krone, die Normen für ihr Verhalten prägten. In Großbritannien war die Monarchie vor allem einer moralischen Kritik ausgesetzt, die in gewisser Weise an das Narrativ der französischen Halsbandaffäre anknüpfte. Der Bruch der monogamen Ehe, die finanzielle Verschwendung oder das Glücksspiel bildeten allesamt Themen, bei denen bürgerlich-puritanische Normen ebenso spöttisch wie nachdrücklich an den Monarchen herangetragen wurden. Gerade weil sich das britische Königshaus seit der ersten Hälfte des 19. Jahrhunderts stärker aus der Politikgestaltung zurückgehalten hatte, verlagerten sich die Aufmerksamkeit, die Anforderungen und das mögliche Potential für Skandale auf Fragen der moralischen Lebensführung. Der spätere König Edward VII. wurde deshalb schon lange vor seinem Thronantritt durch Skandale auf die Rolle eines moralischen Vorbildes festgelegt. Dagegen wiesen in Deutschland moralische Fragen eine vergleichsweise geringe Bedeutung auf. Dies erklärt sich nicht nur durch die deutsche Pressezensur, sondern vor allem durch die größeren politischen Gestaltungsspielräume der Monarchen, die eher politische Skandalisierungen begünstigten. Die deutschen Skandale schrieben daraufhin die Rollenerwartung fest, dass der Monarch sich aus der Tagespolitik heraushalten solle.

Während die Monarchie in den letzten Lebensjahren von Wilhelm I. und Queen Victoria gerade durch die Medienöffentlichkeit an Glanz gewonnen hatte, trugen die Skandale in beiden Ländern zur Entzauberung der Thronfolger bei. Die Skandale hinterfragten deren Verhaltensweisen, durchbrachen ihre Selbstinszenierung und verspotteten diese. In Großbritannien geschah dies über Veröffentlichungen aus Privatbereichen, die auch und gerade für das Königshaus nicht als privat gelten sollten. Die Publikation privater Briefe des Prince of Wales oder die Berichte über seine stets mitgeführten Spielsteine banalisierten den Thronfolger. In Deutschland kam es dagegen zu Veröffentlichungen über bisher eher arkane politische Handlungsabläufe, die Wilhelm II. als unselbständige und unmündige Figur erscheinen ließen. Bereits die mehrfache Offenlegung von Berater- und Kontrollsystemen, die das politische Handeln des Monarchen eingegrenzten, raubte ihm den Nimbus eines souveränen Herrschers.

Stärker als bei allen anderen Skandaltypen unterschieden sich die sprachlichen Formen, in denen in den beiden Ländern während der Skandale über die Monarchen gesprochen wurde. Während in Großbritannien frühzeitig Zeitungskommentare mit mahnenden Worten direkt den Monarchen kritisierten, wiesen die deutschen Skandale noch in den 1890er Jahren eine spielerisch-versteckte Sprache auf, die an die Zeit des Vormärzes erinnerte, aber das Tor zu expliziten Formulierungen öffnete. Erst nach 1900 etablierte sich auch in der deutschen 
Tagespresse eine direktere Kritik. Ebenso verlagerte sich erst in dieser Phase die stellvertretend artikulierte Empörung über die schlechten Ratgeber des Kaisers schrittweise auf den Monarchen selbst. In beiden Ländern zeigten sich dabei die geringen Kontrollmöglichkeiten, die die Monarchen gegenüber den Medien bei den Skandalen besaßen. In Großbritannien ließ sich der Skandal nicht dadurch abmildern, dass der Prince of Wales im Kreuzverhör privilegiert behandelt wurde. Und obgleich in Deutschland rigide Zensurmöglichkeiten bestanden, sahen der Kaiser und sein Umfeld bereits seit den 1890er Jahren Prozesse gegen Journalisten als problematisch an, da sie die Dynamik der Skandale intensivierten, so dass seit der Jahrhundertwende zunehmend auf Verfolgungen verzichtet wurde.

Nicht bestätigen ließ sich die Annahme, dass die britischen Monarchieskandale stärker durch einen investigativen Journalismus angestoßen und geprägt wurden. Bei den hier untersuchten Skandalen bildeten wie bei andere Skandaltypen Gerichtsprozesse, in die das Königshaus verwickelt war, den Anstoß und die Quellenbasis für kritische Enthüllungen. Über moralische Normverstöße, die zumindest als Gerücht wohl bekannt waren, recherchierte und veröffentlichte hingegen auch die britische Presse des ausgehenden 19. Jahrhunderts nicht eigenständig. Selbst einzelne abseitig veröffentlichte Andeutungen über derartige Normbrüche griff die Mehrheit der Tagespresse nicht auf, um die Krone nicht zu diskreditieren. Und nicht zufällig konzentrierten sich die Skandale vor allem auf den Prince of Wales, während das Verhalten der regierenden Monarchin zwar kritisiert, aber eben kaum skandalisiert wurde. Monarchie-Skandale, die aus Prozessen heraus entstanden, wurden in Deutschland dagegen bereits dadurch verhindert, dass eine gerichtliche Vernehmung eines führenden Mitgliedes des Königshauses undenkbar blieb. Den Anstoß für die MonarchieSkandale gaben in den 1890er Jahren vielmehr konservative Eliten, die verdeckt ihre Kritik am Verhalten des Monarchen und seines Umfeldes artikulierten, was dann wiederum von der restlichen Presse in einer offeneren und kritischeren Form aufgegriffen wurde. Auf diese Weise trug die deutsche Presse durchaus entscheidend dazu bei, die Skandale auszulösen.

Die Orte, an denen sich bei den Skandalen die Empörung äußerte, veränderten sich im 19. Jahrhundert. Während sie sich in der ersten Jahrhunderthälfte nicht nur über Medien, sondern auch häufiger durch Proteste in der Straßenöffentlichkeit artikulierte, blieben diese in der zweiten Hälfte des 19. Jahrhundert bei Monarchie-Skandalen eher die Ausnahme, auch wenn einzelne Fälle zu Protestversammlungen führten. Stattdessen formulierten die Presse und die Parlamente stellvertretend die Empörung, wobei die emotionale Monarchiekritik im Zuge der Skandale die Grenzen von politischen Milieus überwand. Im Vergleich zu anderen Skandaltypen war das Parlament jedoch bei den Monarchie-Skandalen in beiden Ländern weniger aktiv beteiligt als die Presse. Kritik am König wurde aus Rücksicht auf die Monarchie kaum originär von den Abgeordneten aufgebracht. Diese verstärkten in diesem Skandalfeld eher die Debatten in der Presse. 
Die Skandale standen in beiden Ländern für den Versuch, die Monarchen zu erziehen. Auch bei starken Befürwortern der Monarchie galten die Skandale oft als verdiente Lektionen. Die kritischen Zeitungsartikel der bürgerlichen Zeitungen sahen sie als pädagogisches Mittel und bittere Medizin, um den Monarchen oder Prinzen auf den rechten Weg zu bringen. Damit galt nicht mehr das Königshaus als Vorbild und Erzieher des Volkes, sondern umgekehrt die Öffentlichkeit als Mentor der Monarchen, die der politischen oder moralischen Lenkung bedurften.

Die Folgen der Monarchie-Skandale mögen auf den ersten Blick vergleichsweise gering erscheinen, da sie nur selten zum Rücktritt der Monarchen oder zu direkten Reformen im Verfassungsgefüge führten. In beiden Länder erschien jedoch die zunehmend artikulierte Drohung, die Monarchie verspiele durch die skandalisierten Normverstöße ihre Existenzberechtigung, nicht folgenlos. Dies galt insbesondere, weil die Skandale den Monarchen moralische und politische Grenzen setzten und ihr Erscheinungsbild in der Öffentlichkeit veränderten. Besonders in Deutschland legte die zunehmende Häufigkeit und Intensität der Skandale seit den 1890er Jahren dem Monarchen und seinem politischen Umfeld nahe, sich allmählich den öffentlichen Forderungen anzupassen. Insofern formten die Skandale eben nicht nur kollektive Deutungen über die Monarchen, sondern auch deren Auftreten und Handeln. 